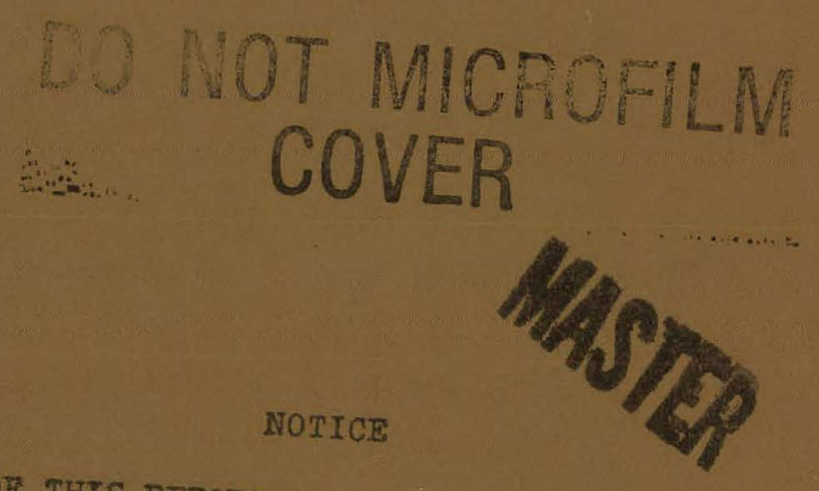

PORTIONS OF THIS REPORT ARE ILLEGIBLE. IE has been reproduced from the best available ability.

\title{
Calculations of Increased Solar UV Fluxes and DUV Doses Due to Stratospheric-Ozone Depletions
}

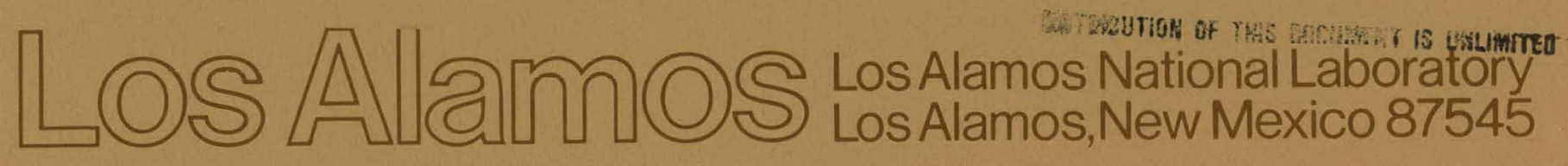




\section{DISCLAIMER}

This report was prepared as an account of work sponsored by an agency of the United States Government. Neither the United States Government nor any agency Thereof, nor any of their employees, makes any warranty, express or implied, or assumes any legal liability or responsibility for the accuracy, completeness, or usefulness of any information, apparatus, product, or process disclosed, or represents that its use would not infringe privately owned rights. Reference herein to any specific commercial product, process, or service by trade name, trademark, manufacturer, or otherwise does not necessarily constitute or imply its endorsement, recommendation, or favoring by the United States Government or any agency thereof. The views and opinions of authors expressed herein do not necessarily state or reflect those of the United States Government or any agency thereof. 


\section{DISCLAIMER}

Portions of this document may be illegible in electronic image products. Images are produced from the best available original document. 
This work was supported by the Environmental Protection Agency.

\section{DISCLAIMER}

This report was prepared as an account of work sponsored by an agency of the United States Government. Neither the United States Government nor any agency thereof, nor any of their employees, makes any warranty, express or implied, or assumes any legal liability or responsibility for the accuracy, completeness. or usefulness of any information, apparatus, product, or process disclosed, or represents that its use would not infringe privately owned rights. References herein to any specific commercial product, process, or service by trade name, trademark, manufacturer, or otherwise, does not necessarily constitute or imply its endorsement, recommendation, or favoring by the United States Government or any agency thereof. The views and opinions of authors expressed herein do not necessarily state or reflect those of the United States Government or any agency thereof. 


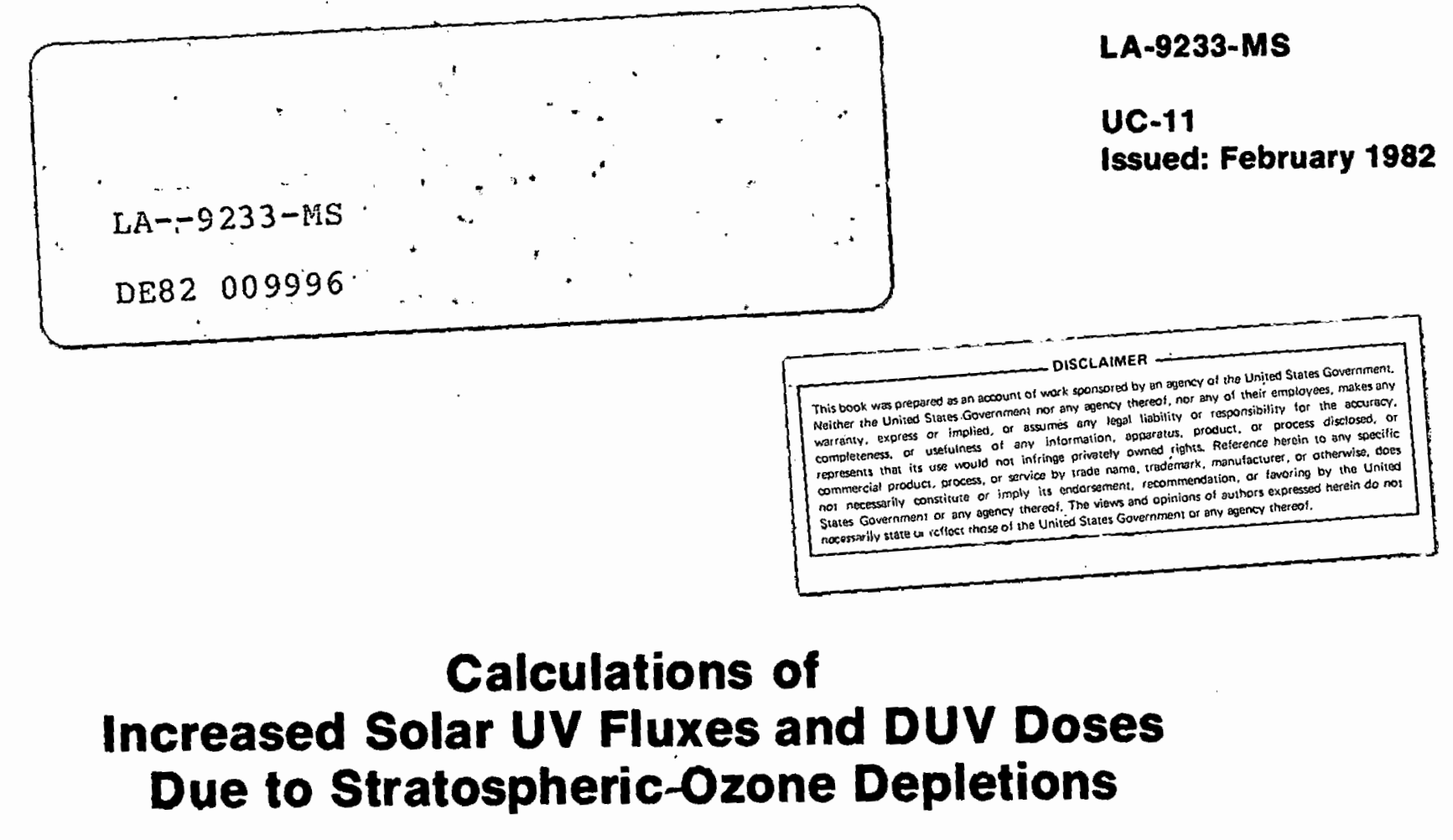

Andrew Zardecki

Siegfried A. W. Gerstl

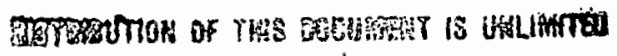

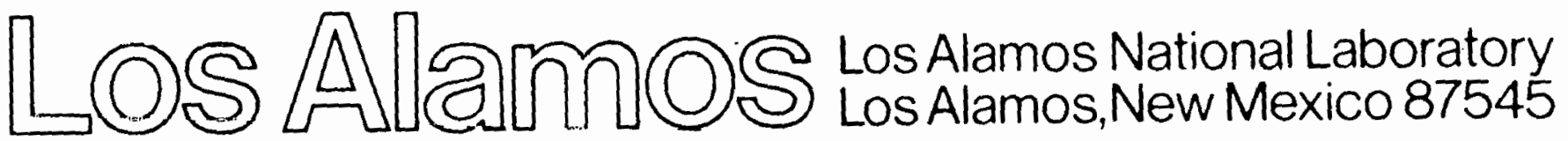


CALCULATIONS OF INCREASED SOLAR UV FLUXES AND DUV DOSES

DUE TO STRATOSPHERIC OZONE DEPLETIONS

by

Andrew Zardecki and Siegfried A. W. GerstI

\begin{abstract}
Accurate radiative transfer calculations are performed in the middle ultraviolet spectral region for aerosol-loaded atmospheres with the goal of determining the solar irradiance at the ground and quantifying the irradiance perturbations due to the presence of aerosols and various ozone depletions. The extent of the increase of UV-B radiation as a function of wavelength and solar zenith angle is calculated for five model atmospheres. In addition, the damaging ultraviolet dose rates and radiation amplification factors are evaluated at different latitudes and seasons for erythemal and DNA action spectra.
\end{abstract}

\title{
I. INTRODUCTION
}

Many recent studies ${ }^{1-3}$ indicate that the release of CFCs (chlorofluorocarbons)--mainly CFMs (chlorofluoromethanes)--into the atmosphere acts to deplete the stratospheric ozone layer. A probable value calculated for the eventual ozone depletion due to continued release of CFMs at the 1977 level is 16.5\%. However, changes in the tropospheric chemistry cause changes in the stratosphere. The kinetics of reactions resulting in $\mathrm{HO}_{x}$ and $\mathrm{NO}_{x}$ plays a primary role in the ozone reduction; a moderate increase in $\mathrm{NO}_{x}$, for example, would reduce the effect of halocarbons on ozone. According to a recent study by Wine et al., ${ }^{4}$ the calculated $\mathrm{O}_{3}$ depletion due to $\mathrm{CFM}$ release can thus be reduced from 14 to $9.5 \%$. In calculations based on two-dimensional models, ${ }^{5,6}$ any change of ozone is not uniform, but shows variations with latitude and season. This enables one to account for local ozone changes and their impact on ultraviolet radiation reaching the ground. The known relationship between skin cancer and IV radiation ${ }^{7,8}$ implies 
that enhanced UV radiation at the ground leads to an increased skin cancer incidence rate. ${ }^{9}$ In addition, decreasing the average ozone concentration will increase the average intensity of biologically damaging ultraviolet radiation (DUV) in natural daylight causing injury to DNA.

The purpose of this report is twofold. First, we estimate the extent of the increase of UV-B radiation as a function of wavelength and solar zenith angle for five model atmospheres developed by McClatchey et al. ${ }^{10}$ We will confine our attention to the 0.28 - to $0.34-\mu \mathrm{m}$ region of the spectrum, as it is the only region for which the ground irradiance might be significantly affected by changing ozone concentrations. The discrete ordinates $\left(\mathrm{S}_{\mathrm{N}}\right)$ code ONETRAN, ${ }^{11}$ which has been developed to a high degree of computational efficiency and accuracy primarily for nuclear radiation shielding applications, reduces considerably the computer time when employed in the adjoint mode. ${ }^{12}$ Our method can thus advantageously be compared to other discrete ordinate computations of the middle ultraviolet reaching the ground. 13,14 Second, we investigate the damaging ultraviolet dose rate for erythemal and DNA action spectra. We will consider both global ozone depletions consistent with 1-D models and latitude- and season-dependent depletions as predicted by the 2-D model of Pyle. 5,6

\section{PROJECTED CHANGES IN STRATOSPHERIC OZONE}

Ozone occurs in the atmosphere in very small quantities, If all the ozone in a vertical column of the atmosphere were reduced to standard pressure and temperature, its thickness would be only about $3 \mathrm{~mm}$. In comparison, the atmosphere is about $8 \mathrm{~km}$ thick when reduced to the same standard pressure and temperature. $^{15}$ The importance of the relatively small amount of ozone lies mainly in its ability to absorb the biologically harmful ultraviolet radiation from the sun and to prevent most of it from reaching the surface. In addition, ozone plays an important role in determining the slimate of the Earth. ${ }^{2}$

The overall Chapman scheme of reactions, in which ozone is both produced and destroyed in the stratosphere by the UV Hartley/Huggins and visible Chappius absorption, leads to an excess of stratospheric ozone. Several reaction schemes have been suggested to explain this inconsistency. They involve chemical compounds that contain hydrogen $\left(\mathrm{HO}_{x}\right)$, nitrogen $\left(\mathrm{NO}_{x}\right)$, and chlorine $\left(\mathrm{ClO}_{x}\right)$. These compounds enter into catalytic chain reactions in which one molecule can destroy many ozone molecules before being removed by some competing processes. For example, the decomposition of ozone by $\mathrm{NO}_{x}$ has been identified in the Climatic 
Impact Assessment Program ${ }^{16}$ as being potentially crucial, because aircraft engines emit significant quantities of oxides of nitrogen. The release of halocarbons, such as CFMs, seem to be of greatest and most immediate threat. It now appears, however, that the effect of chlorine compounds on the ozone cycle is strongly coupled to the actions of other trace species, such as stratospheric odd-nitrogen compounds .

The NAS report ${ }^{2}$ selects four scenarios in which the release of $F-11$ and F-12 remains constant at the 1977 value until 1980 or 1983 and then is reduced by a certain factor to correct for feedback effects and the possible existence of a tropospheric sink. The following model estimates appear particularly significant: (a) a $2 \%$ change of ozone has already occurred due to $F-11$ and $F-12$ release; (b) the ozone depletion by the year 1990 due to F-11 and F-12 is near 5\%, almost independent of the assumed scenario; (c) the final steady-state ozone depletion estimates range from 18.6 to $10.6 \%$; and (d) half the steady-state values would be reached in 15 to 30 years, depending on the scenario.

It is now well known that the percentage change of the ozone amount due to the CFM release will depend strongly on the simultaneous action of both oddhydrogen ( $\mathrm{HO}_{x}$ ) and odd-nitrogen $\left(\mathrm{NO}_{x}\right)$ oxides. The $\mathrm{HO}_{x}$ species reduce the ozone amount due to reactions of the form

$$
\mathrm{HO}+\mathrm{O}_{3} \rightarrow \mathrm{HO}_{2}+\mathrm{O}_{2}
$$

and

$$
\mathrm{HO}_{2}+\mathrm{O}_{3} \rightarrow \mathrm{HO}+\mathrm{O}_{2}+\mathrm{O}_{2}
$$

At lower altitudes, $\mathrm{HO}_{\mathrm{x}}$ reactions are more efficient than $\mathrm{NO}_{\mathrm{x}}$ reactions in catalytic destruction of ozone. However, the injection of $\mathrm{NO}_{x}$ at these altitudes leads, as a net effect, to a reduction of $\mathrm{HO}_{\mathrm{x}}$ and an increase in net oxygen production, both of which contribute to an increase in ozone. Recently, Wine et al. ${ }^{4}$ measured the rate constant for the reaction of $\mathrm{HO}$ with $\mathrm{HNO}_{3}$. Their results, indicating a higher than previously accepted rate at lower temperatures, yield a stratospheric $\mathrm{HNO}_{3}$ removal rate that is faster than currently assumed. Results of model calculations show that the implication of this result depends on the products of the reaction (that is, $\mathrm{H}_{2} \mathrm{O}+\mathrm{NO}_{3}$ or $\mathrm{H}_{2} \mathrm{O}_{2}+\mathrm{NO}_{2}$ ). If the products are $\mathrm{H}_{2} \mathrm{O}+\mathrm{NO}_{3}$, the calculated $\mathrm{O}_{3}$ depletion due to CFM release is reduced from 14 to $9.5 \%$. 
The figures cited thus far are based on calculations using 1-D models, in which only vertical motions of chemical substances are considered. The justification for this approximation is that, when all the motions are summed over all latitudes and longitudes, the effects of horizontal motions of substances largely cancel and the vertical movements dominate. It is to be noted that the 1-D models predict both the global average change of ozone within a total column and the change of ozone as a function of altitude. In Ref. 2, the fractional change in ozone for three scenarios is presented. Notwithstanding the mathematical appeal of 1-D models and their high confidence level, the advantages of 2-D models cannot be underestimated. These models are useful in suggesting the latitudinal variation of the ozone change, which is needed for estimating possible local increases of UV radiation and hence regional biological impacts of ozone changes.

In this report, we assume first a global ozone depletion of $10-20 \%$, which is consistent with the work of Wine et al. and with previous findings. Then, using the predictions of the $2-\mathrm{D}$ model of Pyle, ${ }^{5,6}$ we study latitude- and seasondependent ozone changes and their biological effect involving erythemal- and DNAdamage weighting functions.

\section{ATMOSPHERF. MODEL}

Transmittance of radiation through the atmosphere is a complex function of molecular and aerosol characteristics. In the UV window region, in addition to the model of atmospheric attenuation based upon the US Standard Atmosphere, more refined models describing different environments with varying aerosol contents have been developed. 17,18 Since the scattering and absorption coefficients depend on molecules and aerosols in the atmospheric path, a realistic representation of an atmosphere model has to contain the following quantities:

$$
\begin{aligned}
& \beta_{\mathrm{m}}=\text { molecular absorption coefficient, } \\
& \beta_{\mathrm{sc}}=\text { molecular scattering coefficient, } \\
& \beta_{\mathrm{a}}=\text { aerosol absorption coefficient, and } \\
& \beta_{a s}=\text { aerosol scattering coefficient. }
\end{aligned}
$$

The radiation emitted by the sun needs to be described either in the tabulated form of spectral irradiance data or by means of an adequate analytic approximation. 


\section{A. Ozone Distribution}

The only atmospheric molecule contributing significantly to the absorption in the spectral region from 0.28 to $0.34 \mu \mathrm{m}$ is ozone. Its absorption coefficient, $\beta_{m}$, is given by the defining equation

$$
\beta_{m}(\lambda, h)=A_{V}(\lambda) \rho(h),
$$

where $\lambda$ is the wavelength $(\mu \mathrm{m}), \mathrm{h}$ is the altitude $(\mathrm{km}), \mathrm{A}_{\mathrm{V}}$ is the Vigroux ${ }^{19}$ ozone absorption coefficient $\left(\mathrm{cm}^{-1}\right)$, and $\rho$ is the ozone concentration $\left(\mathrm{cm} \mathrm{km}^{-1}\right)$. Apart from the situations where resolutions of the order of $10^{-3} \mu \mathrm{m}$ are necessary, the experimental absorption coefficient $A_{V}$ can be approximated adequately by the analytical formula ${ }^{13}$

$$
A_{V}(\lambda)=k_{0} \exp \left[-\left(\lambda-\lambda_{0}\right) / d\right]
$$

where $\mathrm{k}_{0}=10 \mathrm{~cm}^{-1}, \lambda_{0}=0.3 \mu \mathrm{m}$, and $\mathrm{d}=0.008 \mu \mathrm{m}$.

The ozone concentration profile, $\rho(\mathrm{h})$; is determined by the choice of one of the following atmospheric models. 10

Model

Tropical

Midlatitude Summer

Midlatitude Winter

Subarctic Summer

Subarctic Winter
Ozone Amount (cm-atm)

0.23

0.32

0.38

0.34

0.44

In Ref. 20, the vertical profiles of $\beta_{\mathrm{m}}$ are tabulated for several typical laser wavelengths. Using the values corresponding to $\lambda=0.3371 \mu \mathrm{m}$, by virtue of Eqs. (1) and (2), we obtain

$$
\beta_{\mathrm{m}}(\lambda, \mathrm{h})=\beta(\lambda=0.3371, \mathrm{~h}) \exp [(0.3371-\lambda) / \mathrm{d}] .
$$

Equation (3) is used to determine the molecular absorption coefficient over the entire UV-B spectral window. For the different amounts of ozone depletion used in the various calculations presented in the next section, we used a fixed shape for density profiles and simply scaled this density at all heights by an appro- 
priate factor. Thus, instead of $\beta_{m}(\lambda, h)$, as given by Eq. (3), we use

$$
\tilde{\beta}_{m}(\lambda, h)=s_{o z} \beta_{m}(\lambda, h)
$$

where $\mathrm{S}_{\mathrm{oz}}$ is the scaling factor chosen to represent the desired ozone reduction.

\section{B. Molecular Scattering}

The molecular scattering coefficient depends only on the number density of molecules in the radiation path--in contrast to the molecular absorption coefficient, which is also a function of the local temperature and pressure of the gas. The wavelength dependence of molecular (Rayleigh) scattering is very nearly $\beta_{\mathrm{SC}} \sim \lambda^{-4}$. In this report, we employ for extracting molecular scattering profiles the AFGL data base, which uses the models described in Refs. 17 and 18. The data at $\lambda=0.55 \mu \mathrm{m}$ are thus rescaled, with the aid of Rayleigh's law, to obtain the profile at a required wavelength. If $\beta_{0.55}$ denotes the molecular scattering coefficient at wavelength $\lambda=0.55 \mu \mathrm{m}$, our scaling law is expressed by the simple formula

$$
\beta_{\lambda}=\beta_{0.55}\left[\frac{0.55}{\lambda}\right]^{4},
$$

where $\lambda$ is the wavelength in micrometers.

\section{Aerosol Model}

As described in Ref. 18, the variation of the aerosol optical properties with altitude is modeled by dividing the atmosphere into four altitude regions, each having a different type of aerosol distributinn function. These regions are the boundary mixing layer $(0-2 \mathrm{~km})$, the upper troposphere $(2-10 \mathrm{~km})$, the lower stratosphere $(10-30 \mathrm{~km})$, and the upper atmosphere $(30-100 \mathrm{~km})$. The range of conditions in the boundary layer is represented by three different aerosol models (rural, urban, or maritime) for each of several meteorological ranges beween 2 and $50 \mathrm{~km}$, and as a function of humidity. In the following, we select the rural model, intended to represent the aerosol conditions one finds in continental areas that are not directly influenced by urban or industrial aerosol sources. The rural aerosols are assumed to be composed of a mixture of $70 \%$ of water-soluble substance (ammonium and calcium sulfate with organic compounds) 
and $30 \%$ dust-like aerosols. For simplicity the humidity effects will be neglected, since the effect is much less pronounced as compared with other factors.

\section{Mixing Molecules and Aerosol Data}

The aerosol angular scattering is represented by a Henyey-Greenstein phase function

$$
P_{H-G}(h, \hat{\mu})=(1 / 4 \pi)\left[1-g^{2}(h)\right]\left[1+g^{2}(h)-2 g(h) \hat{\mu}\right]^{-3 / 2}
$$

in which the asymmetry parameter $g$, depends on height $h$, and $\hat{\mu}$ is the cosine of the scattering angle. In terms of the Legendre polynomials, $\mathrm{P}_{\mathrm{H}-\mathrm{G}}(\mathrm{h}, \hat{\mu})$ has the expansion

$$
\mathrm{P}_{\mathrm{H}-\underline{\mathrm{C}}}(\mathrm{h}, \hat{\mu})=\sum_{\ell=0}^{\mathrm{L}} \frac{2 \ell+1}{4 \pi}[\mathrm{g}(\mathrm{h})]^{\ell} \mathrm{P}_{\ell}(\hat{\mu}) .
$$

The ONETRAN code performs, for each altitude zone and for each wavelength group, the mixing of aerosol scattering coefficients, $\beta_{\text {as }}^{\ell}=\beta_{\text {as }}[g(h)]^{\ell}$, and molecular scattering coefficients describing Rayleigh scattering. The latter are obtained after Legendre expansion of Rayleigh's phase function, which has the form

$$
P_{R}(\hat{\mu})=(3 / 16 \pi)\left(1+\hat{\mu}^{2}\right) .
$$

Therefore, the expansion coefficients $\sigma_{s c}^{\ell}$ for molecular Rayleigh scattering, defined through the equation

$$
\mathrm{P}_{\mathrm{R}}(\hat{\mu})=\sum_{\ell=0}^{\infty} \frac{2 \ell+1}{4 \pi} \quad \sigma_{\mathrm{sc}}^{\ell} \mathrm{P}_{\ell}(\hat{\mu}),
$$

are

$$
\begin{aligned}
& \sigma_{s c}{ }^{0}=1, \\
& \sigma_{s c}^{1}=0, \\
& \sigma_{s c}{ }^{2}=0.1,
\end{aligned}
$$


and

$$
\sigma_{\mathrm{sc}}^{\ell}=0, \text { for } \ell>2
$$

The mixing, reduced here to a simple superposition, is performed as follows:

$$
\beta_{\text {total }}^{l}=\beta_{\mathrm{as}}^{\ell}+\beta_{\mathrm{sc}}^{\ell}, \quad \ell=1, \ldots, \mathrm{L},
$$

where $\beta_{s c}^{\ell}=\beta_{S C} \sigma_{s c}^{\ell}$. Similarly, the total absorption coefficient

$$
\beta_{\text {total }}^{(\operatorname{abs})}=\beta_{a}+\beta_{m}
$$

is a sum of aerosol and molecular absorption coefficients.

\section{E. Incident Sunlight}

To a reasonable approximation the extraterrestrial solar irradiance $H(\lambda)$ in low resolution in the 0.28 - to $0.34-\mu \mathrm{m}$ region may be approximated by the linear relationship 13

$$
H(\lambda)=K\left[1+\left(\lambda-\lambda_{0}\right) / d\right],
$$

where $\mathrm{K}=552.0 \mathrm{~W} / \mathrm{m}^{2} \mu \mathrm{m}, \mathrm{d}=0.37 \mu \mathrm{m}$, and $\lambda_{0}=0.3 \mu \mathrm{m}$. This formula is consistent with the solar spectral irradiance data as compiled by Johnson. 20

IV. DOWNWARD SOLAR FLUX REACHING THE GROUND

By varying the scaling factor $\mathrm{s}_{\mathrm{oz}}$, introduced in $\mathrm{Eq}$. (4), we have considered, in addition to standard ozone for each of the five models discussed in Sec. III.A, the following ozone depletions: 1, 2, 3, 4, 5, 10, 15, and $20 \%$. Throughout, the adjoint mode of the transport equation was used. For the sake of completeness, and having in mind the computation of DUV doses in Sec. V, we summarize here the essential steps of our procedure.

\section{A. Theoretical Preliminaries}

A linear Boltzmann operator $\mathrm{L}$ may be defined by writing the time-independent form of the radiative transfer equation as ${ }^{12}$ 
$\mathrm{L} \psi(\mathrm{x}, \underline{\Omega}, \lambda)=Q(\mathrm{x}, \underline{\Omega}, \lambda)$.

In Eq. (12), where plane geometry is assumed, $x$ denotes the linear coordinate along the axis normal to the plane of stratification directed from the top of the atmosphere towards the ground, $\underline{\Omega}$ is the unit vector specifying some direction at $x$, and $\lambda$ is the wavelength. We note that $\underline{\Omega}$ is defined in terms of polar and azimuthal angles $\theta$ and $\phi$ or, equivalently, in terms of $\mu$ and $\phi$, where $\mu=$ $\cos \theta$.

In the case of elastic scattering considered here, the operator $\mathrm{L}$ in Eq. (12) is

$L \psi(x, \underline{\Omega}, \lambda)=\mu \frac{\partial}{\partial x} \psi(x, \underline{\Omega}, \lambda)+\Sigma_{t}(x, \lambda) \psi(x, \underline{\Omega}, \lambda)$

$$
-\int \mathrm{d} \Omega^{\prime} \Sigma_{\mathrm{s}}(\mathrm{x}, \lambda) \mathrm{f}\left(\mathrm{x}, \underline{\Omega}^{\prime} \rightarrow \underline{\Omega}, \lambda\right) \psi\left(\mathrm{x}, \underline{\Omega}^{\prime}, \lambda\right)
$$

where $\Sigma_{s}$ and $\Sigma_{t}$ denote the (volume) scattering and extinction coefficients in $\mathrm{km}^{-1}$, while $\mathrm{f}$ is the scattering phase function. In terms of the notation of Sec. III, $\Sigma_{s}=\beta_{s c}+\beta_{\text {as }}$ and $\Sigma_{t}=\beta_{m}+\beta_{s c}+\beta_{a}+\beta_{a s}$. If only solar radiation is considered, then the source distribution $Q$ in Eq. (12) may be written as

$$
\mathrm{Q}(\mathrm{x}, \underline{\Omega}, \lambda)=\mu_{0} \mathrm{H}(\lambda) \delta(\mathbf{x}) \delta\left(\underline{\Omega}-\underline{\Omega}_{0}\right),
$$

where $H(\lambda)$ is the solar spectral irradiance in watts per $m^{2}$ and $\mu \mathrm{m}, \Omega_{0}$ identifies the incident direction for the monodirectional solar flux, and the symbol $\delta$ stands for the Dirac delta function. The main objective of our calculations, the downward directed solar flux (irradiance) at ground level $\mathrm{x}=\mathrm{h}$, is defined as

$$
F_{\lambda} \downarrow(x=h)=\int_{0}^{\infty} d x \int d \Omega R(x, \underline{\Omega}, \lambda) \psi(x, \underline{\Omega}, \lambda)
$$

with a response function $R$ that is independent of $\phi$ and $\lambda$, defined as

$$
R(x, \mu)=\mu \delta(x-h) \theta(\mu) .
$$

Here, $\theta(\mu)$ is the Heavyside step function, which is 1 for $\mu>0$ and 0 for $\mu<0$. 
An operator $\mathrm{L}^{+}$that is adjoint to $\mathrm{L}$ is defined by the requirement that for any function $\psi^{+}$, fulfilling continuity and boundary conditions which may be different from those on $\psi$, the following relation be satisfied.

$$
\left(\psi^{+}, \mathrm{L} \psi\right)=\left(\psi, \mathrm{L}^{+} \psi^{+}\right)
$$

where the scalar product notation $(\psi, \phi)$ implies integration of $\psi \cdot \phi$ over the entire accessible range of independent variables. Explicitly, $\mathrm{L}^{+}$is obtained from $\mathrm{L}$ in Eq. (13) by changing the sign of the derivative-term and by interchanging $\Omega^{\prime}$ and $\Omega$ under the integral sign. ${ }^{21}$ We now formulate the adjoint transport problem with the external source being given by Eq. (16), which represents the response function of the forward problem. Therefore, the adjoint transfer equation is

$$
\mathrm{L}^{+} \psi^{+}=\mathrm{R}
$$

From the defining Eq. (17) and by virtue of Eqs. (12) and (18), we see that $F_{\lambda} \downarrow(x=h)$ as defined in Eq. (15) is given in terms of the solution to Eq. (18) as

$$
\mathrm{F}_{\lambda} \downarrow(\mathrm{x}=\mathrm{h})=\left(\psi^{+}, \mathrm{Q}\right)
$$

Inserting $Q$ from Eq. (14), this becomes

$$
F_{\lambda} \downarrow(x=h)=\psi^{+}\left(x=0, \mu_{0}, \phi_{0}, \lambda\right) H(\lambda) \mu_{0}
$$

Actually, symmetry considerations for a plane-parallel atmosphere enable us to drop the azimuthal dependence in Eq. (20). In fact, since the response function in Eq. (16) is $\phi$-independent, the downward-directed solar flux can be computed by using a 1-angle plane geometry transport equation instead of a 2-angle plane geometry equation. 29 This implies that the actually monodirectional incident solar flux is replaced by a fictitious flux distributed over a cone forming an angle $\theta_{0}=\cos ^{-1} \mu_{0}$ with the z-axis. Consequently, in the adjoint problem, the simpler 1-angle plane geometry formulation can also be employed. The final expression for the irradiance at ground level thus becomes 


$$
F_{\lambda} \downarrow(x=h)=\psi^{+}\left(x=0, \mu_{0}, \lambda\right) H(\lambda) \mu_{0},
$$

where $\psi^{+}$is a solution to the adjoint transfer equation in 1-angle plane geometry. Equation (21) enables one to obtain the irradiance for all solar zenith angles $\theta_{0}=\cos ^{-1} \mu_{0}$ and all desired wavelengths simultaneously.

\section{B. Numerical Results}

By using the ONETRAN discrete ordinates transport code in the adjoint mode, the downward solar flux at ground level (irradiance) was calculated for the entire UV-B spectrum from 0.2825 to $0.3400 \mu \mathrm{m}$. We have chosen angular quadrature order $\mathrm{S}_{\mathrm{N}}=40$ and 24 wavelength groups. Since the number of different solar zenith angles is $\mathrm{S}_{\mathrm{N}} / 2$, this has resulted in 20 zenith angles whose values are fixed by the ONETRAN code. These values are $\Theta_{\Theta}=4.75,10.89,17.04,23.14$, $29.17,35.11,40.94,46.62,52.13,57.43,62.50,67.29,71.25,75.84,79.51$, $82.71,85.39,87.48,88.97$, and $89.80^{\circ}$. Our choice of 24 wavelength values implies that the interval $0.28-0.34 \mu \mathrm{m}$ was subdivided into wavelength bins of width $0.0025 \mu \mathrm{m}$.

To illustrate the significance of seasonal and latitude changes, we show the downward flux at ground level as a function of wavelength (at a fixed solar zenith angle) and as a function of zenith angle (at fixed wavelength) for the midlatitude winter model in Figs. 1-14, for the subarctic summer model, Figs. 15-26, and for the subarctic winter model, Figs. 27-38.

\section{BIOLOGICALLY EFFECTIVE UV RADIATION}

The relative effectiveness of different wavelengths (the action spectrum) increases with decreasing wavelength for most biologically damaging effects. ${ }^{1}$ At any given wavelength $\lambda$, the product of the action spectrum $E(\lambda)$ and the solar irradiance, $I(\lambda)=F_{\lambda} \downarrow(x=h)$, gives a value that reflects the number of photons within a spectral bin $d \lambda$, weighted by their biological effectiveness. The biologically effective snlar UV-B irradiance, designated as DUV dose rate, is defined as

$$
\operatorname{DUV}=\int_{0.28}^{0.32} \mu \mathrm{m}
$$

where $\lambda$ is the wavelength in micrometers. 
With minor modifications, the results of the preceding section permit us to study the DUV dose rate as a function of solar zenith angle. To this end, we note that Eq. (22) combined with Eqs. (15) and (16) yields

$$
\operatorname{DUV}=\int_{0.28}^{0.32} \mu \mathrm{m} d \lambda \int_{0}^{\infty} \mathrm{dx} \int \mathrm{d} \Omega E(\lambda) \mu \delta(\mathrm{x}-\mathrm{h}) \theta(\mu) \psi(\mathrm{x}, \underline{\Omega}, \lambda),
$$

where we have replaced the irradiance $I(\lambda)$ with $F_{\lambda} \downarrow(x=h)$ from Eq. (15). By inspection, the new response function $R^{\prime}(x, \mu, \lambda)$ in Eq. (23) is

$$
R^{\prime}(x, \mu, \lambda)=E(\lambda) \mu \delta(x-h) \theta(\mu)
$$

Once again, the response function is $\phi$-independent.

As in Sec. IV, we now formulate the adjoint problem

$$
\mathrm{L}^{+} \psi^{+}=\mathrm{R}^{\prime}
$$

with vacuum boundary condition and with ground-level boundary source $R^{\prime}$. In terms ot the scalar product notation introduced earlier, we obtain

$$
\mathrm{DUV}=\left(\psi, \mathrm{R}^{\prime}\right)=\left(\psi^{+}, \mathrm{Q}\right)
$$

More explicitly, Eq. (26) is written as

$$
\mathrm{DUV}=\int \mathrm{d} \lambda \mathcal{\mathrm { dx }} \int \mathrm{d} \Omega \mu \mathrm{H}(\lambda) \delta(\mathrm{x}) \delta\left(\underline{\Omega}-\underline{\Omega}_{0}\right) \psi^{+}(\underline{\mathrm{x}}, \Omega, \lambda)
$$

Finally, when the integrations over $\mathrm{x}$ and $\Omega$ are carried out, we obtain

$$
\operatorname{DUV}=\int_{0.28 \mu \mathrm{m}}^{0.32} \mu_{0} H(\lambda) \psi^{+}\left(0, \underline{\Omega}_{0}, \lambda\right) \mathrm{d} \lambda
$$

In plane geometry, $\psi^{+}\left(0, \Omega_{0}, \lambda\right)$ is actually a function $\psi^{+}\left(0, \mu_{0}, \lambda\right)$ with no azimuthal dependence. When the concept of the effective zenith angle is introduced in Sec. VI.A, we will be able to translate the zenith angle dcpendence into a 2-D function of latitude and season. 


\section{A. Erythemal Action Spectrum}

In view of the concern about the possibility of increases in skin cancer due to ozone depletion, we focus on the human erythemal (sunburn) action spectrum for the weighting function $\mathrm{E}(\lambda)$. It is believed, moreover, that although human sunburn is not itself relevant to effects in other organisms, use of an erythemal weighting function yields a reasonable relative DUV reduction measurement for a typical biological effect. ${ }^{1}$ The standard weighting function describing the erythemal dose was measured by Coblentz and Stair. ${ }^{22}$ The figures that follow show, for each atmospheric model described in Sec. III.A, both the percentage change in DUV dose rate and the radiation amplification factor (RAF) as a function of solar zenith angle. The RAF is defined as a percentage increase in the relative DUV dose per percentage decrease in the ozone-layer thickness (or total ozone amount in $\mathrm{cm}$ atm):

$$
\text { RAF }=\frac{\Delta \% \text { DUV dose }}{-\Delta \% \text { total ozone amount }}
$$

As can be seen from Figs. 39-58, the RAF shows pronounced variations with the percentage of ozone depletion, latitude, and season.

In general, Earth's curvature has a greater influence on path length (and hence on the transmittance) than atmospheric refraction. For long slant paths with zenith angles close to $90^{\circ}$, in the lower atmosphere refractive effects can cause a significant increase in the path length. ${ }^{23}$ As indicated by Kondratyv, 24 optical air mass is adequately described by a simple sec $\theta_{0}$ law only for solar zenith angles $\theta_{0}<60^{\circ}$. As the ONETRAN code, applicd to plane geometry, has no built-in capability to account for Earth curvature effects or for atmospheric refraction, all our results for zenith angles larger than about $75^{\circ}$ cannot be considered accurate for realistically curved atmospheres. Although some of our computer plots extend to full $90^{\circ}$ the data for $\theta_{0}>75^{\circ}$ should not be used unless corrections for the Earth's curvature and for atmospheric refraction are applied. Such corrections for a spherical atmosphere were considered in some detail by Shettle and Green. 13

\section{B. DNA Action Spectrum}

Lesions in human tissue may result when DNA absorbs UV radiation, most commonly in pyrimidine bases. These lesions result in loss of DNA biological 
activity. $^{25}$ Green and Miller ${ }^{26}$ calculated an analytic representation of the long-wavelength tail of a DNA action spectrum compiled by Setlow. 27 In the following, we use their representation, which has the form

$$
\mathrm{E}_{\mathrm{DNA}}(\lambda)=\exp \left\{\mathrm{k}\left[\frac{1}{1+\exp \left[\left(\lambda-\lambda_{0}\right) / \lambda_{\mathrm{f}}\right]}\right]-1\right\},
$$

where $k=13.82, \lambda_{0}=0.31 \mu \mathrm{m}$, and $\lambda_{f}=0.009 \mu \mathrm{m}$. In Figs. 59-78, we show percentage change in DUV dose and RAF as a function of solar zenith angle.

VI. DUV VARIATION AS A FUNCTION OF LATITUDE AND SEASON

As shown previously, the solar flux at ground level depends strongly on the solar zenith angle $\theta_{0}$, which, in turn, varies with the time of day, latitude, and season. Therefore, if daily values of DUV or RAF are desired, an integration over the diurnal variation of $\theta_{0}$ must be performed. However, these diurnal sums will still vary with latitude and season because $\theta_{0}$ depends on latitude and date of the year. Our aim is, therefore, to determine an effective solar zenith angle that is averaged over any given day and can be given as a function of latitude and season (date). Considering such an effective solar zenith angle we can then correlate daily DUV doses or RAF values with latitude and season. Once the effective solar zenith angle is determined for a given latitude and date, the percentage change in the daily DUV dose and the RAFs can be read off the graphs described in Sec. V. Considering also the latitudinal and seasonal variation of the estimated ozone depletions, for example as given by Pyle and Derwent, ${ }^{6}$ contour plots of RAFs vs latitude and season can be derived, as presented in Sec. VI.B.

\section{A. Effective Solar Zenith Angle}

Considering the celestial sphere, spherical trigonometry allows the derivation of the following relation for the solar zenith angle $\theta_{0}$ as a function of time and location on the Earth's surface. 28

$$
\mu_{0}=\cos \theta_{0}=\sin \phi \sin \delta+\cos \phi \cos \delta \cos \omega,
$$

where $\phi$ is the latitude, $\delta$ is the sun's declination against the celestial equator, and $w=\frac{2 \pi}{T} \cdot t$ is the hour angle of the sun with $T$ the duration of daylight. An effective solar zenith angle 


$$
z_{0}=\cos ^{-1}\left\langle\mu_{0}\right\rangle
$$

can now be defined as the daily average zenith angle calculated from

$$
\left\langle\mu_{0}\right\rangle=\frac{1}{\mathrm{~T}} \int_{t}^{t_{\text {sunrise }}} \mu_{0}(t) d t,
$$

where $\mu_{0}(t)$ is taken from Eq. (30). The limits of integration, as well as the duration of sunlight, $T$, depend on latitude and date of the year and must be obtained separately. Inserting $\mu_{0}(t)$ from Eq. (30) into Eq. (32) the integration can be performed analytically because the solar declination $\delta$ can be considered time independent for any one day.

$$
\begin{aligned}
\left\langle\mu_{0}\right\rangle & =\frac{1}{2 \pi} \int_{-w_{0}}^{+w_{0}} \mu_{0}(w) d w \\
& =\frac{1}{\pi}\left(w_{0} \sin \phi \sin \delta+\sin \omega_{0} \cos \phi \cos \delta\right) .
\end{aligned}
$$

The value of $w_{0}$ at given latitude and $\delta$ is obtained from the sunrise and sunset condition for the solar zenith angle of $90^{\circ}$ when $\mu_{0}=0$. From Eq. (30) follows then

$$
\cos w_{0}=-\tan \phi \tan \delta
$$

For high latitudes, when the sun does not set for 24 hours, $w_{0}=\pi$ is appropriate.

Figure 79 gives a contour plot of the effective solar zenith angle $Z_{0}$ vs latitude and season. In the polar zones where $Z_{0}>75^{\circ}$ (near the areas of polar darkness) the definition of an effective solar zenith angle remains useful only for an Earth without the atmosphere, under which condition the above derivations were performed. However, for such large solar zenith angles atmospheric refraction effects should also be considered and Eq. (33) corrected accordingly. We did not apply such corrcctione and have, therefore, shaded these areas on our contour plot of Fig. 79. 


\section{B. Radiation Amplification Factors}

In accordance with our discussion in Sec. II, we assume global ozone depletions of 10,15 , and $20 \%$. The values 15 and $20 \%$ are consistent with the steady-state values as predicted by the scenarios mentioned in Ref. 2, while the $10 \%$ value corresponds to the recent findings of Wine et al. 4

The results shown in Figs. 80-85 represent the RAF-contour plots for erythemal and DNA action spectra. For DNA, the RAF is higher, especially in the subarctic regions. In Figs. 86 and 87 absolute DUV dose changes at 15\% ozone reduction are shown. By considering the estimated reductions in the ozone amount until 1992, as given by Pyle and Derwent, ${ }^{6}$ as a function of latitude and season, we have produced the contour plots depicting RAF on the month of year-latitude plane. As can be seen from Figs. 88 and 89, the DNA damage appears more sensitive to ozone reduction even when the percentage depletion is contained between 1 and $6 \%$.

We note that the RAF plotted as a function of zenith angle, as described in Sec. V, displays a characteristic dip for zenith angles in the vicinity of $85^{\circ}$. We are not in a position to decide whether those dips have a physical meaning or whether they arise from applying the plane geometry ONETRAN code to a curved atmosphere. When the curves of Sec. V are extrapolated in such a way that the dips are ignored, slightly different contour plots, shown in Figs. 90 and 91, result; differences from Figs. 88 and 89 are significant only in the polar regions.

\section{CONCLUSION}

We have performed accurate radiative transfer calculations for varying amounts of stratospheric ozone applicable to different latitudes and seasons. Our main results comprise downward solar UV fluxes at the ground level as a function of wavelength and solar zenith angles, as well as DIJ dose rates and RAFs for erythemal and DNA action spectra.

The popular statement that a $1 \%$ depletion in ozone is equivalent to a $2 \%$ increase in DUV should be modified as already emphasized by Pyle and Derwent. ${ }^{6}$ As our modeling, in which higher values of ozone depletion were assumed, indicates, the "folklore" value of 2 should rather be replaced by a nonlinear functional relationship; the larger the ozone depletion the faster the growth of RAF.

Our results show that the range of variation of RAF, however, is much less pronounced over latitudinal and seasonal variations than would follow from the calculations of Pyle and Derwent. Using their percentage depletion values, we 
arrive at an RAF range between 2.5 and 3.0 for DNA-weighted DUV dose and between 1.95 and 2.25 for erythemally weighted DUV dose.

Influences of changing atmospheric conditions (for example, due to aerosols) have not been considered in the calculations presented here. Analyses are in progress that quantify the effects of aerosols on UV-B radiation and DUV doses.

\section{REFERENCES}

1. "Protection Against Depletion of Stratospheric Ozone by Chlorofluorocarbons," National Academy of Sciences (Washington, D. C., 1979).

2. "Stratospheric Ozone Depletion by Halocarbons, Chemistry, and Transport," National Academy of Sciences (Washington, D. C., 1979).

3. M. J. Molina and F. S. Rowland, "Stratospheric Sink for Chlorofluoromethanes: Chlorine Atom Catalysed Destruction of Ozone," Nature 249, 810-812 (1974).

4. P. H. Wine, A. R. Ravishankra, N. M. Kreutter, R. C. Shah, J. M. Nicovich, R. L. Thompson, and D. J. Wuebbles, "Rate of Reacton of OH with HNO 3 ," J. Geoph. Res. 86, 1105-1112 (1981).

5. J. A. Pyle, "A Simple Calculation of Ozone Depletion by Chlorofluoromethanes Using a Two-dimensional Model," Nature 271, 42-43 (1978).

6. J. A. Pyle and R. G. Derwent, "Possible Ozone Reductions and UV Changes at the Earth's Surface," Nature 286, 373-375 (1980).

7. H. F. Blum, Carcinogenesis by Ultraviolet Light (Princeton University Press, Princeton, N.J., 1953).

8. F. Urbach, The Biologic Effects of Ultraviolet Radiation (Pergamon Press, New York, 1969).

9. A. E. S. Green, G. B. Findley, Jr., K. F. Klenk, W. H. Wilson, and T. Mo, "The Ultraviolet Dose Dependence of Non-Melanoma Skin Cancer Incidence," Photochem. Photobiol. 24, 356-362 (1976).

10. R. A. McClatchey, R. W. Fenn, J. E. A. Selby, F. E. Volz, and J. S. Garing, "Optical Properties of the Atmosphere," Environmental Research Papers, No. 411, Air Force Cambridge Research Laboratory report, AFCRL-72-0497, (August 1972).

11. T. R. Hill, "ONETRAN: A Discrete Ordinates Finite Element Code for the Solution of the One-Dimensional Multigroup Transport Equation," Los Alamos Scientific Laboratory report LA-5990-MS (June 1975).

12. S. A. W. Gerstl, "Application of the Adjoint Method in Atmospheric Radiative Transfer Calculations," Los Alamos Scientific Laboratory paper LA-UR-80-17 (January 1980). 
13. E. P. Shettle and A. E. S. Green, "Multiple Scattering Calculation of the Middle Ultraviolet Reaching the Ground," Appl. Opt. 13, 1567-1581 (1974).

14. A. E. S. Green, T. Sawada, and E. P. Shettle, Photochem. Photobiol. 19, 25125 (1974).

15. M. Griggs, in The Middle Ultraviolet: Its Science and Technology, A. E. S. Green, Ed. (Wiley, New York, 1966), pp. 83-117.

16. E. Bauer, in "The Natural Stratosphere of 1974," CIAP Monograph I (US Dept. of Trans. report DOT-TST-75-51), pp. 1-10.

17. E. P. Shettle and R. W. Fenn, "Models of the Atmospheric Aerosols and Their Optical Properties," NATO Advisory Group for Aerospace Research and Development report AGARD-CP-183 (October 1975).

18. E. P. Shettle and R. W. Fenn, "Models for the Aerosols of the Lower Atmosphere and the Effects of Humidity Variations on Their Optical Properties," Environmental Research Papers No. 676, Air Force Geophysics Laboratory report AFGL-TR-79-0214 (September 1979).

19. E. Vigroux, "Contribution à l'étude expérimentale de l'absorption de l'ozone," Ann. Physique (Paris) 8, 709-761 (1953).

20. Solar Radiation, N. Robinson, Ed. (Elsevier, Amsterdam, London, New York, 1966), p. 2 .

21. G. I. Bell and S. Glasstone, Nuclear Reactor Theory (Van Nostrand, New York, 1970), Sec. 6.

22. W. W. Coblentz and R. Stair, "Data on the Spectral Erythemic Reaction of the Untanned Human Skin to Ultraviolet Radiation," US Bureau of Standards. J. Res. 12, 13-14 (2934).

23. F. X. Kneizys, E. P. Shettle, W. O. Gallery, J. H. Chetwynd, Jr., L. W. Abreu, J. E. A. Selby, R. W. Fenn, R. A. McClatchey, "Atmospheric Transmittance/Radiance, Computer Code LOWTRAN," Environmental Research Papers No. 697, Air Force Geophysics Laboratory report AFGL-TR-80-0067 (February 1980).

24. K. Y. Kondratyev, Radiation in the Atmosphere (Academic Press, New York, 1962).

25. M. C. Caldwel1, Bioscience 23, 520-525 (1979).

26. A. E. S. Green and J. H. Miller, in "Impacts of Climate Change on the Biosphere, Part I: Ultraviolet Radiation Effects," US Dept. of Transportation report DOT-TST-75-55 (1975), pp. 2-60 and 2-70.

27. R. B. Setlow, Proc. Natl. Acad. Sci. U.S.A. 71, 3363-3366 (1974).

28. M. I. Budyko, Climate and Life (Academic Press, New York, 1974). 
29. A. Zardecki and S. A. W. Gerstl, "Calculations of Solar Irradiances in Clear and Polluted Atmospheres and Potential Effects on Plant Life," Los Alamos National Laboratory report LA-9010-MS (October 1981). 
100.0\% OZONE; MIDLATITUDE WINTER

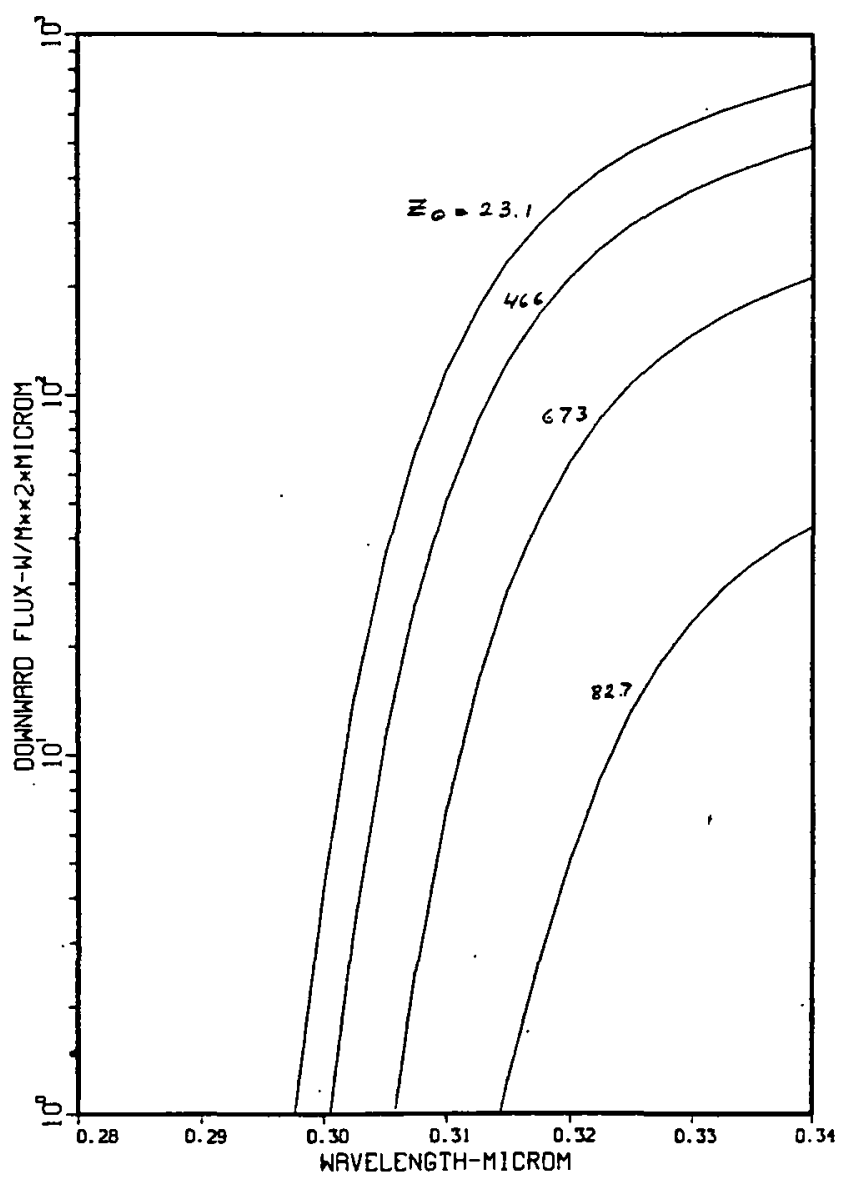

100.0\% OZONE; MIDLATITUDE WINTER

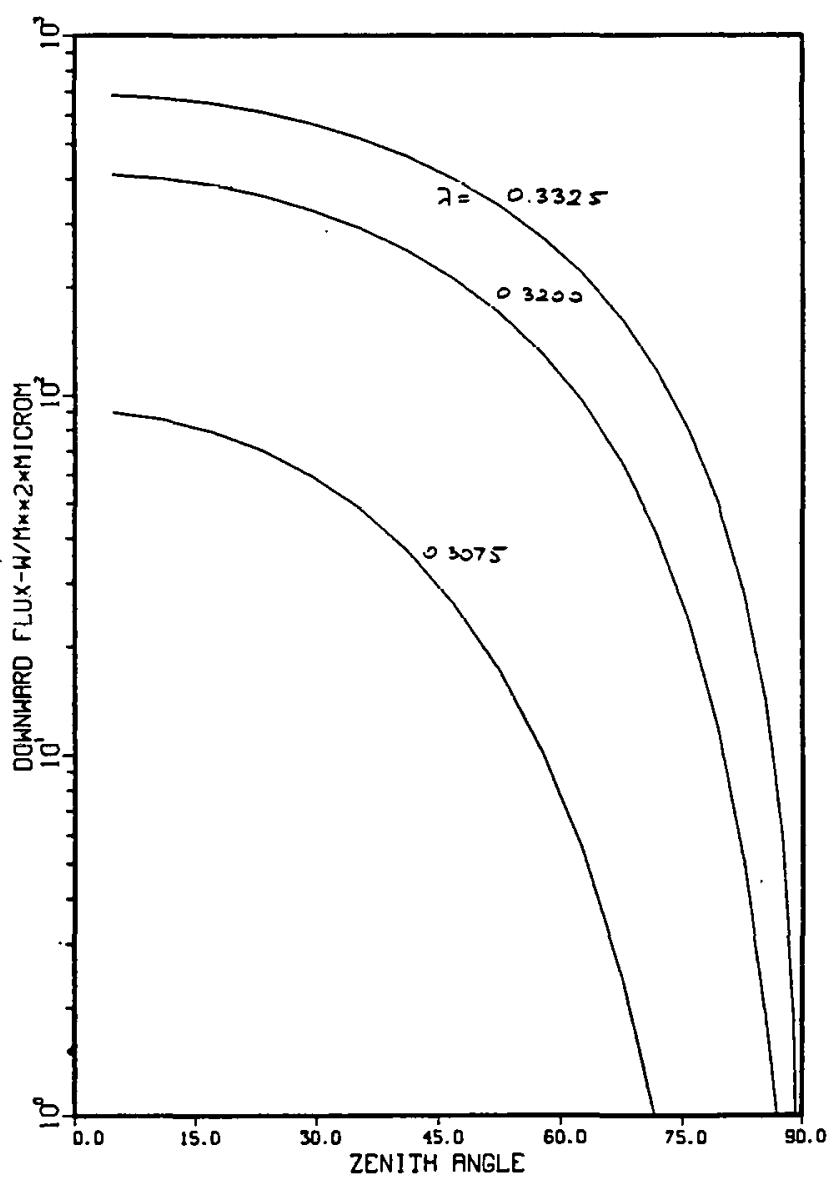

Figure 2 
97.0\% OZONE; MIDLATI IUDE WINTER

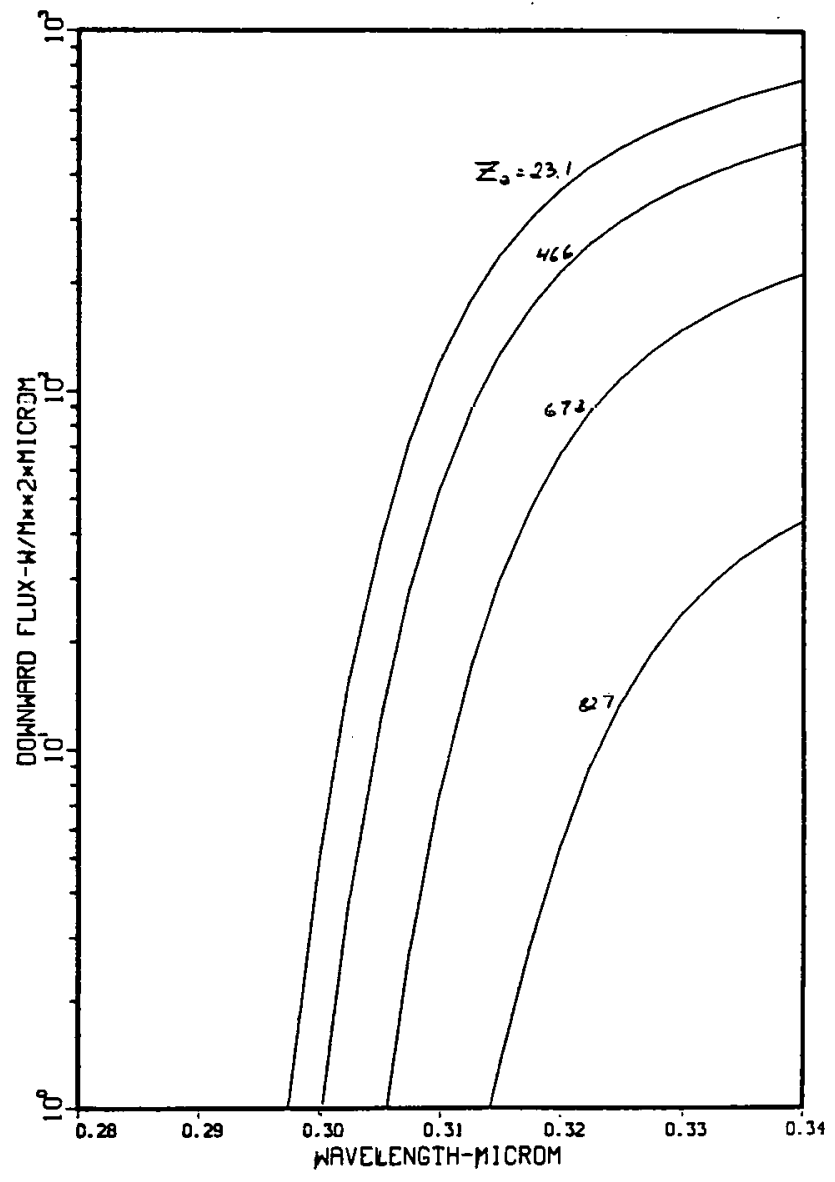

Figure 3
97. 0\% OZONE; MIDLATITUDE WINTER

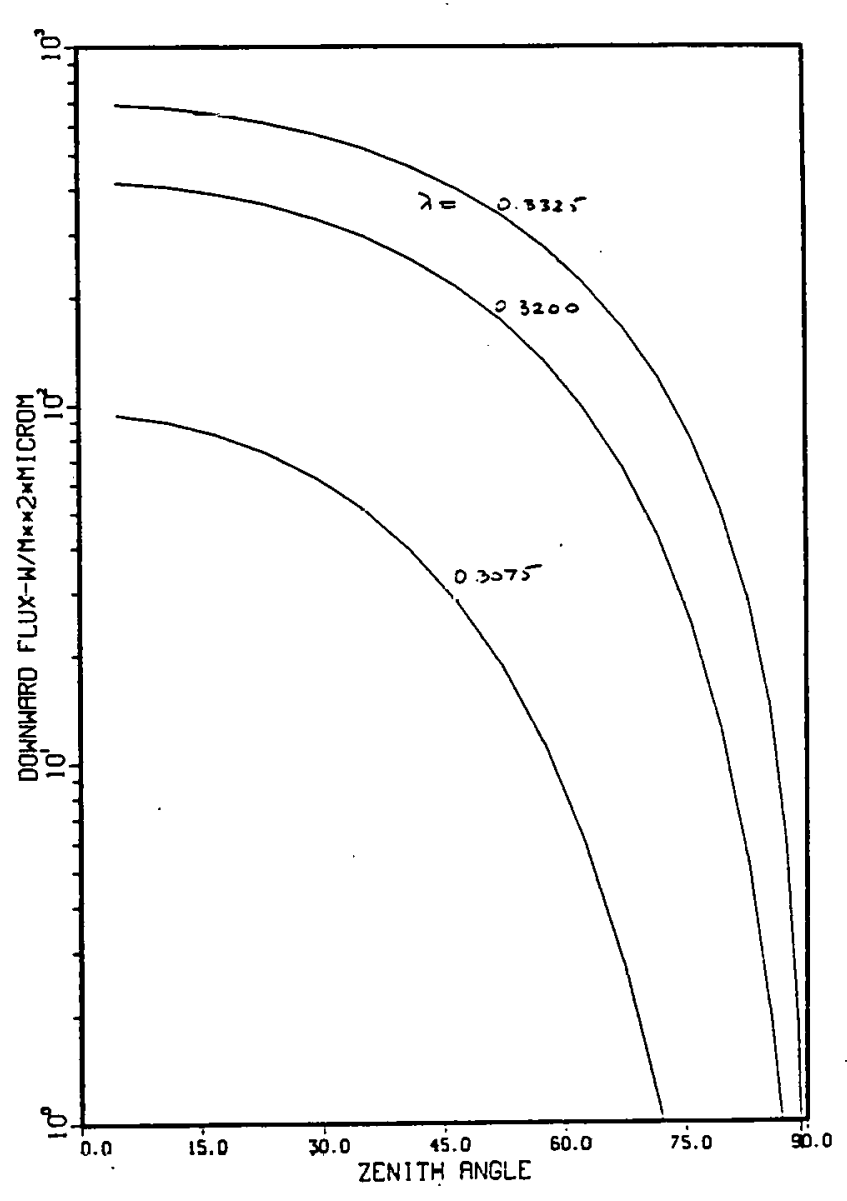

Figure 4 
90.0\% OZONE; MIDLATITUDE WINTER

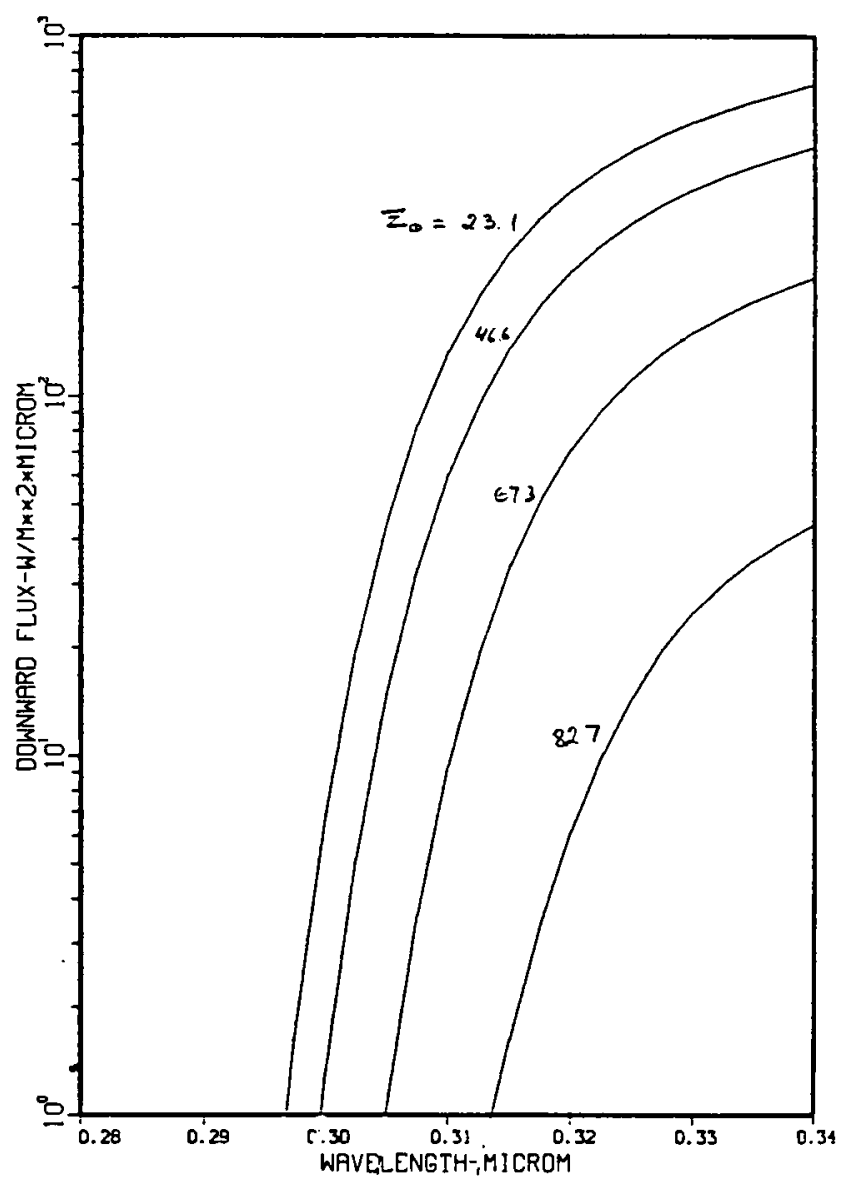

Figure 5
90.0\% OZONE; MIDLATITUDE WINTER

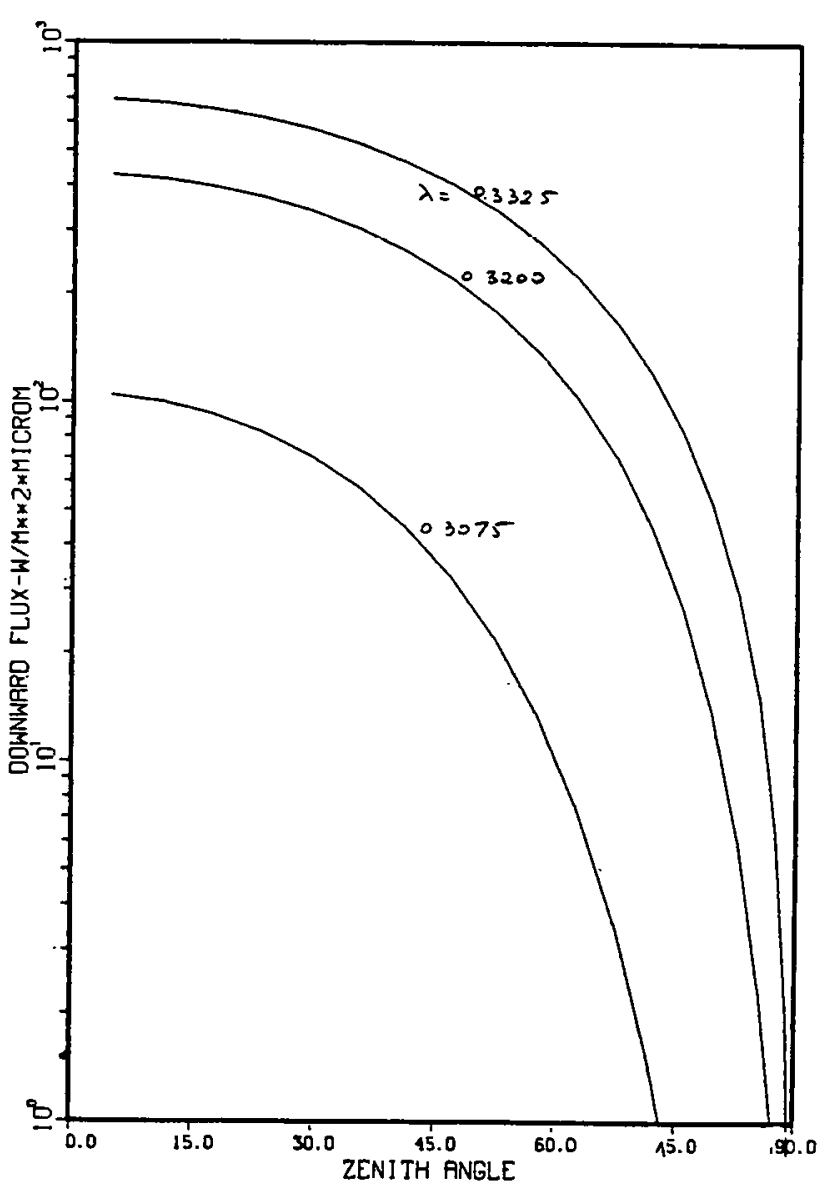

Figure 6 
95.0\% OZONE; MIDLATITUDE WINTER

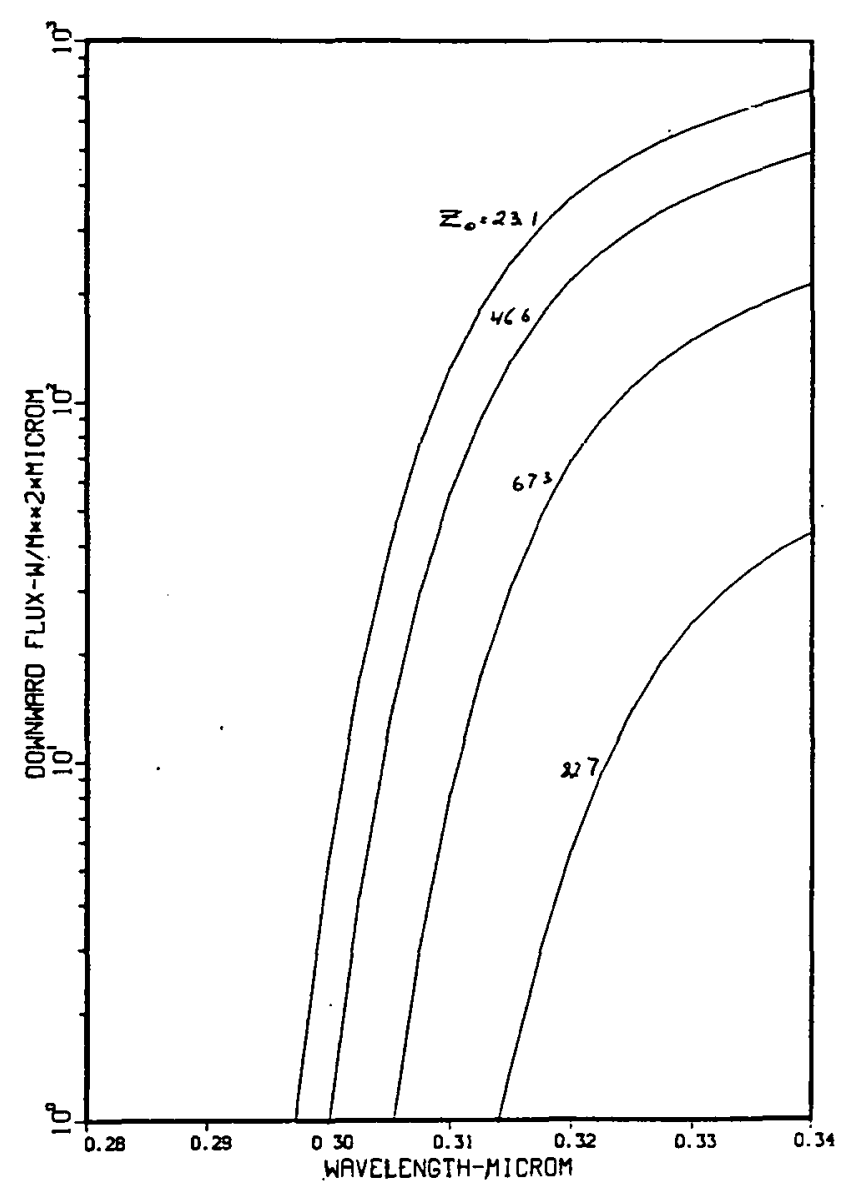

Figure 7

95.0\% OZONE; MIDLATITUDE WINTER

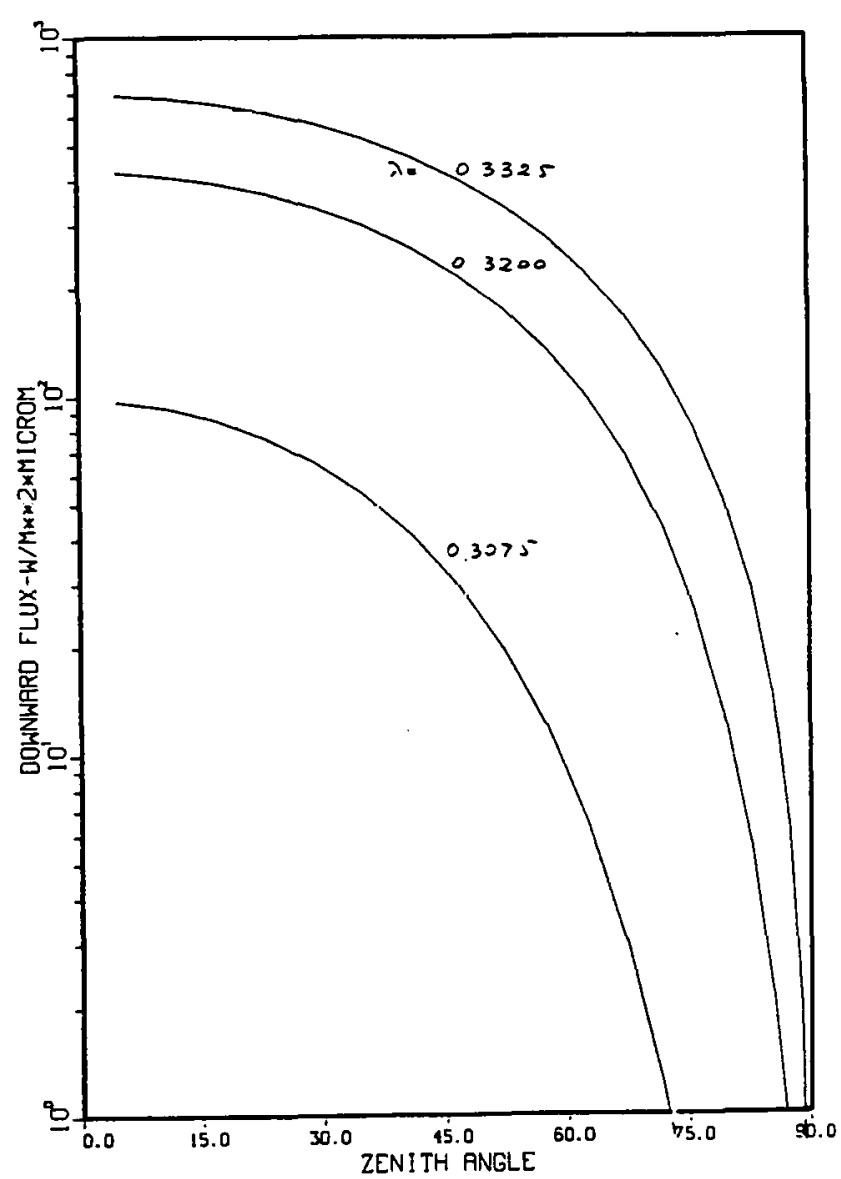

Figure 8 
85.0\% OZONE; MIDLRTITUDE WINJER

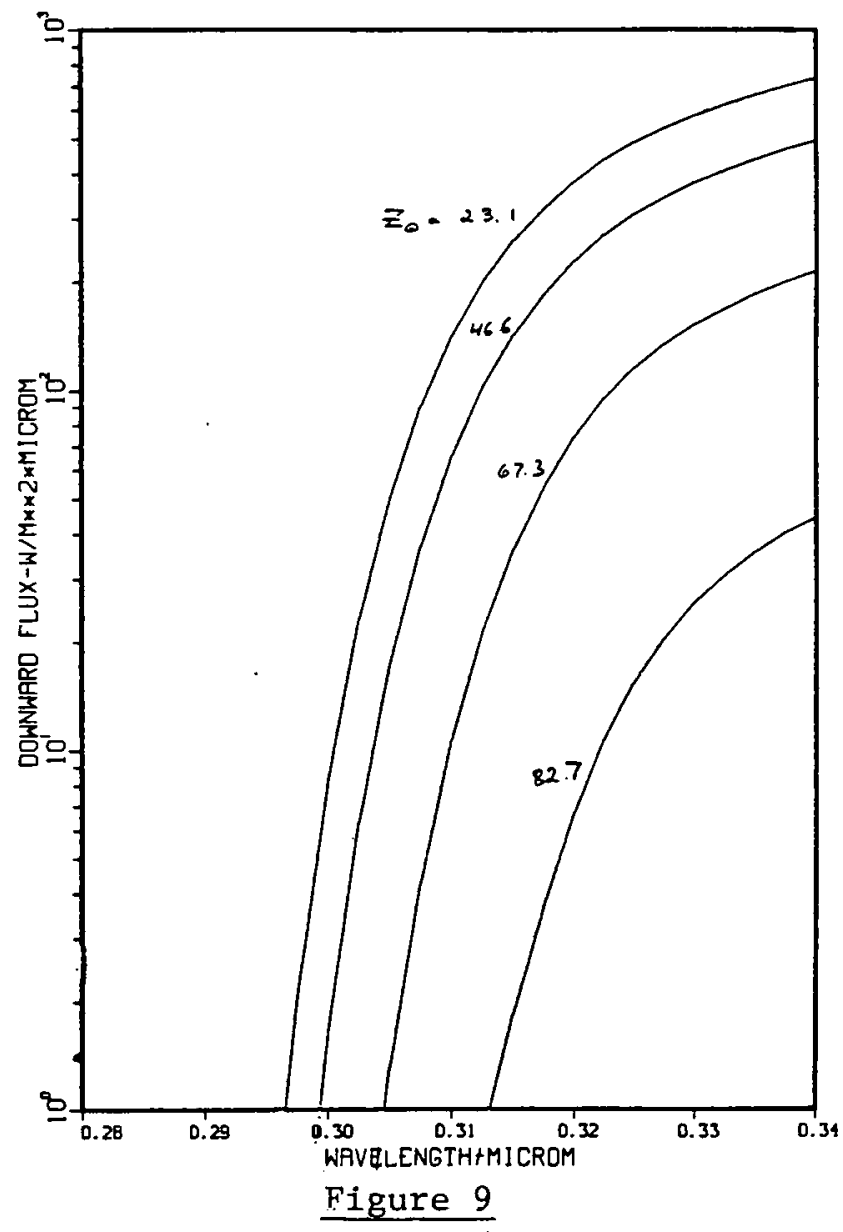

85. 0\% OZONE; MIDLATITUDE WINTER

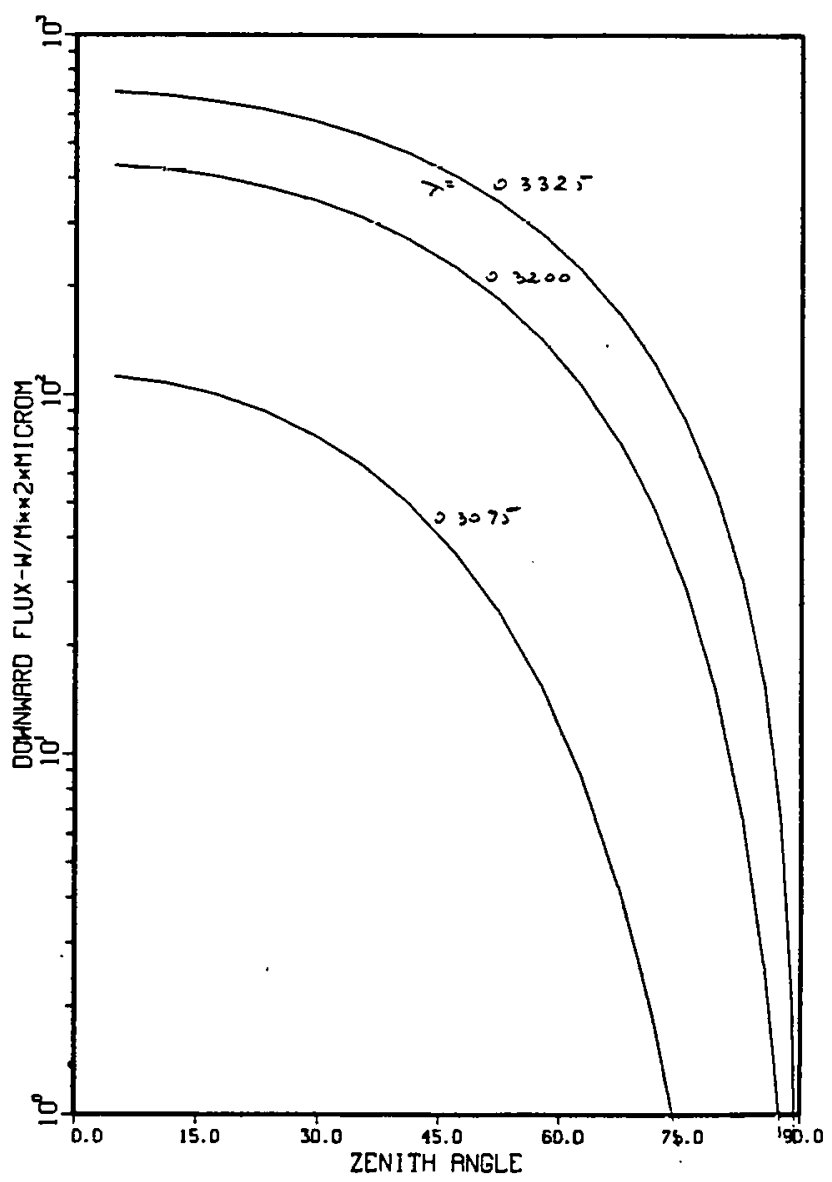

Figure 10 
80.0\% OZONE; MIDLATITUDE WINTER

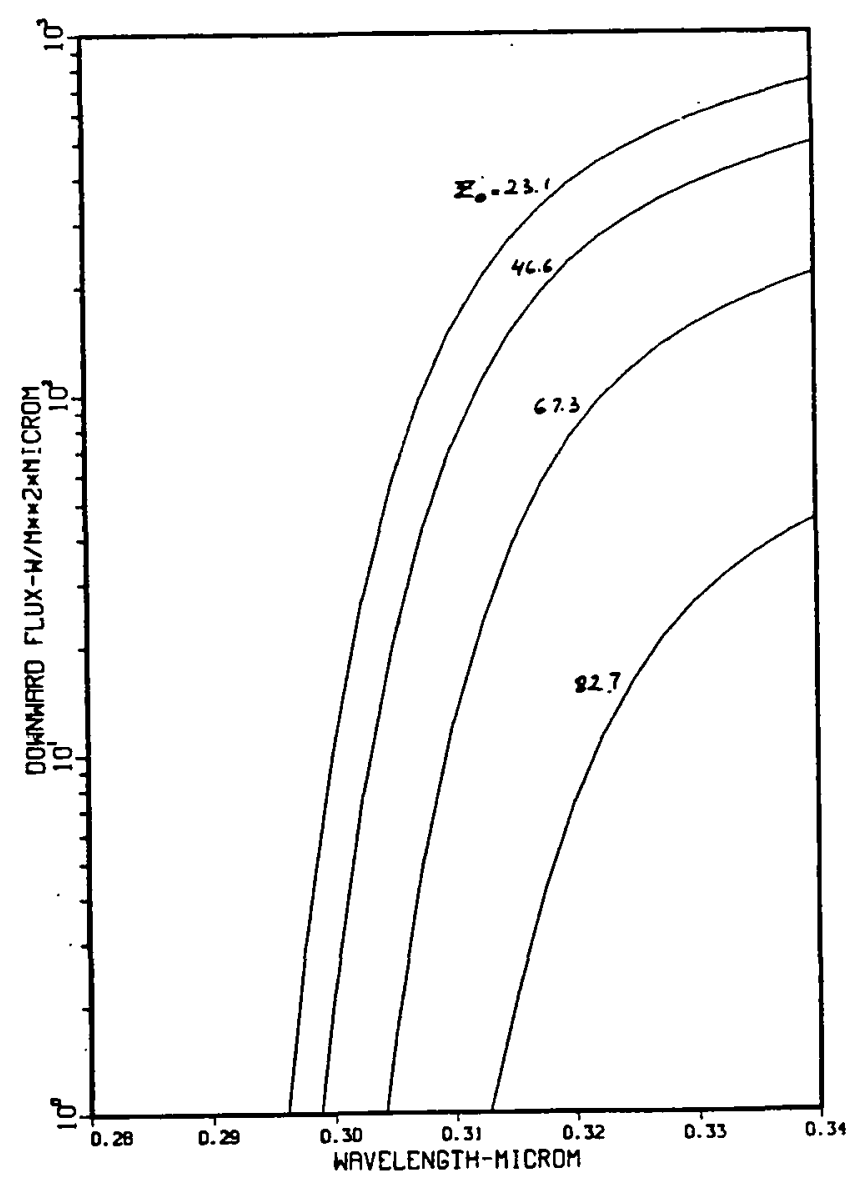

Figure 11

80.0\% OZONE; MIDLATITUDE WINTER

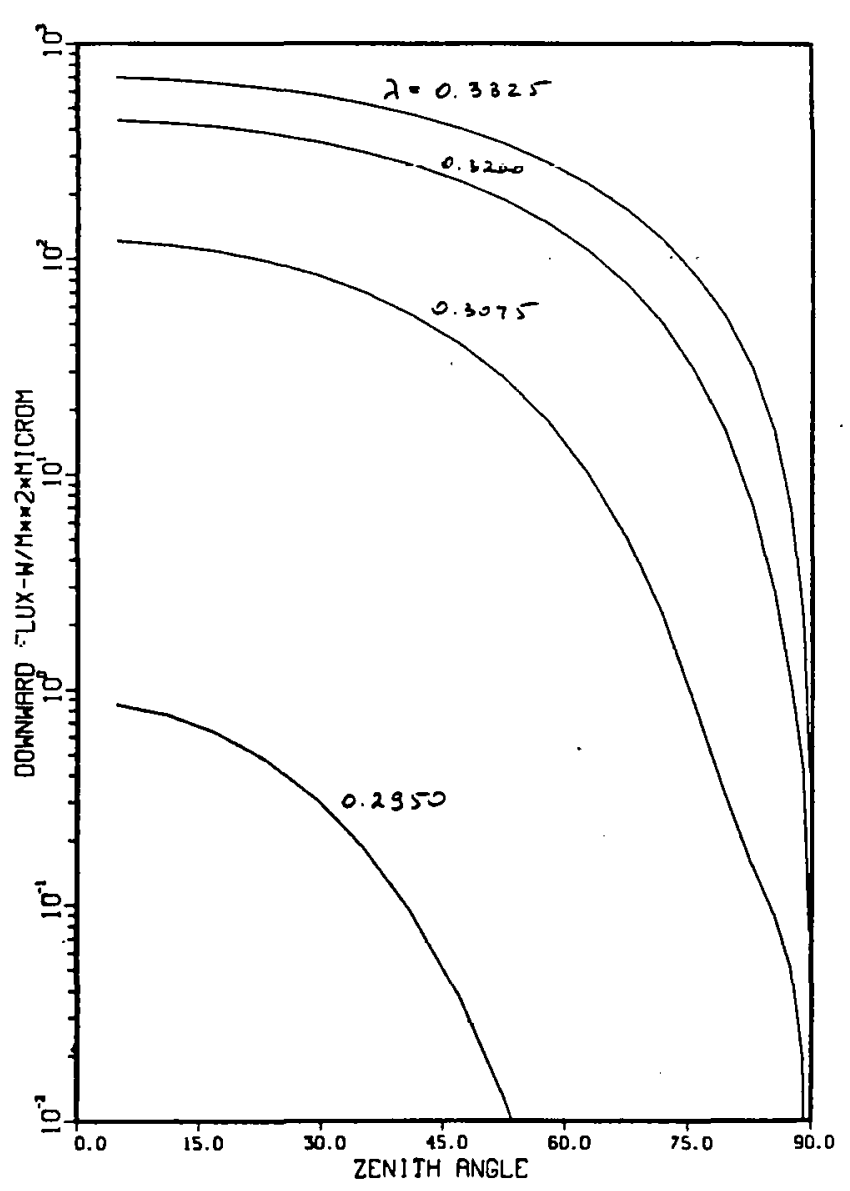

Figure 12 
80.0\% OZONE; MIDLATITUDE WINTER

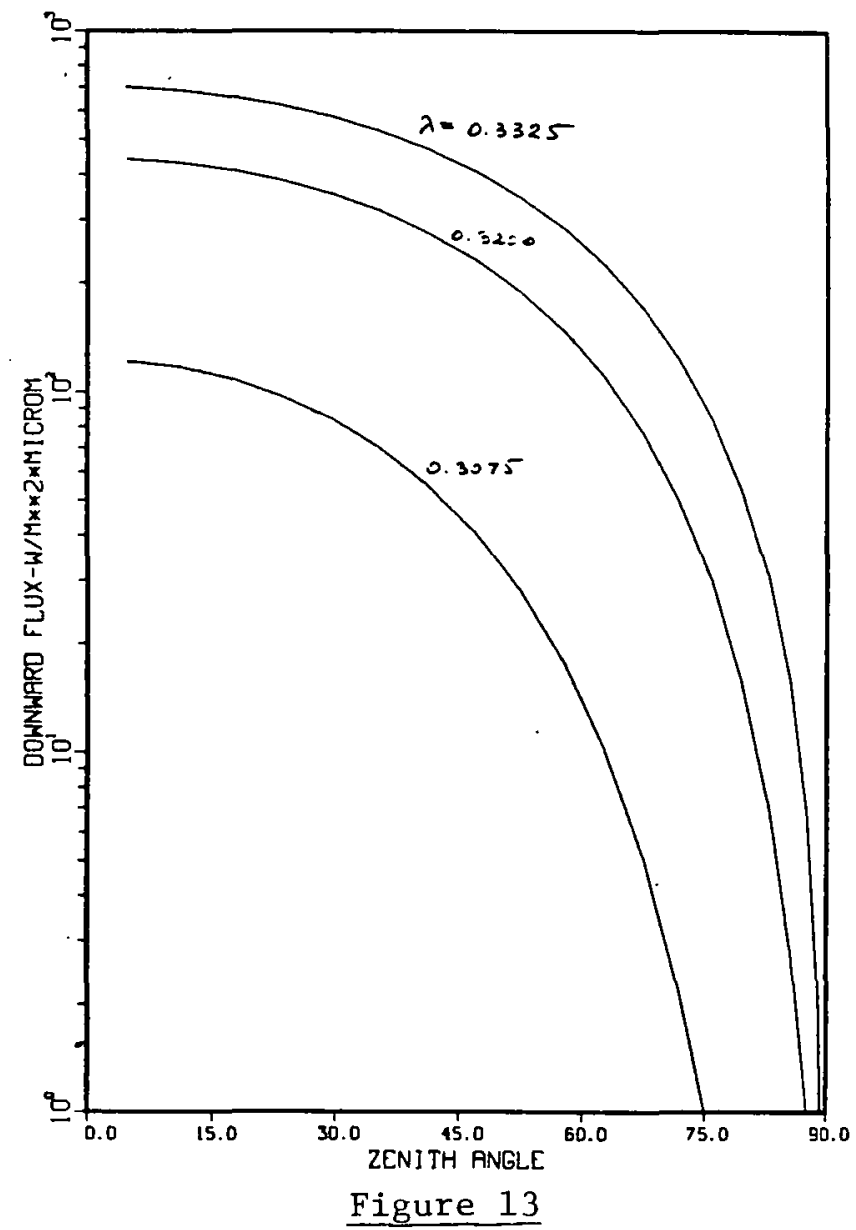

80.0\% OZONE; MIDLRTITUDE WINTER

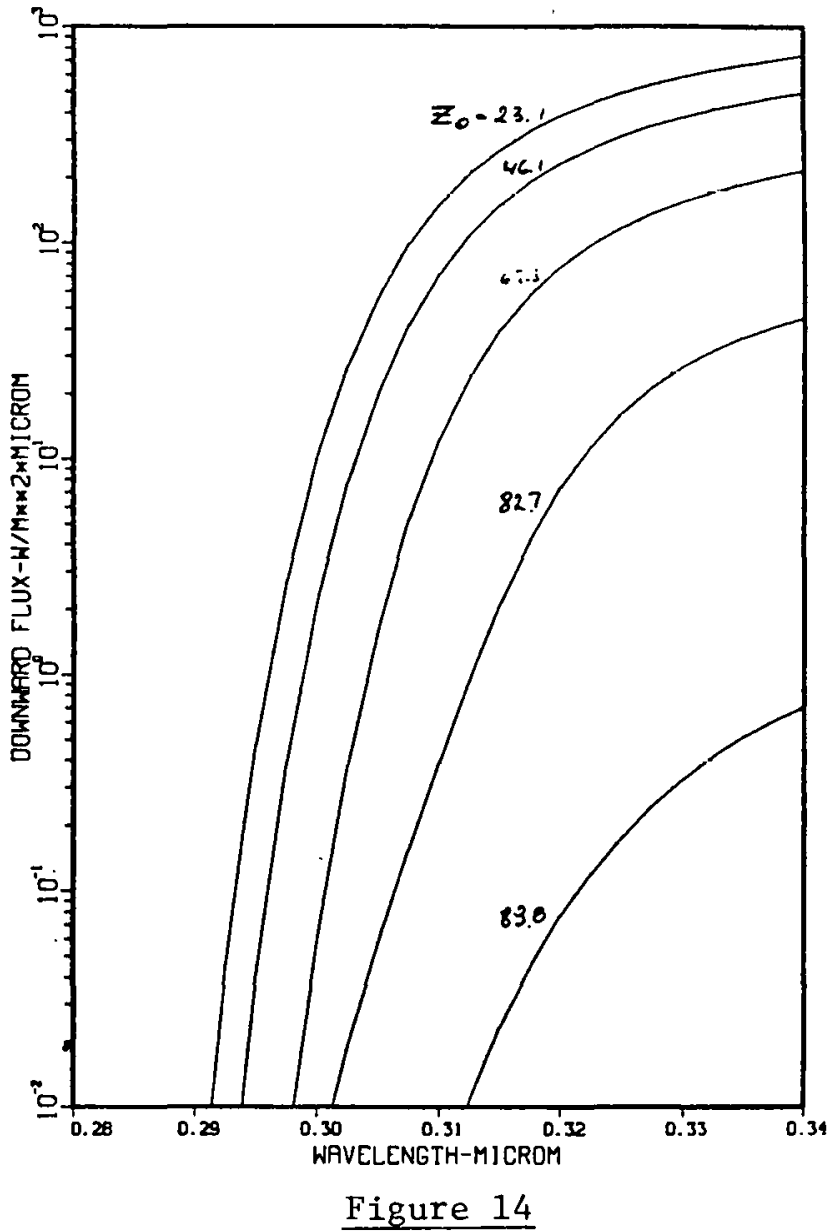


$100.0 \%$ OZONE; SUBARCTIC SUMMER

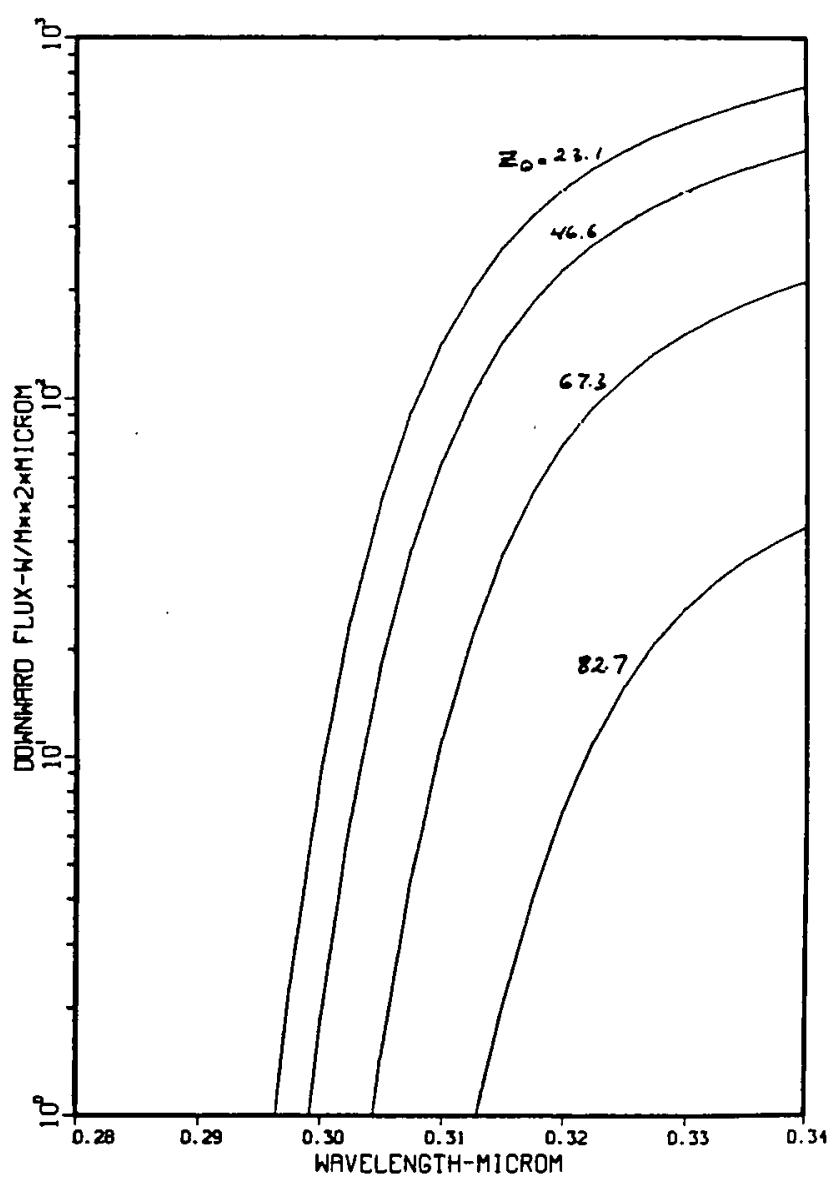

Figure 15
100.0\% OZONE; SUBARCTIC SUMMER

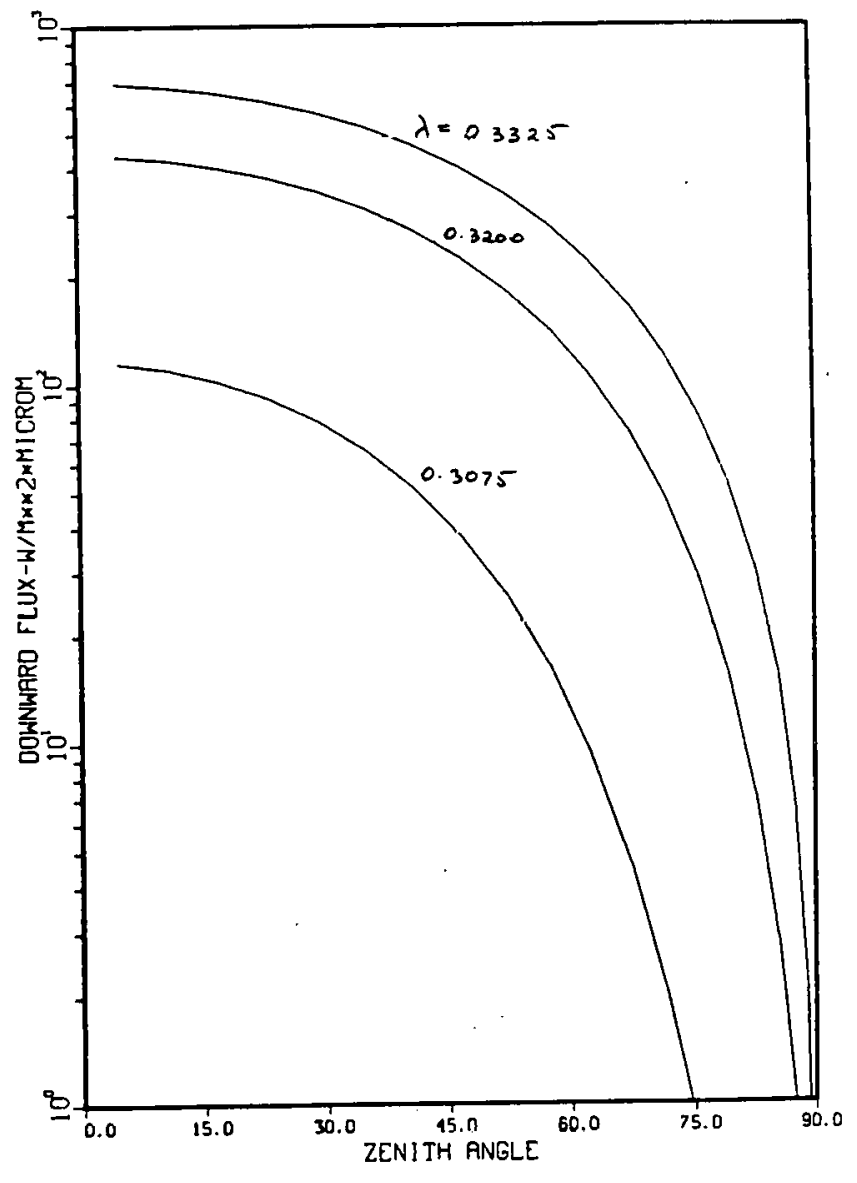

Figure 16 
97.0\% OZONE; SUBARCTIC SUMMER

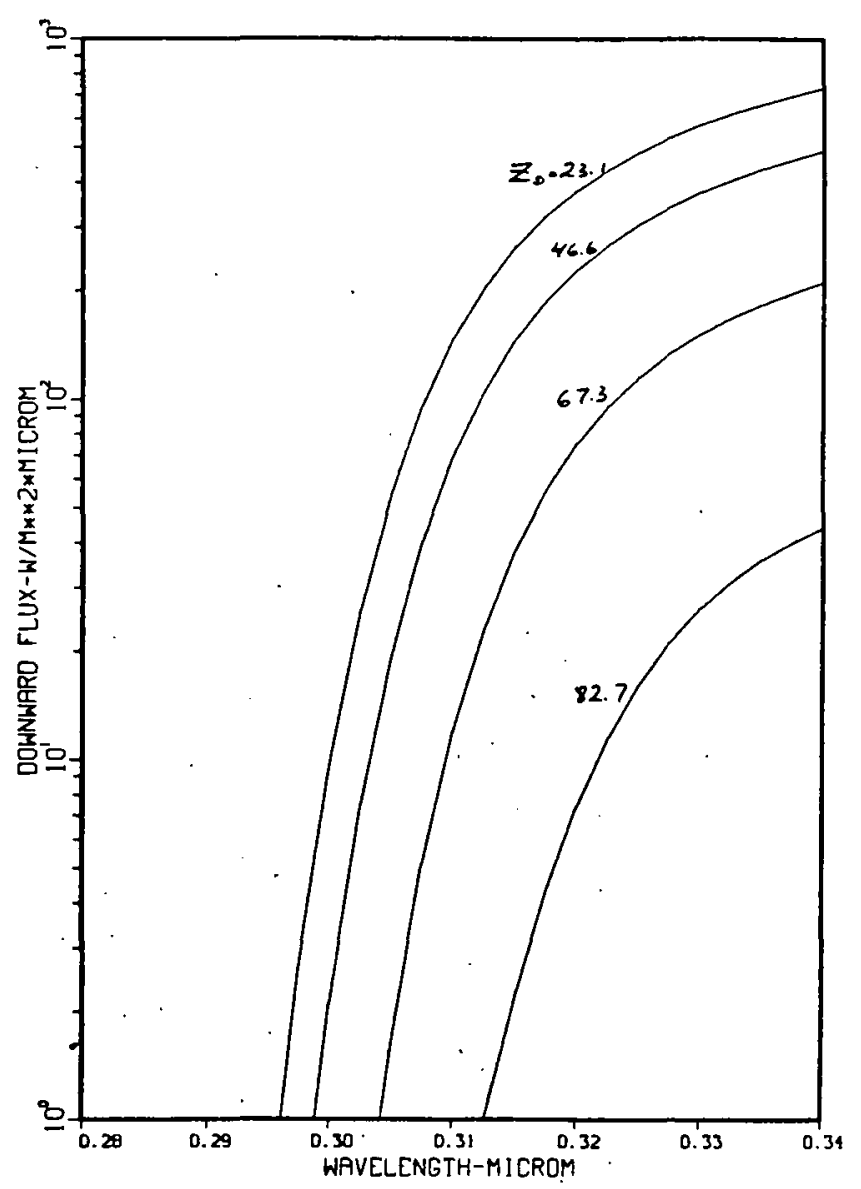

Figure 17
97.0\% OZONE; SUBARCTIC SUMMER

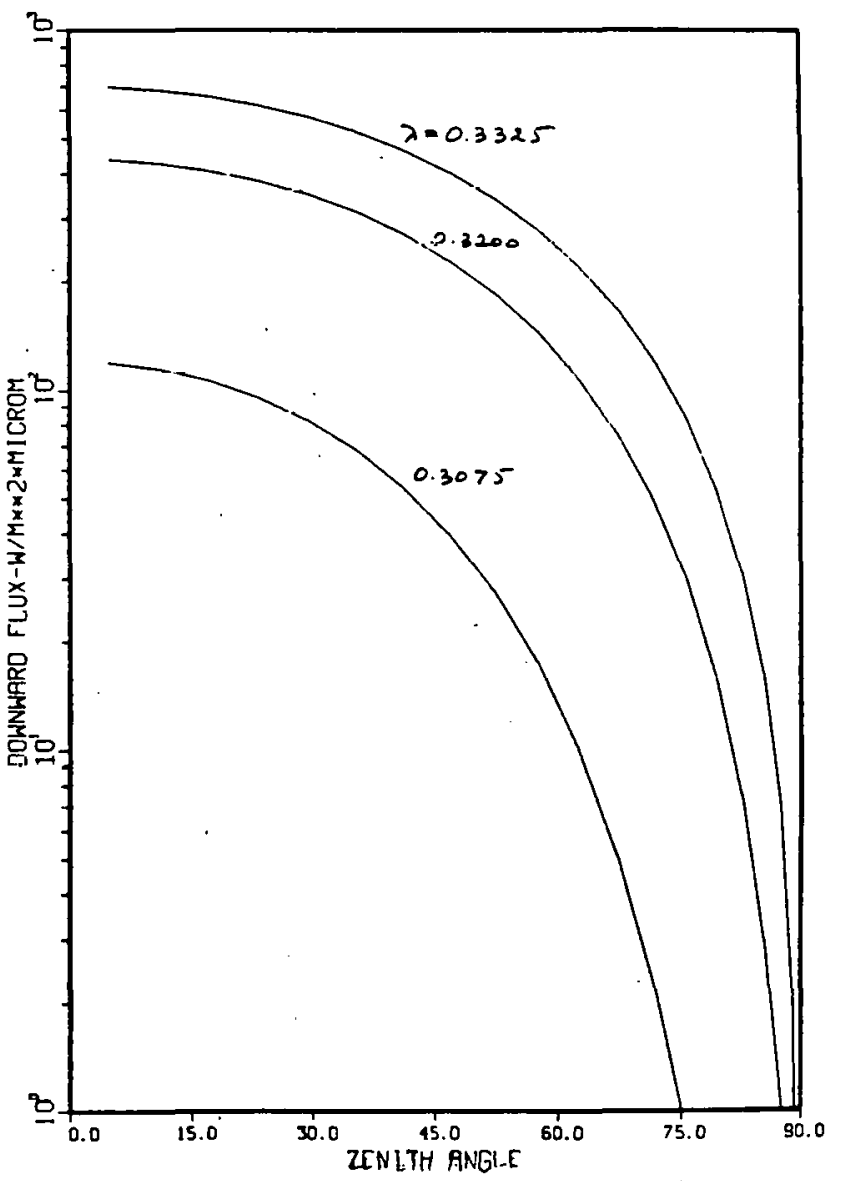

Figure 18 
95.0\% OZONE; SUBARCTIC SUMMER

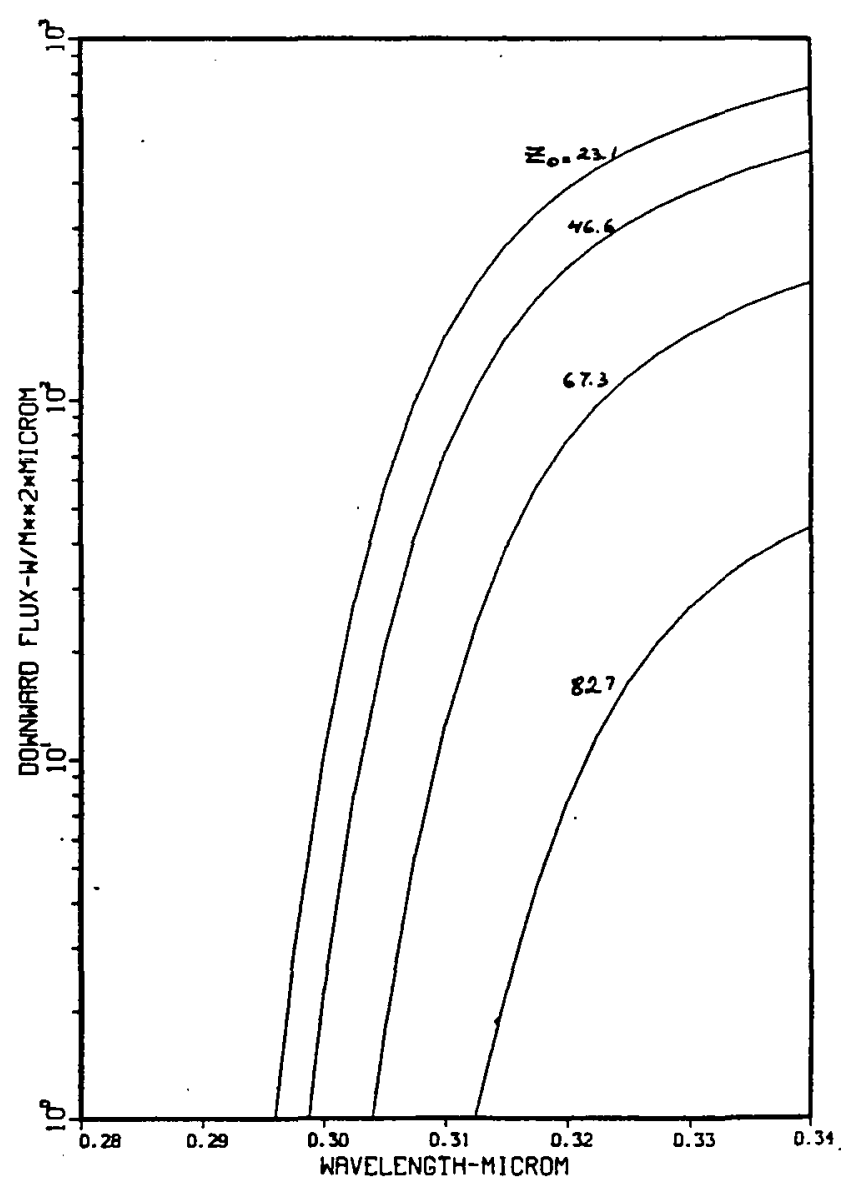

Figure 19
95.0\% OZONE; SUBRRCTIC SUMMER

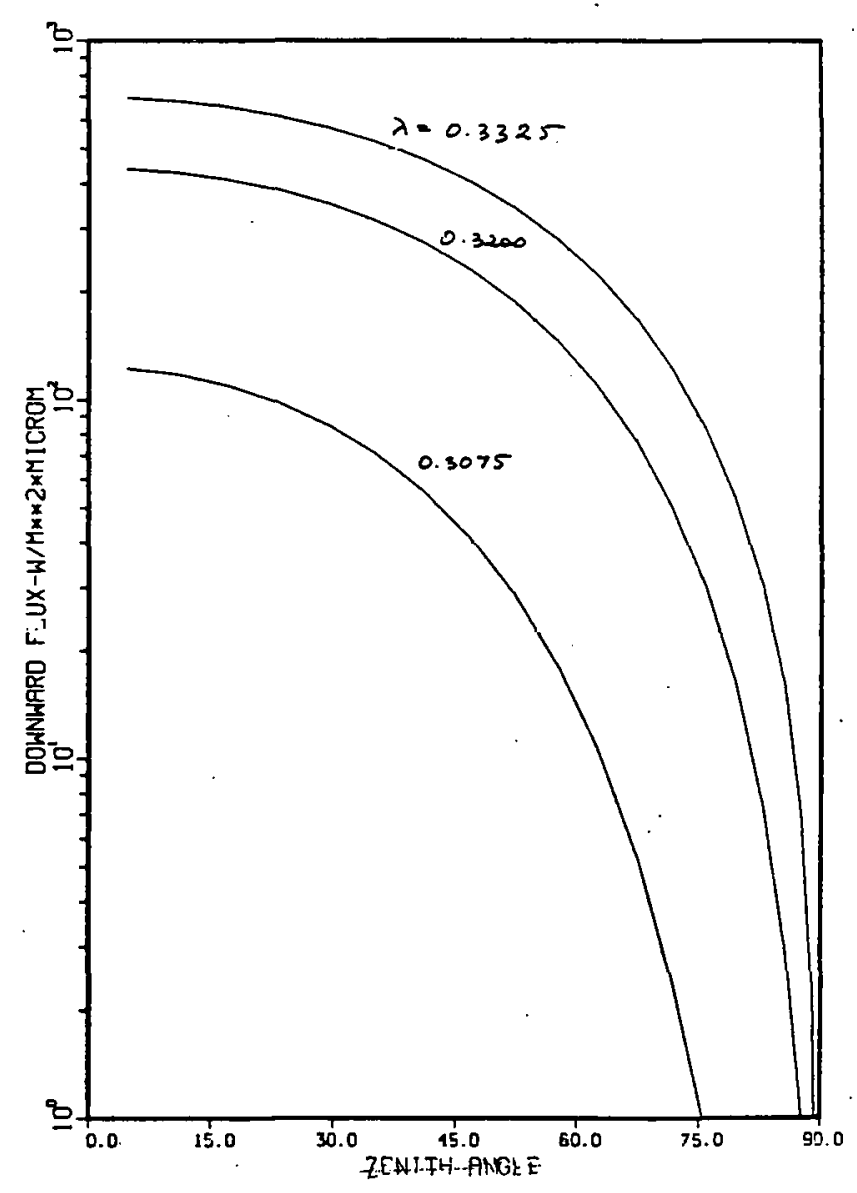

Figure 20 
90.0\% OZONE; SUBRRCTIC SUMMER

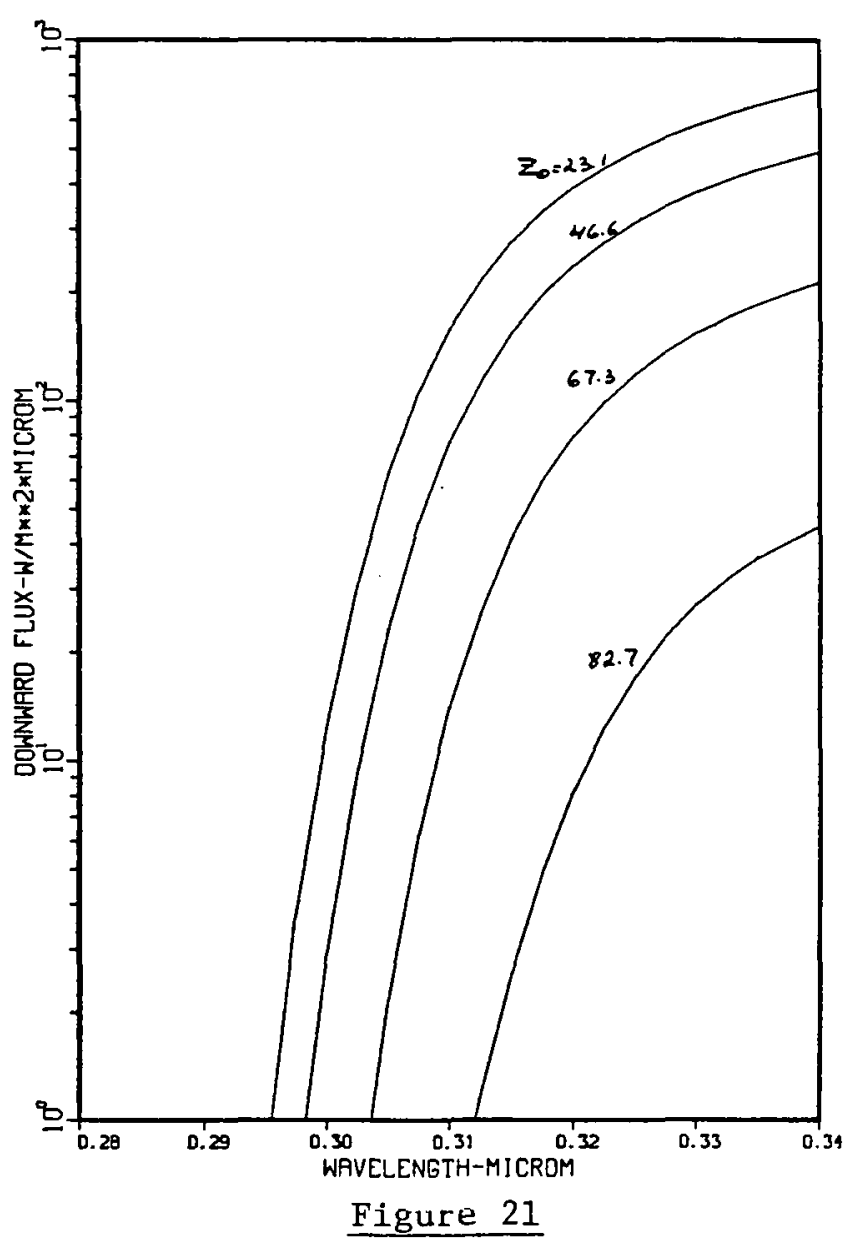

90.0\% OZONE; SUBARCTIC SUMMER

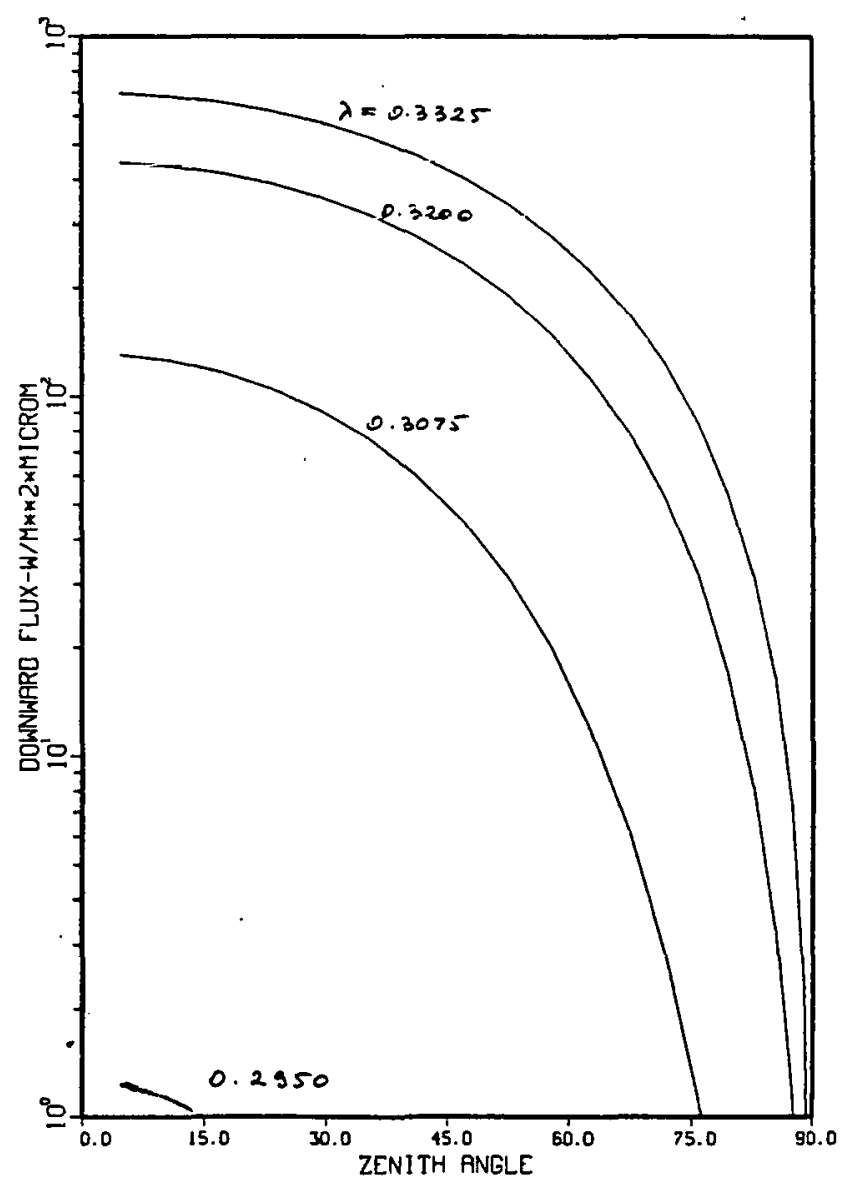

Figure 22 
85. 0\% OZONE; SUBARCTIC SUMMER

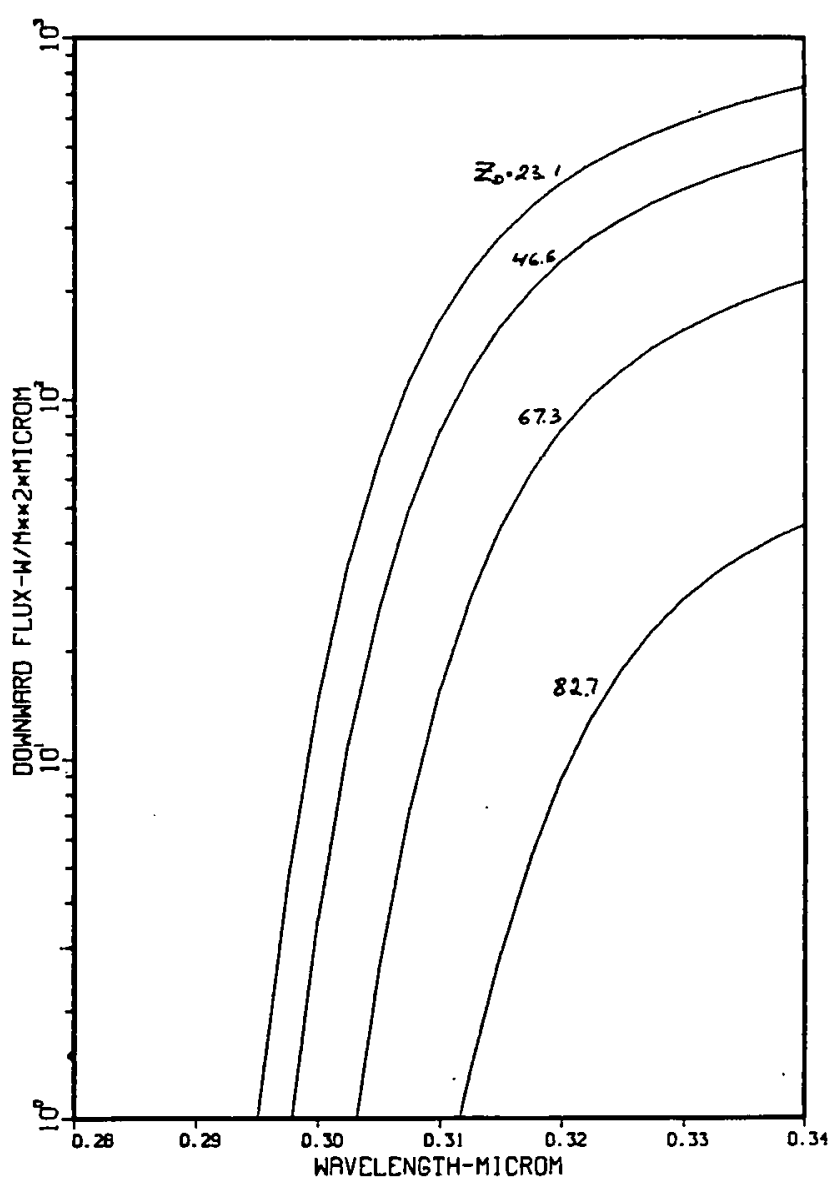

Figure 23

85.0\% OZONE; SUBARCTIC SUMMER

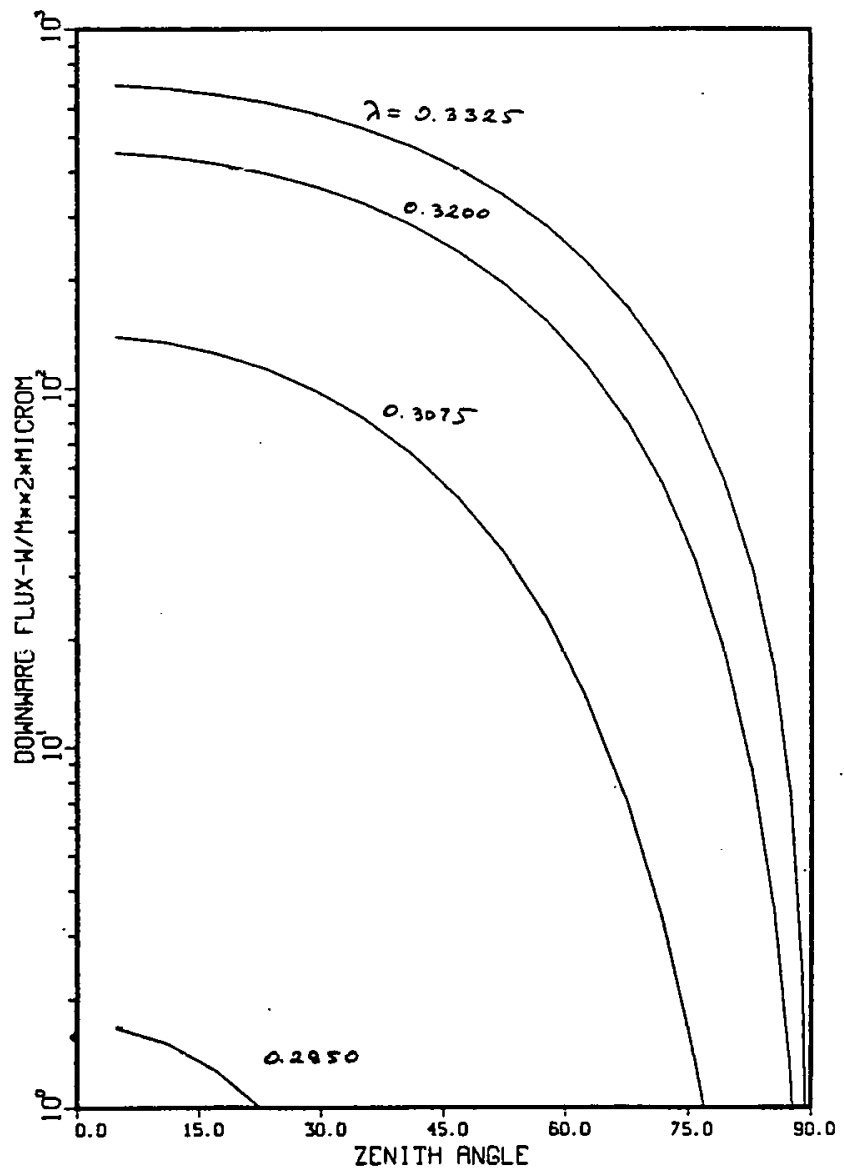

Figure 24 
80.0\% OZONE; SUBRRCTIC SUMMER

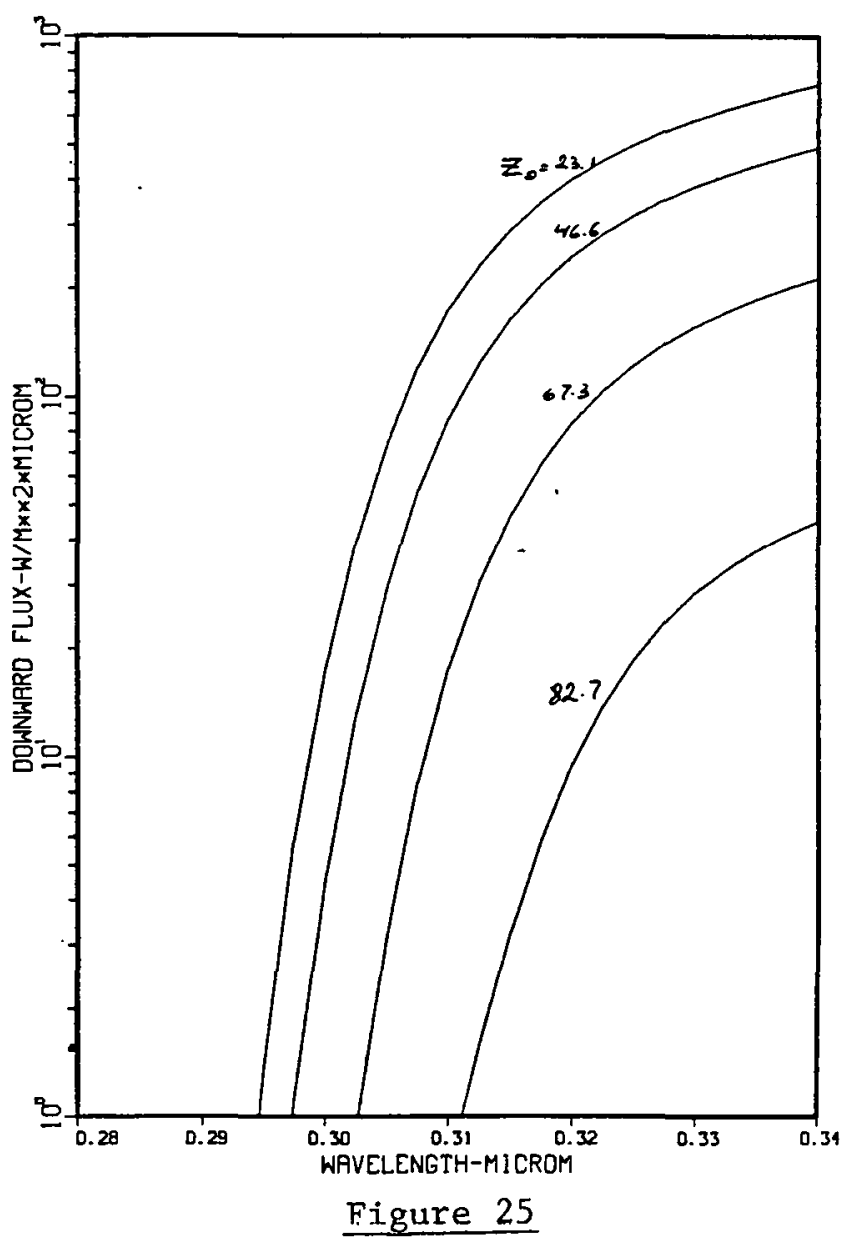

80.0\% OZONE; SUBARCTIC SUMMER

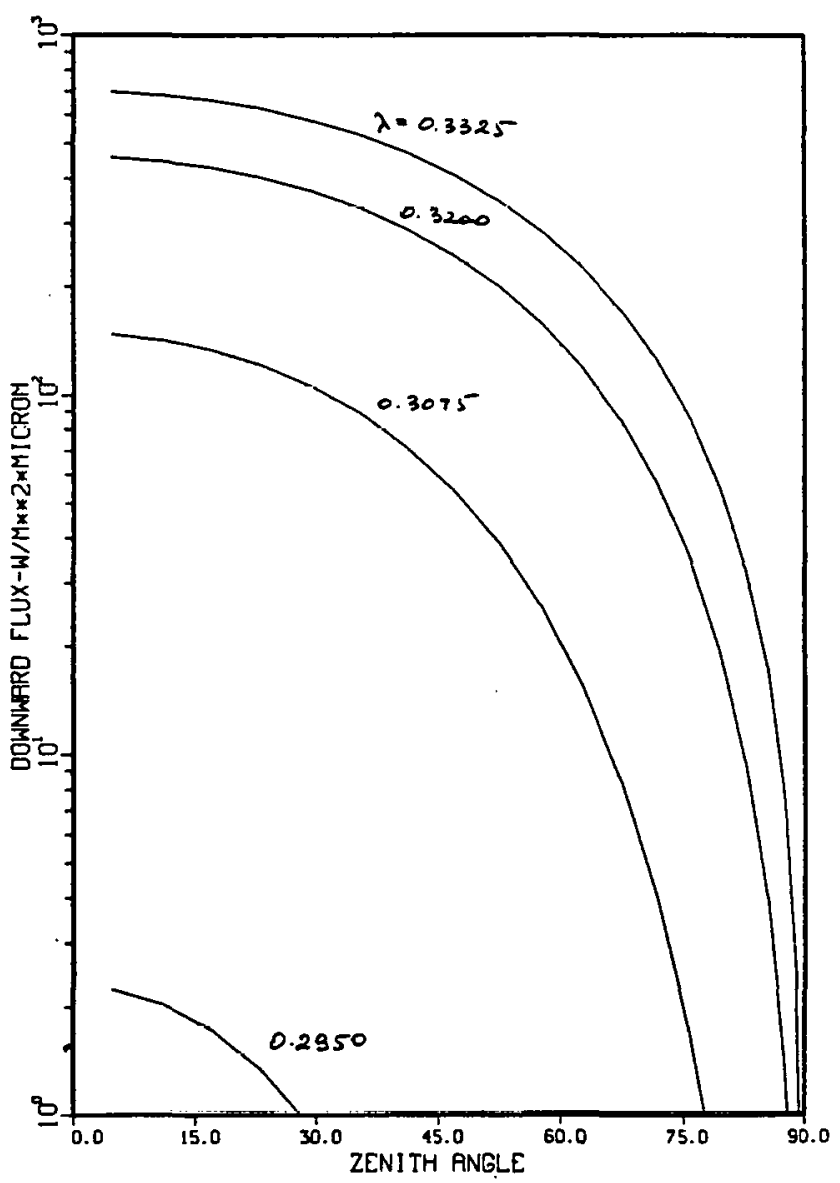

Figure 26 
100.0\% OZONE; SUBARCTIC WINIER

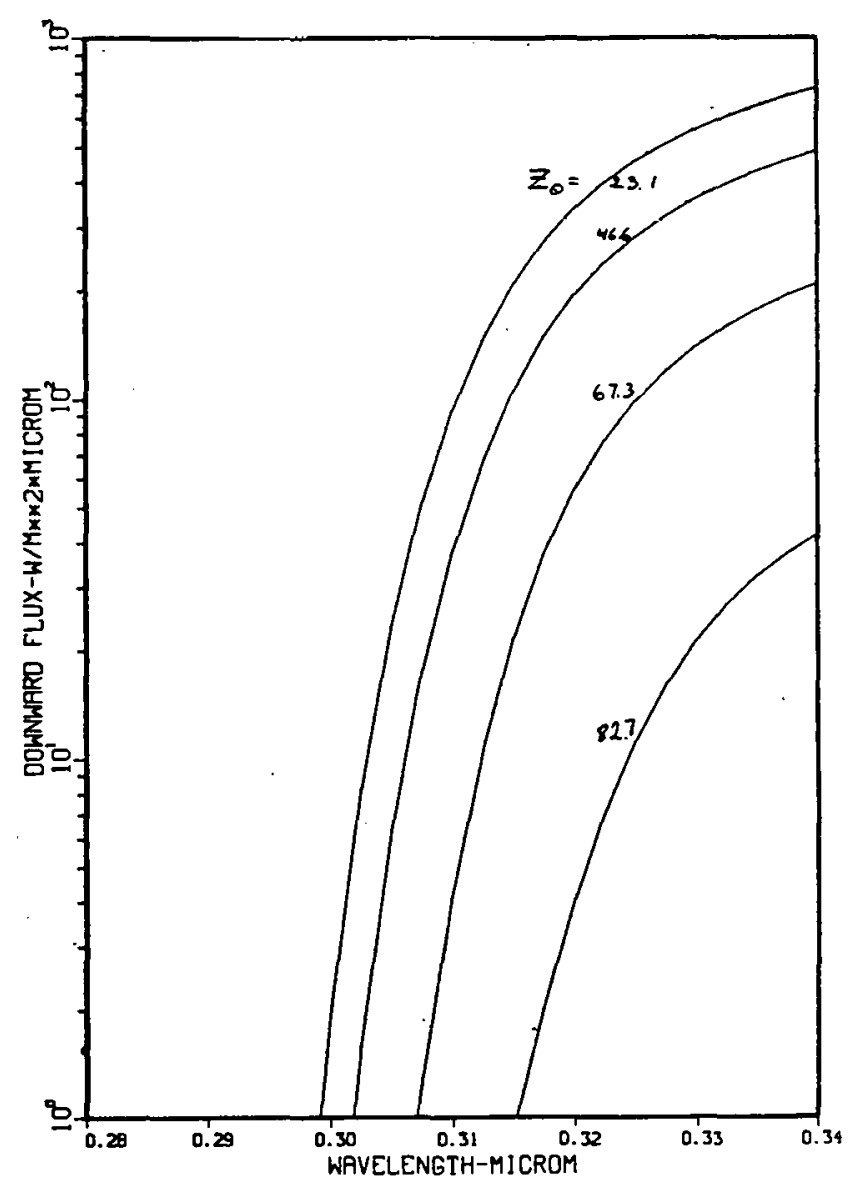

Figure 27
100.0\% OZONE; SUBARCTIC WINTER

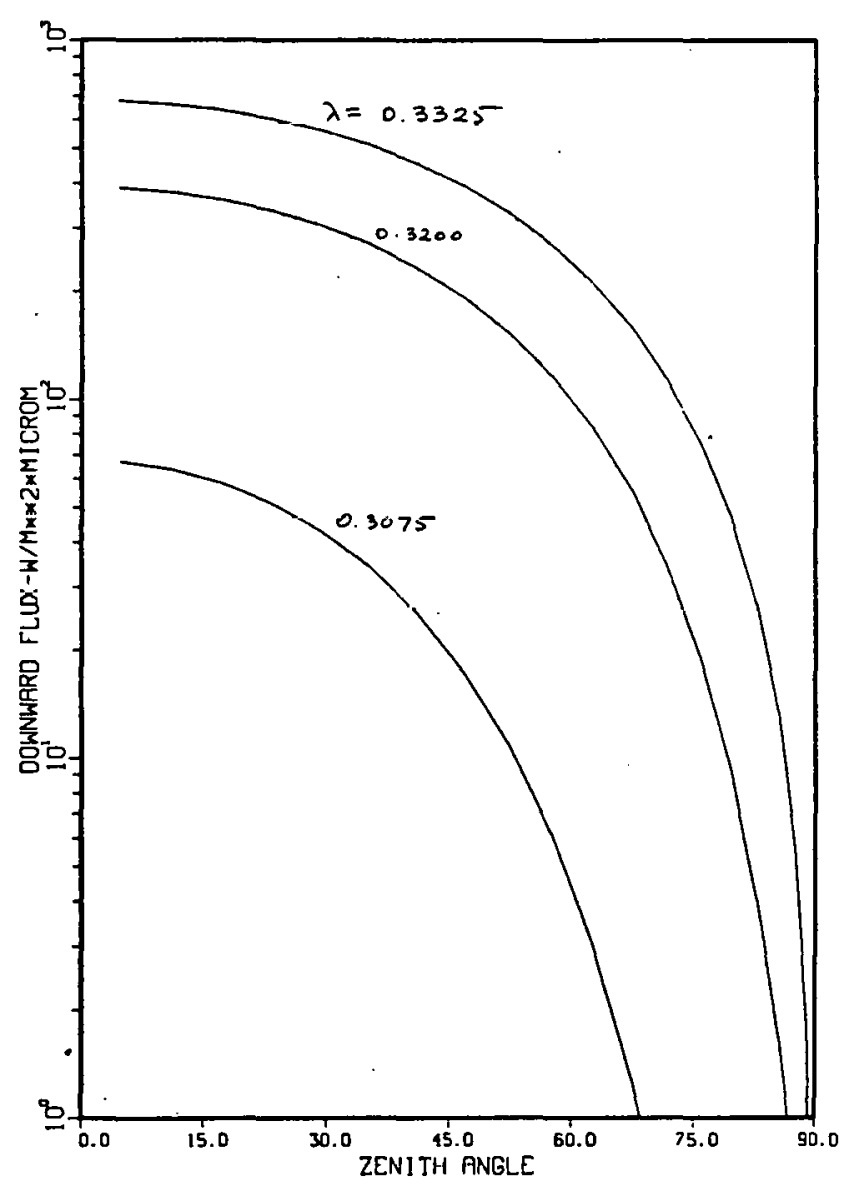

Eigure 28 
97.0\% OZONE; SUBARCTIC WINTER

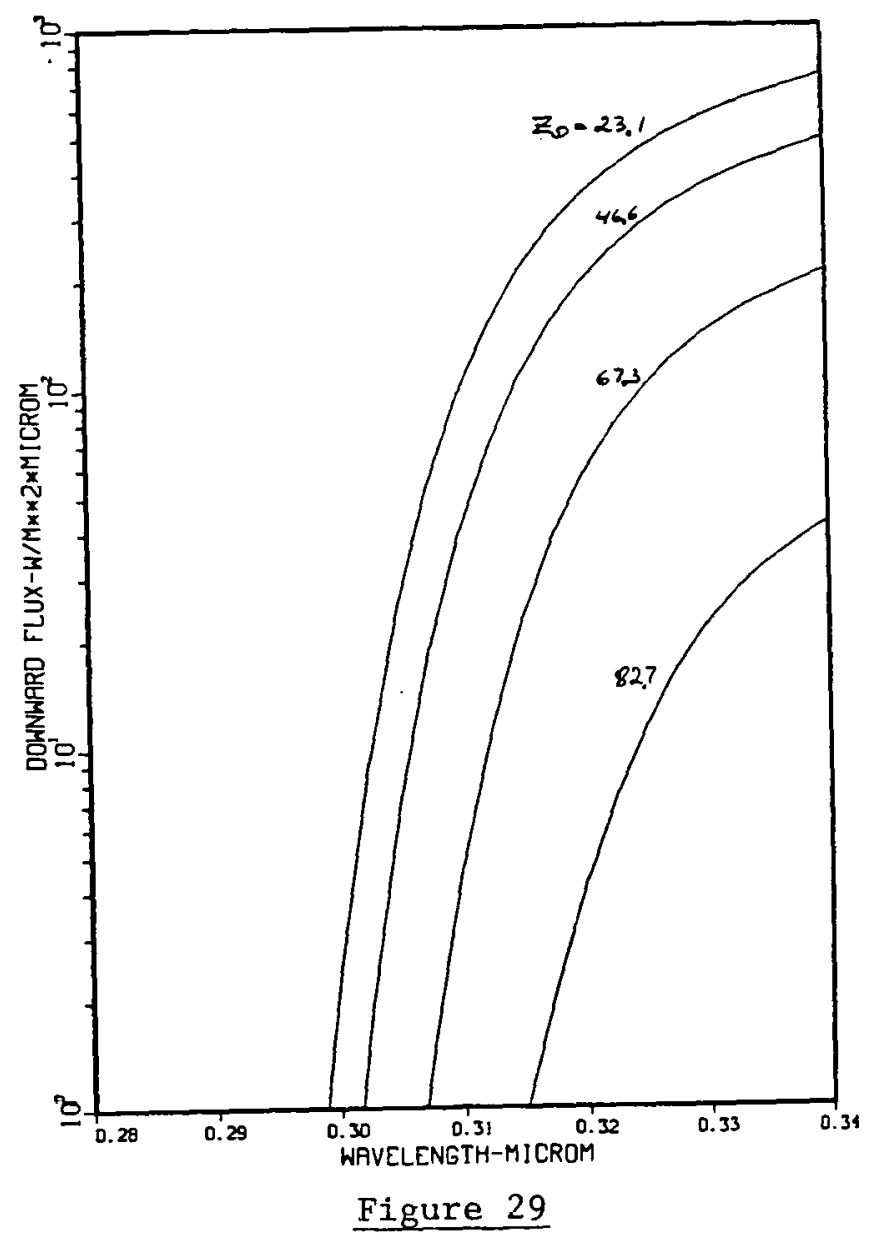

97.0\% OZONE; SUBARCTIC WINTER

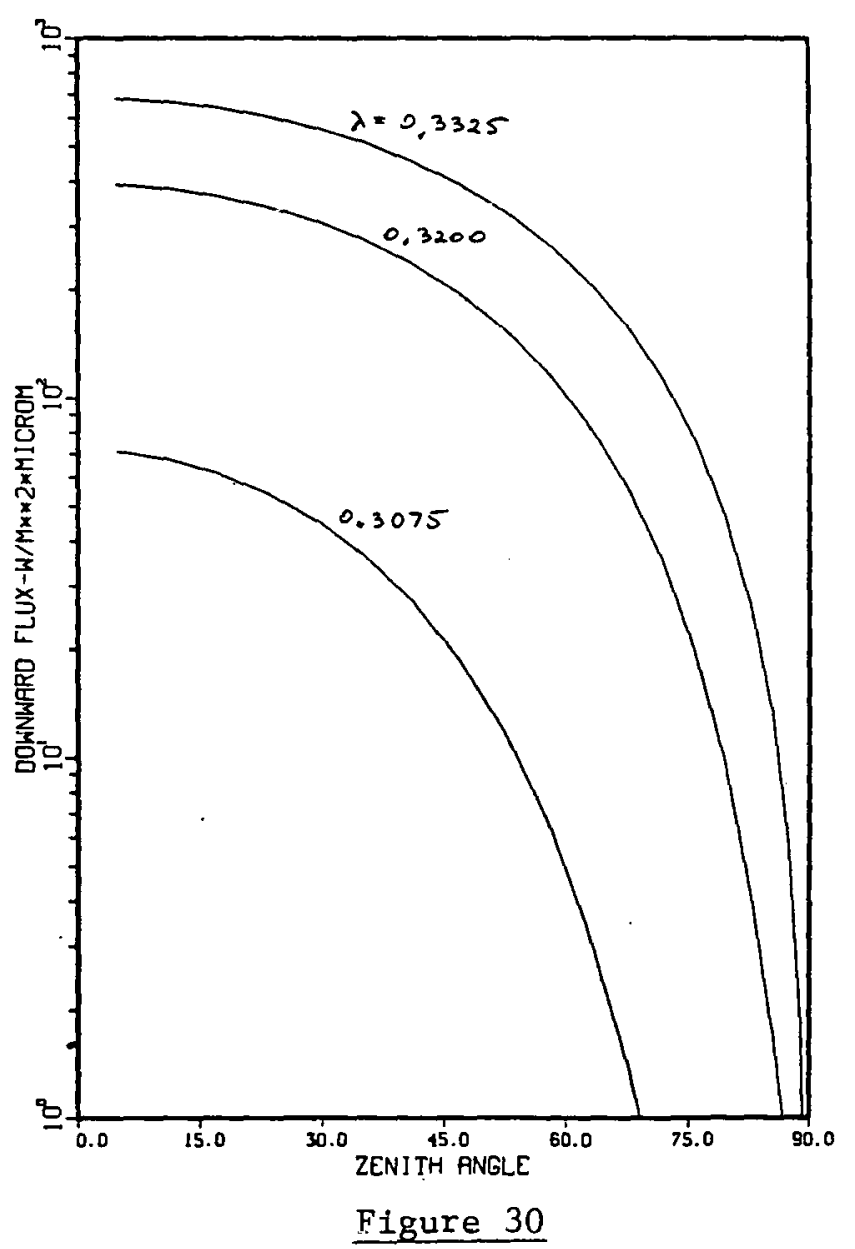


95.0\% OZONE; SUBRRCTIC WINTER

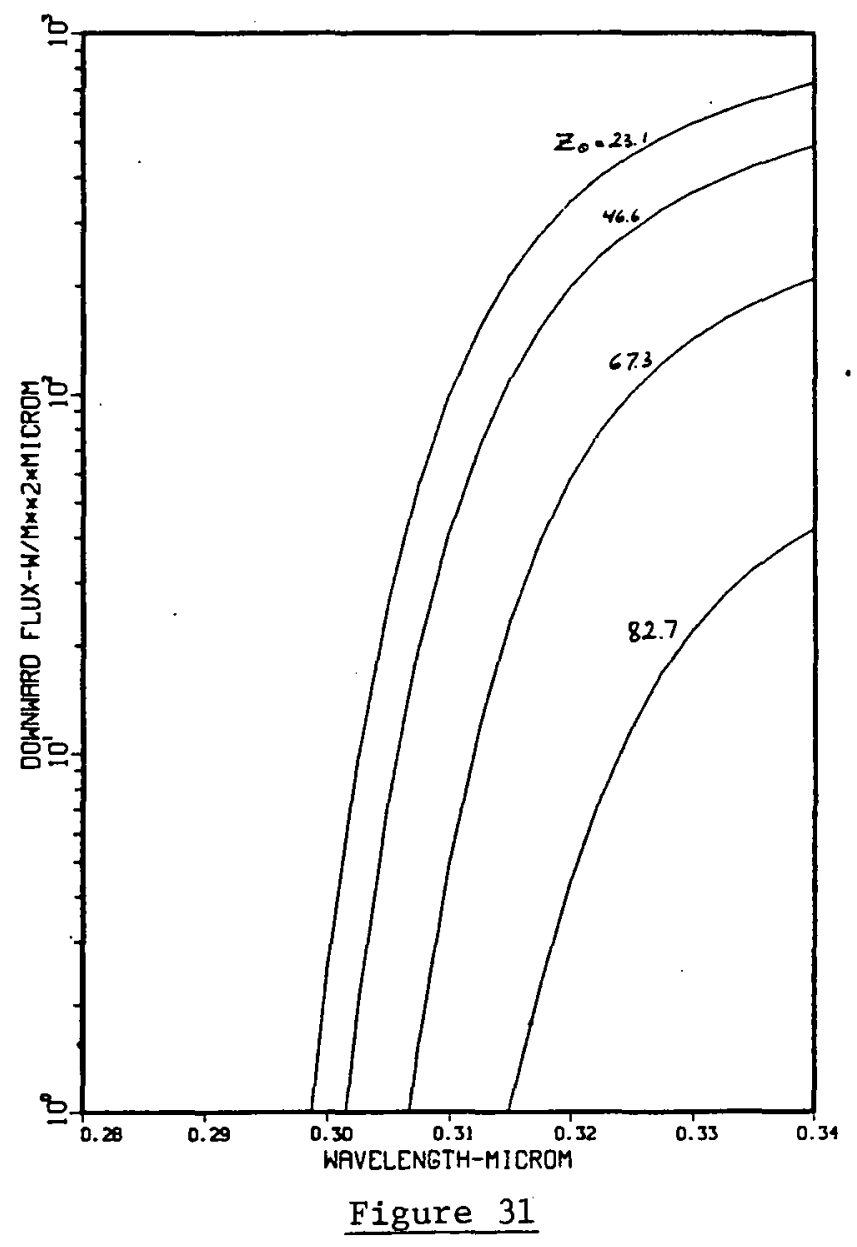

95. 0\% OZONE; SUBARCTIC WINTER

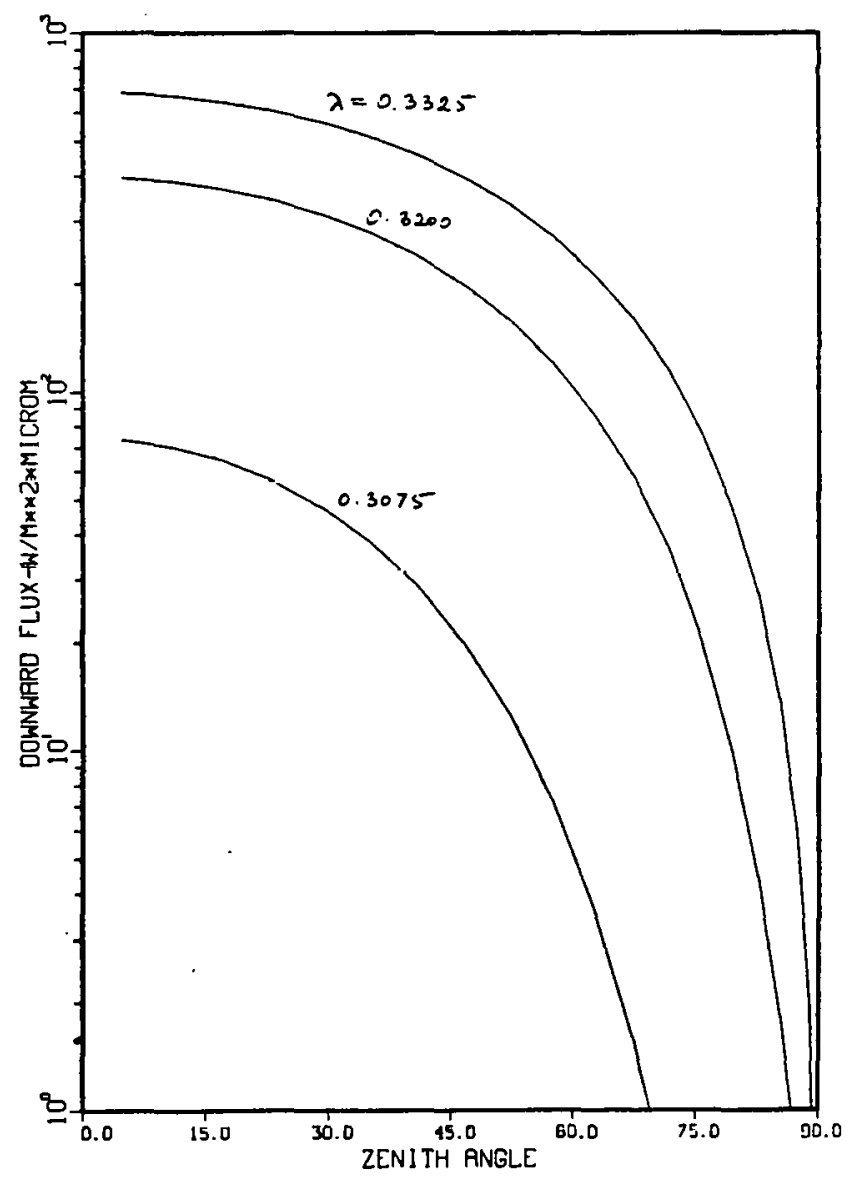

Figure 32 


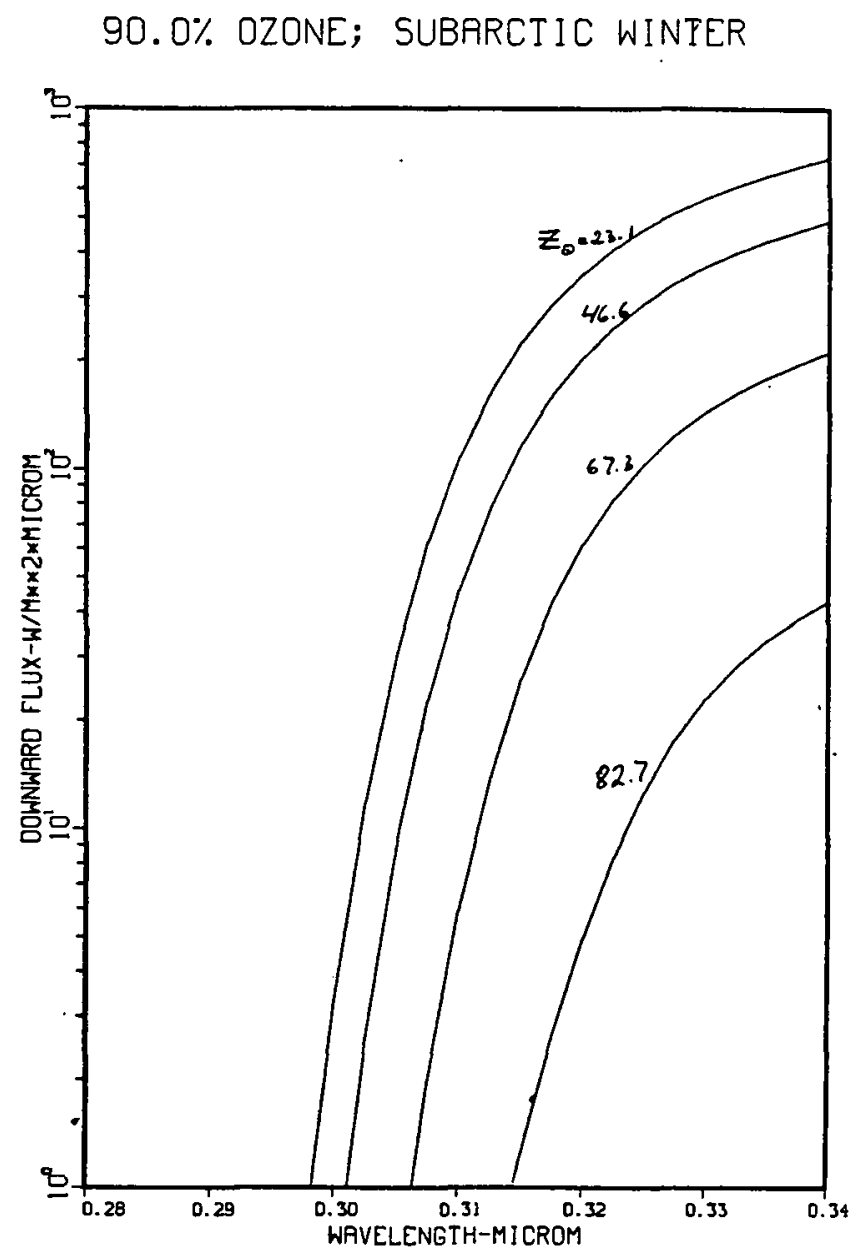

Figure 33
$90.0 \%$ OZONE; SUBARCTIC WINTER

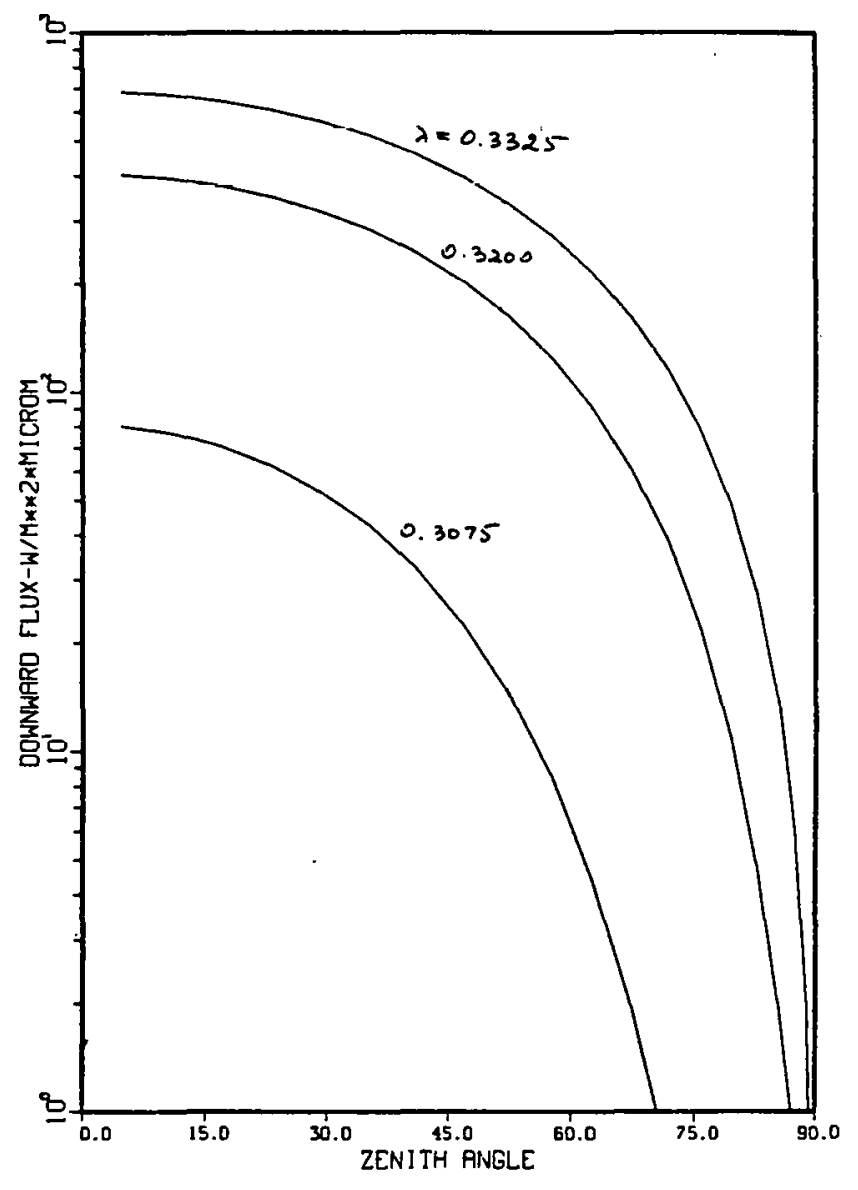

Figure 34 
85.0\% OZONE; SUBARCIIC WINTER

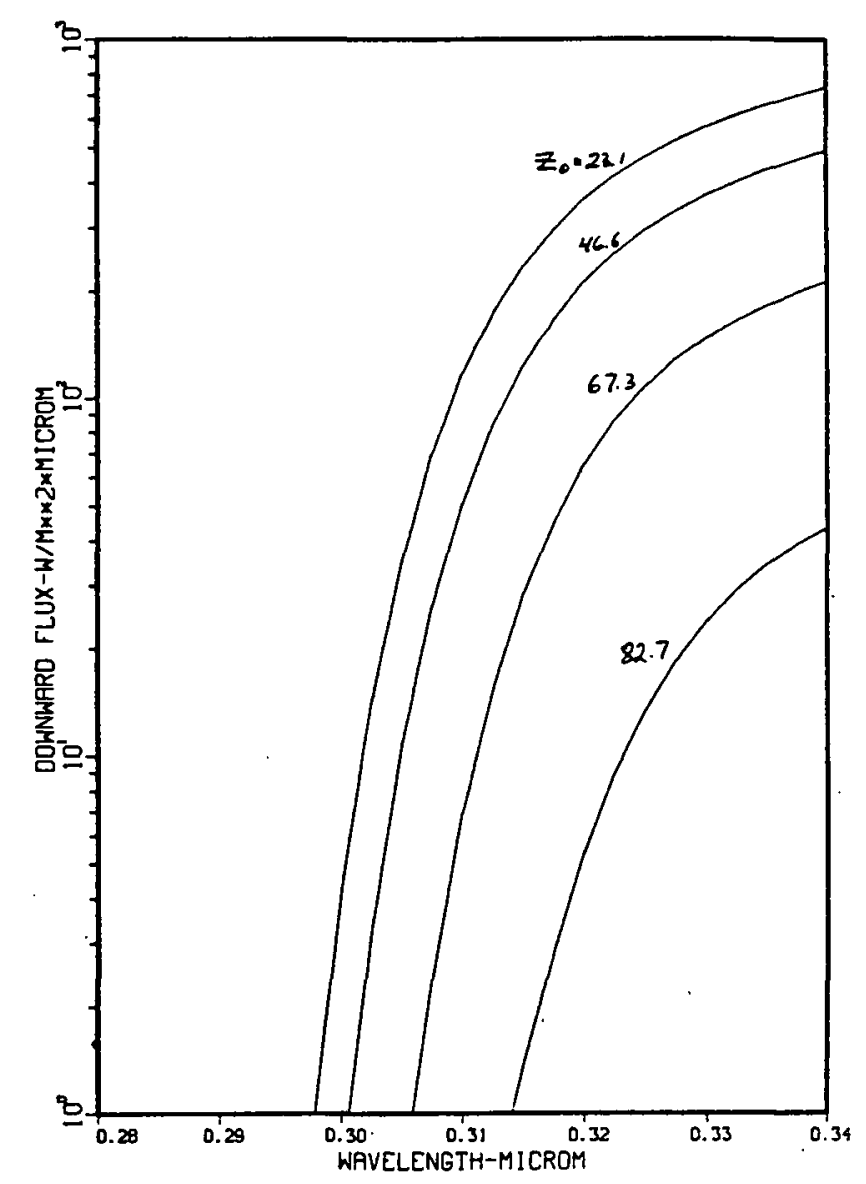

Figure 35

85.0\% OZONE; SUBARCTIC WINTER

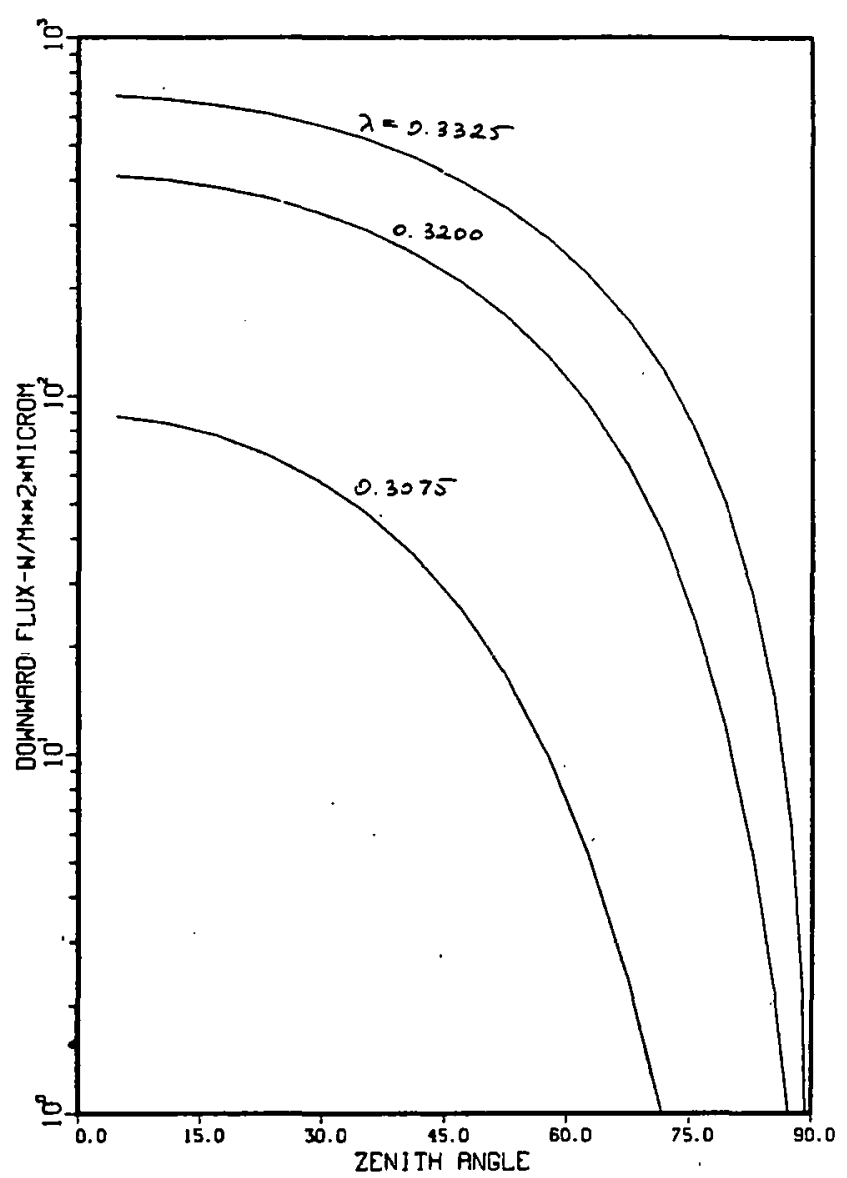

Figure 36 
$80.0 \%$ OZONE; SUBARCTIC WINTER

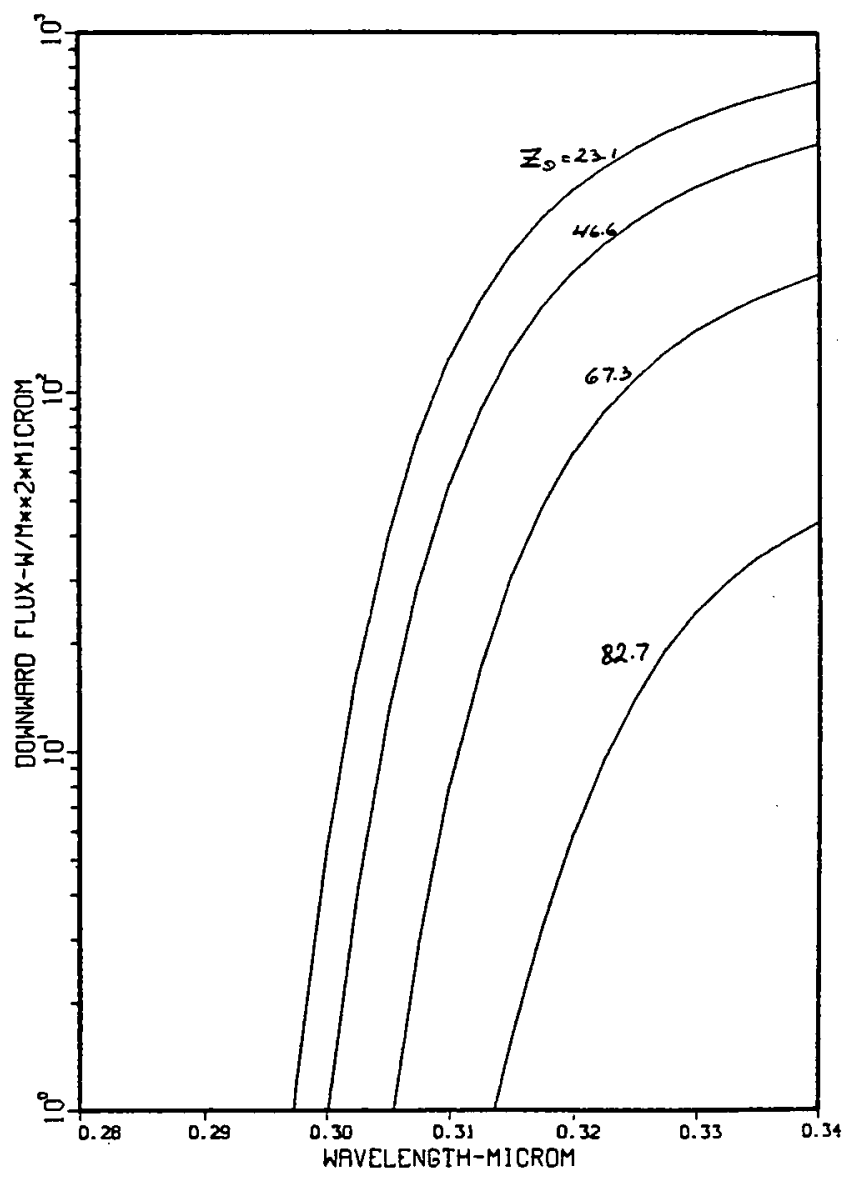

Figure 37

80.0\% OZONE; SUBRRCIIC WINTER

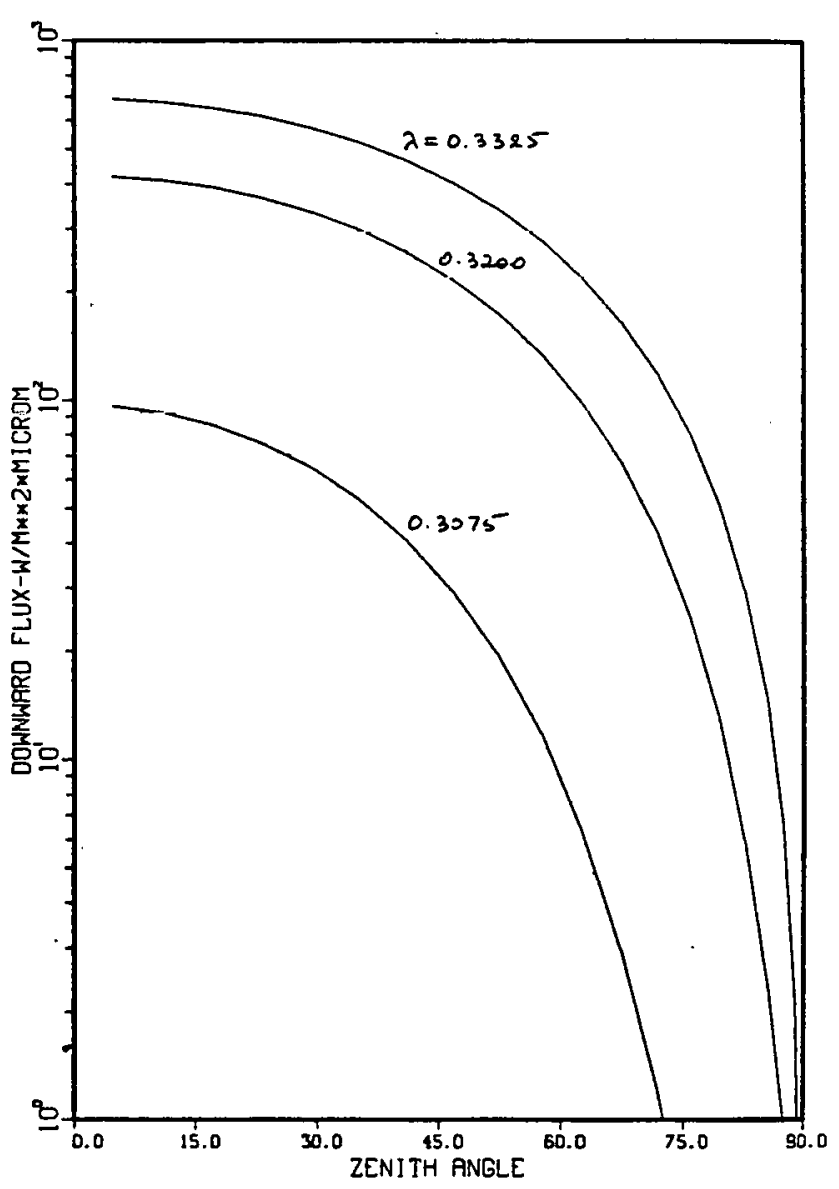

Figure 38 

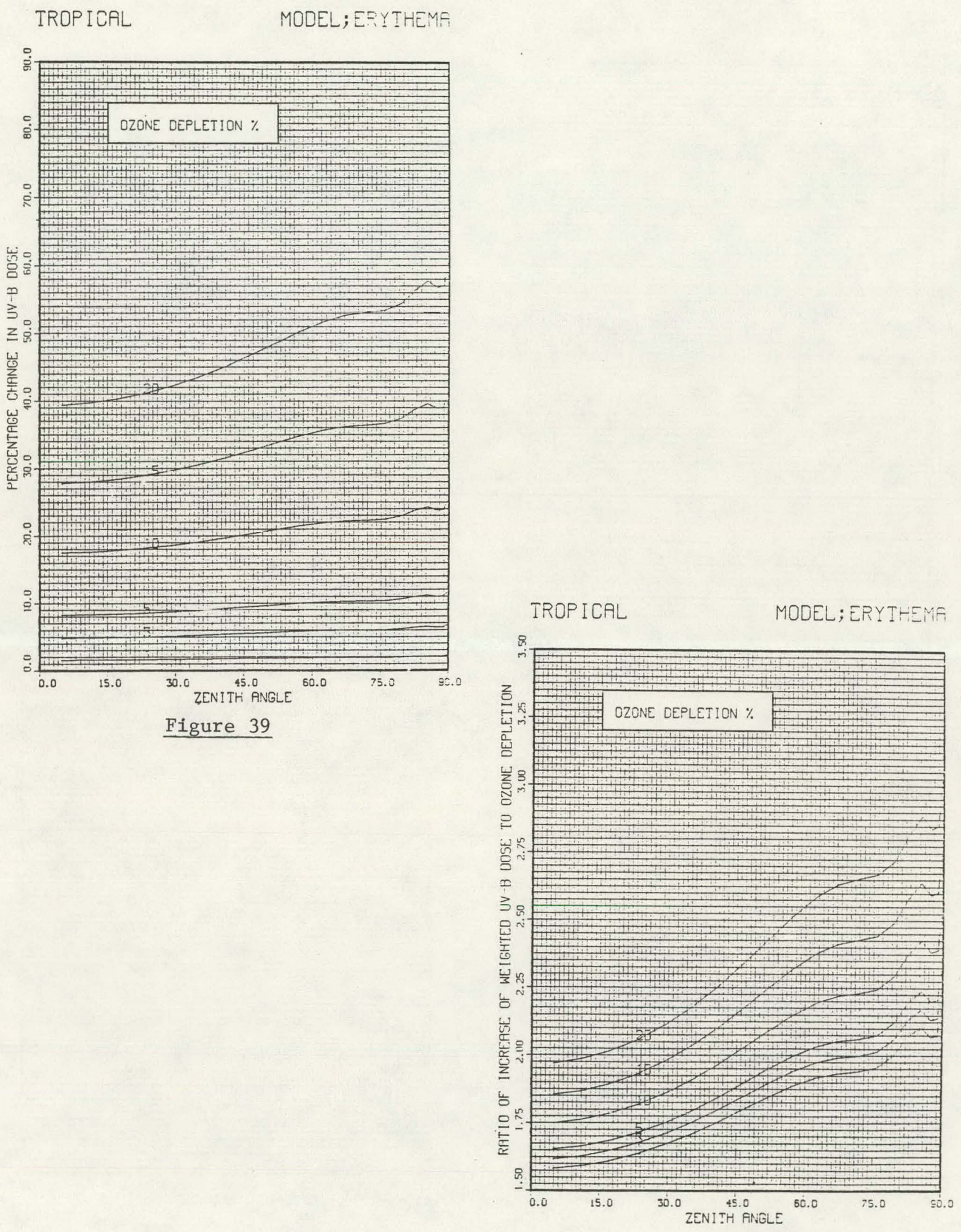

Figure 39

Figure 40 


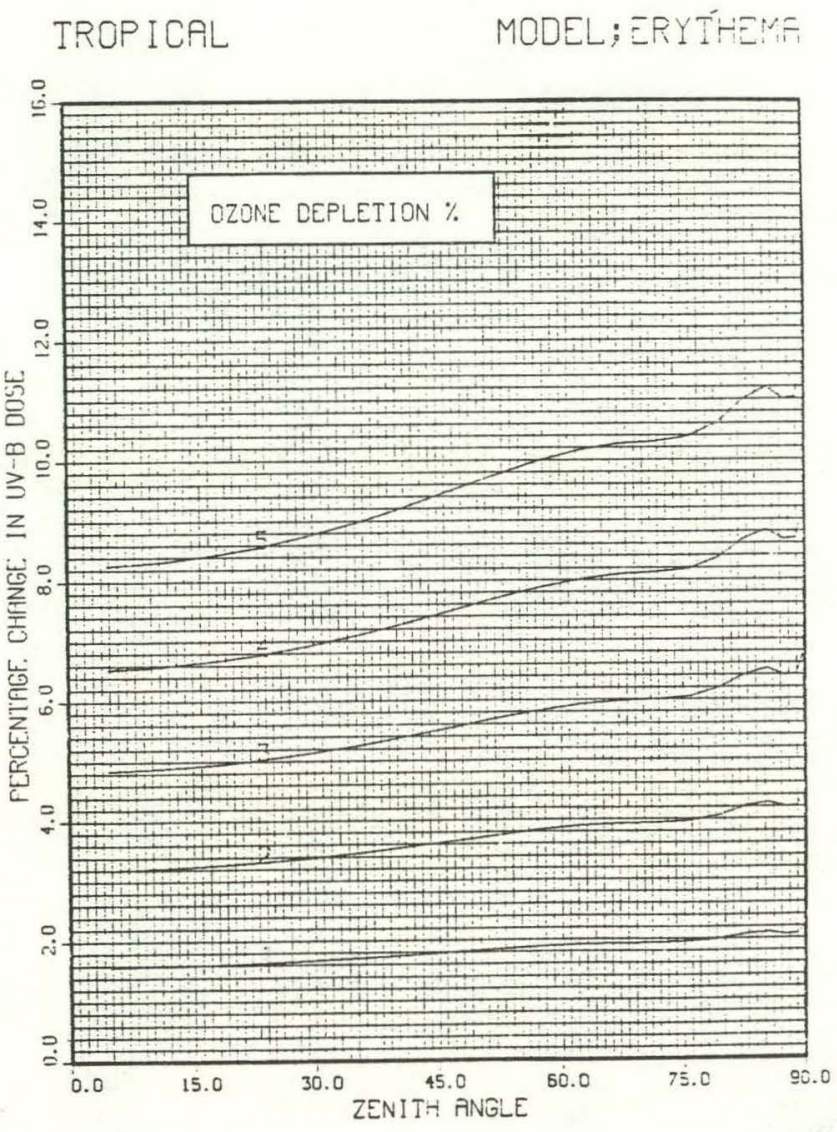

Figure 41

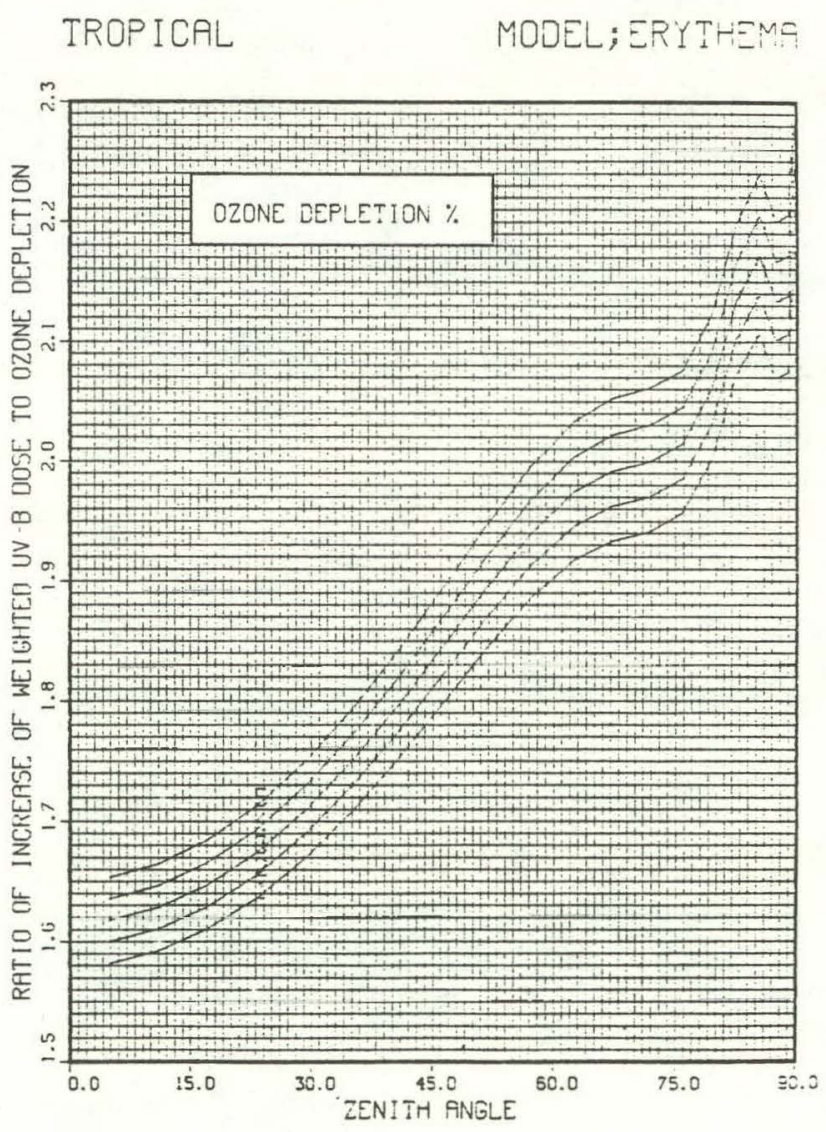

Figure 42 
MIDLATITUDE SUMMER MODEL;ERYTHEMA

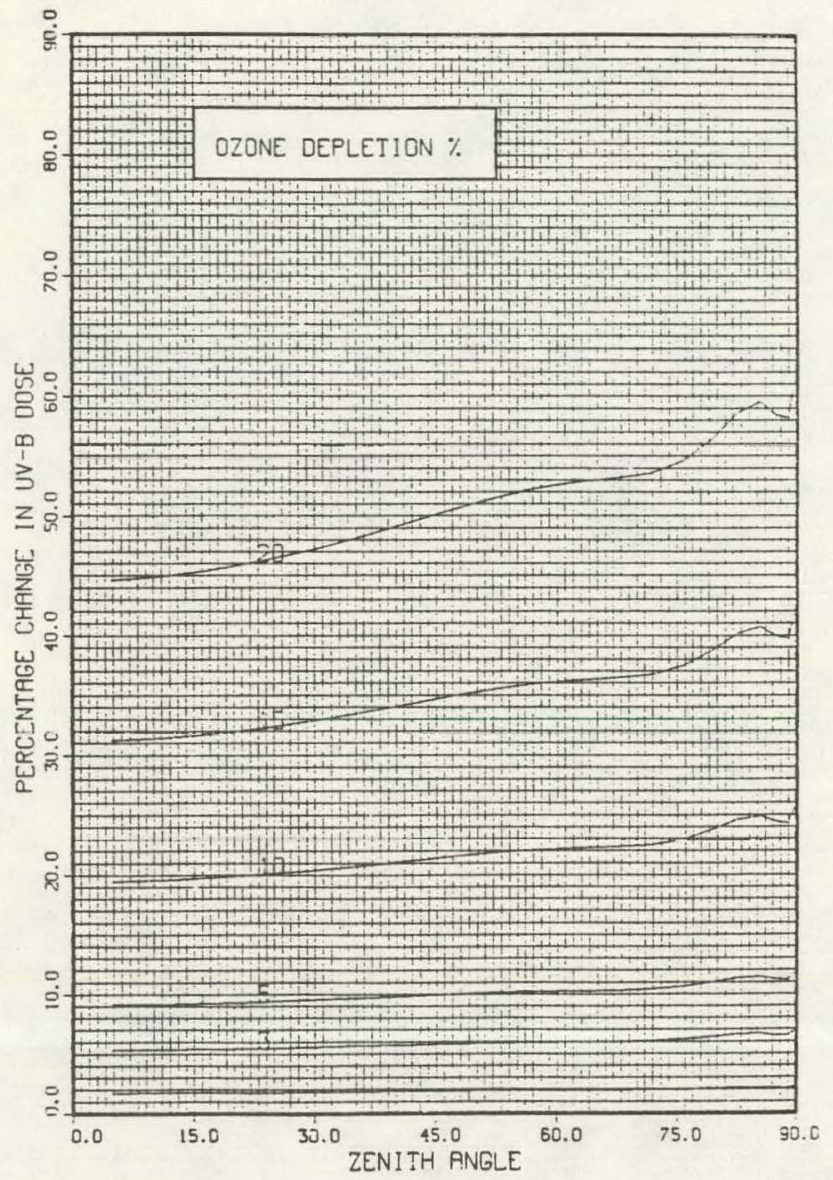

Figure 43
MIDLAIITUDE SUMMER MODEL:ERYTHEY:

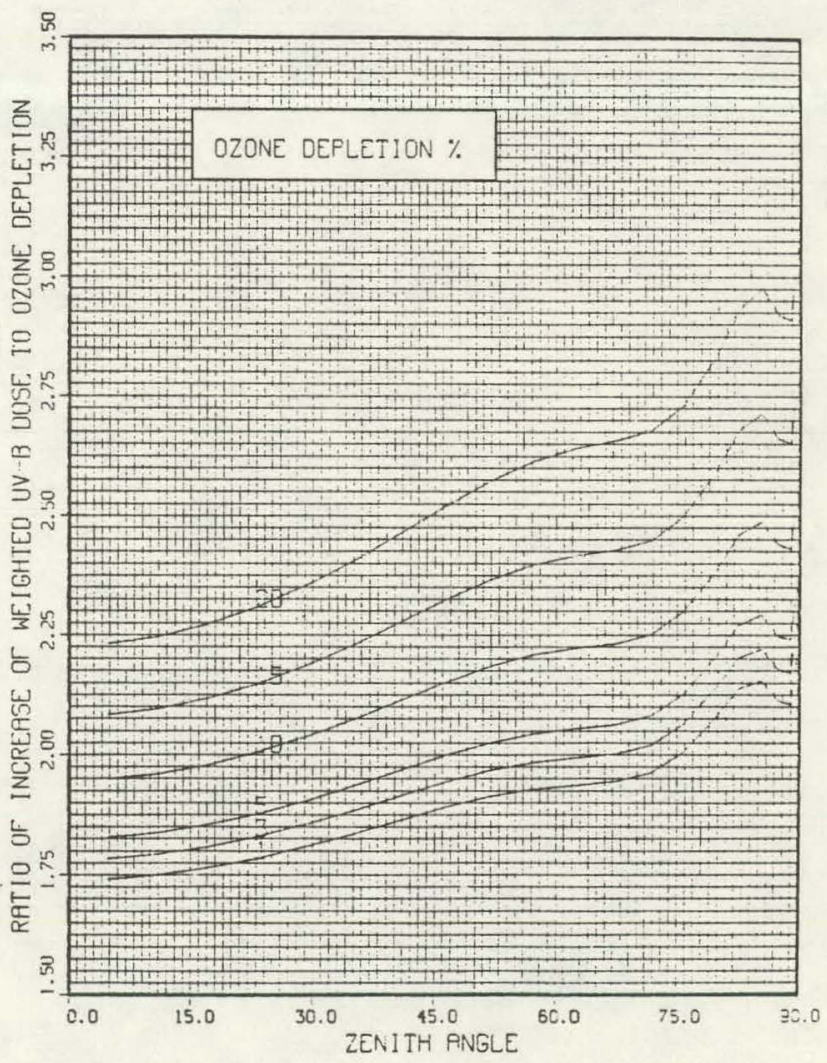

Figure 44 


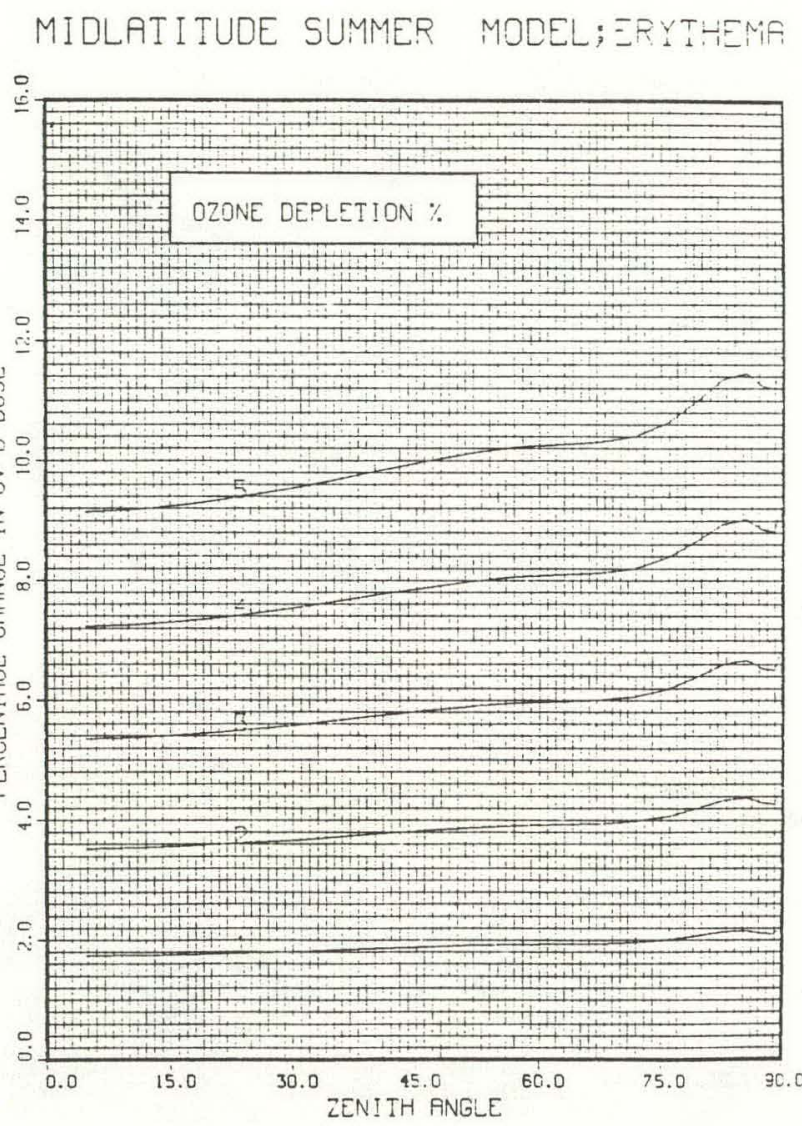

Figure 45

\section{MIDLATITUDE SUMMER MODEL;ERYTHEME}

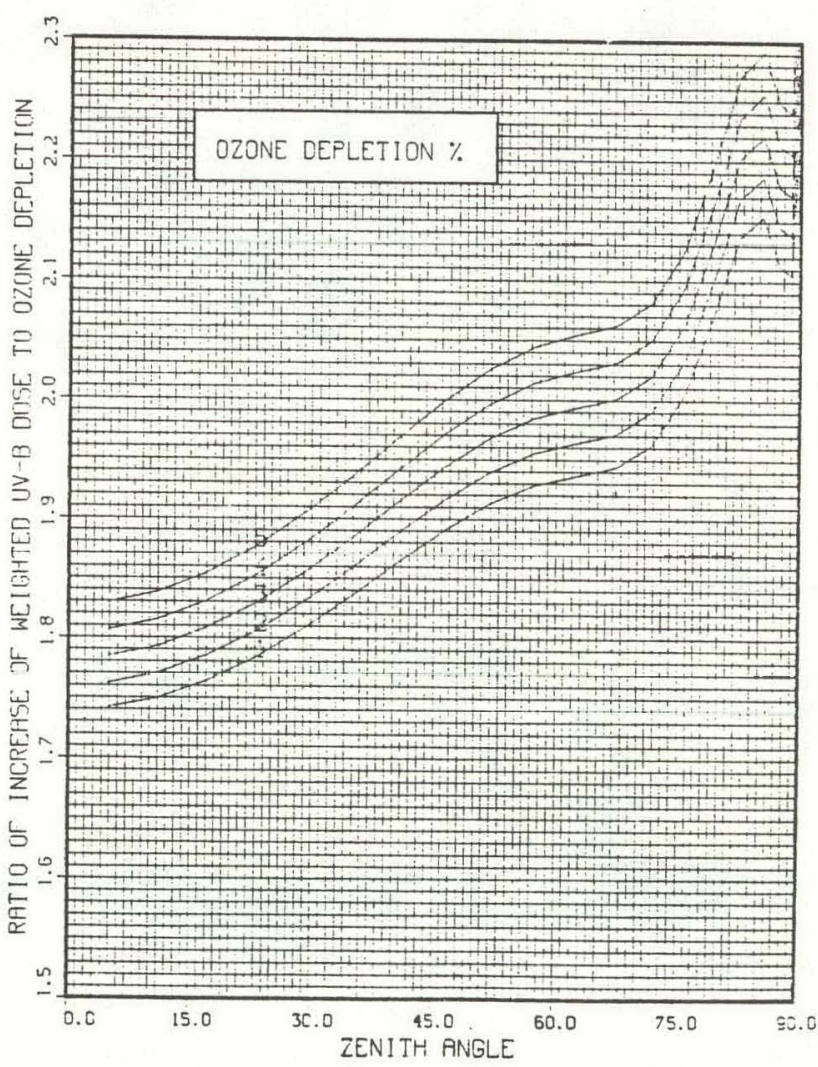

Figure 46 


\section{MIDLATITUDE WINTER MODEL;E=YTHEMF}

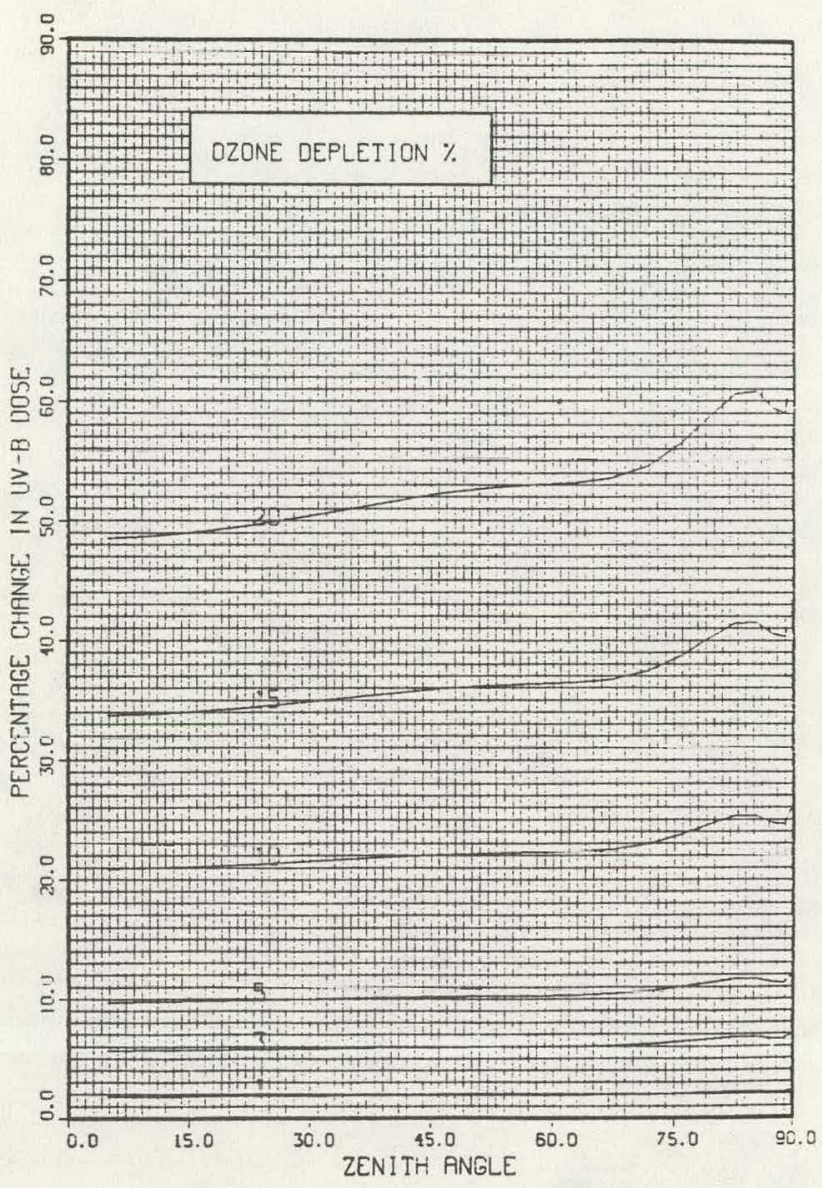

\section{Figure 47}

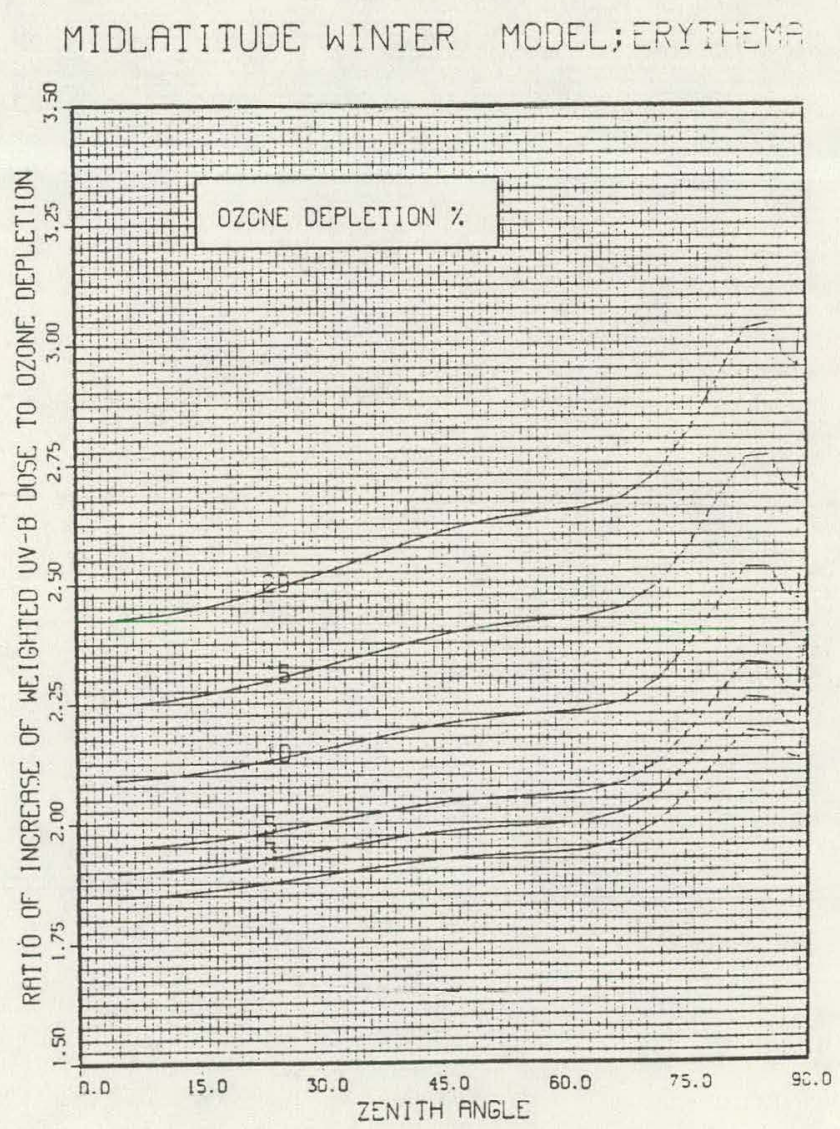

Figure 48 


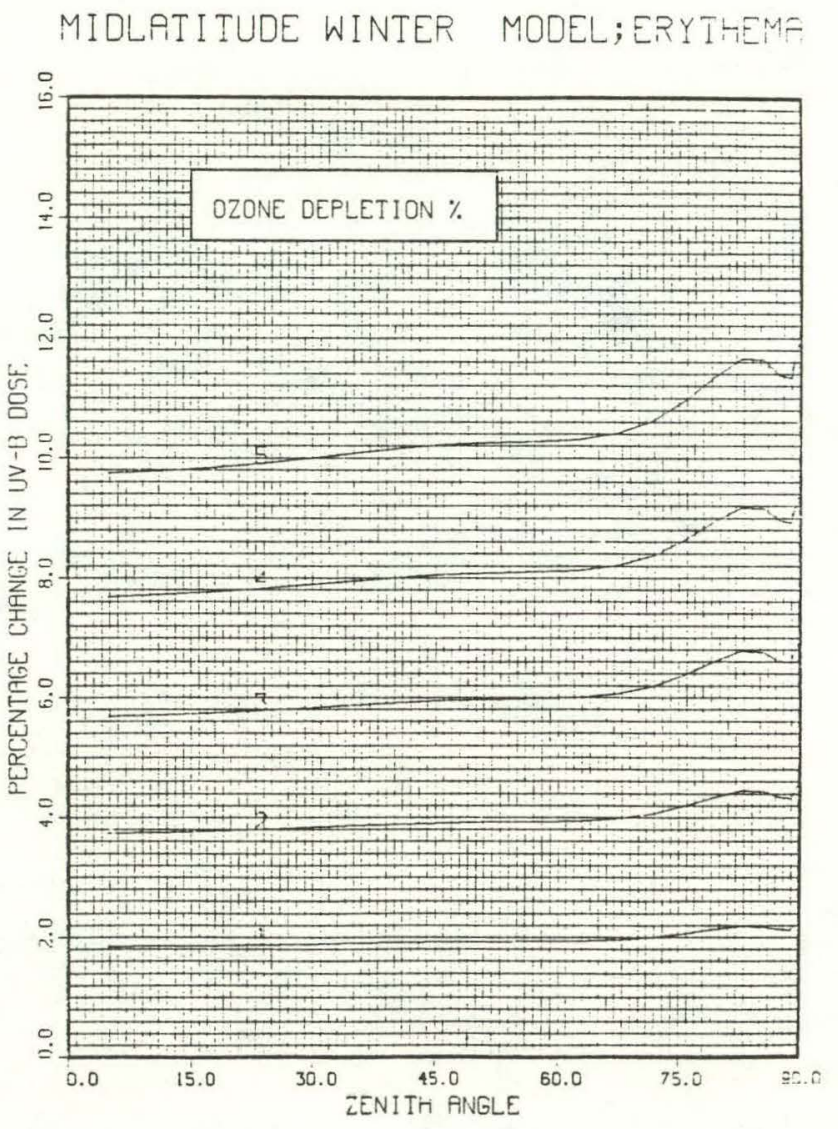

\section{Figure 49}

MIDLATITUDE WINTER MODEL; ERYTHEMA

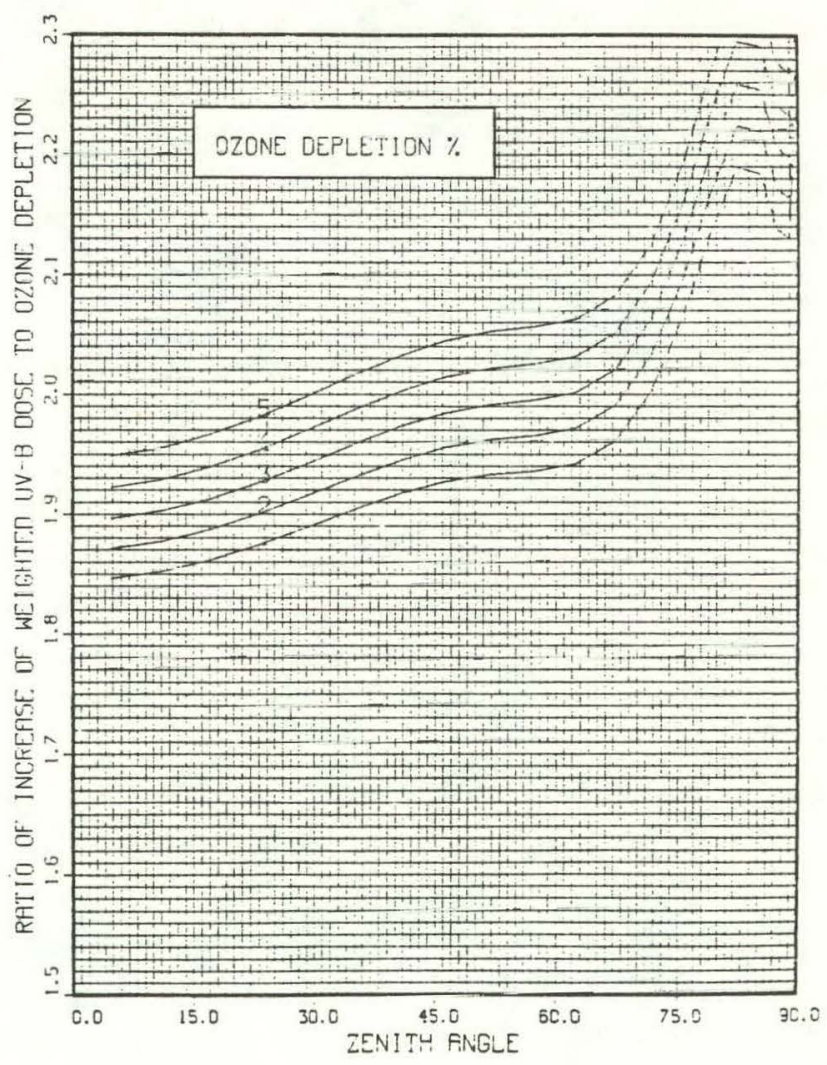

Figure 50 
SUBARCTIC SUMMER MODEL;ERYTHEMA

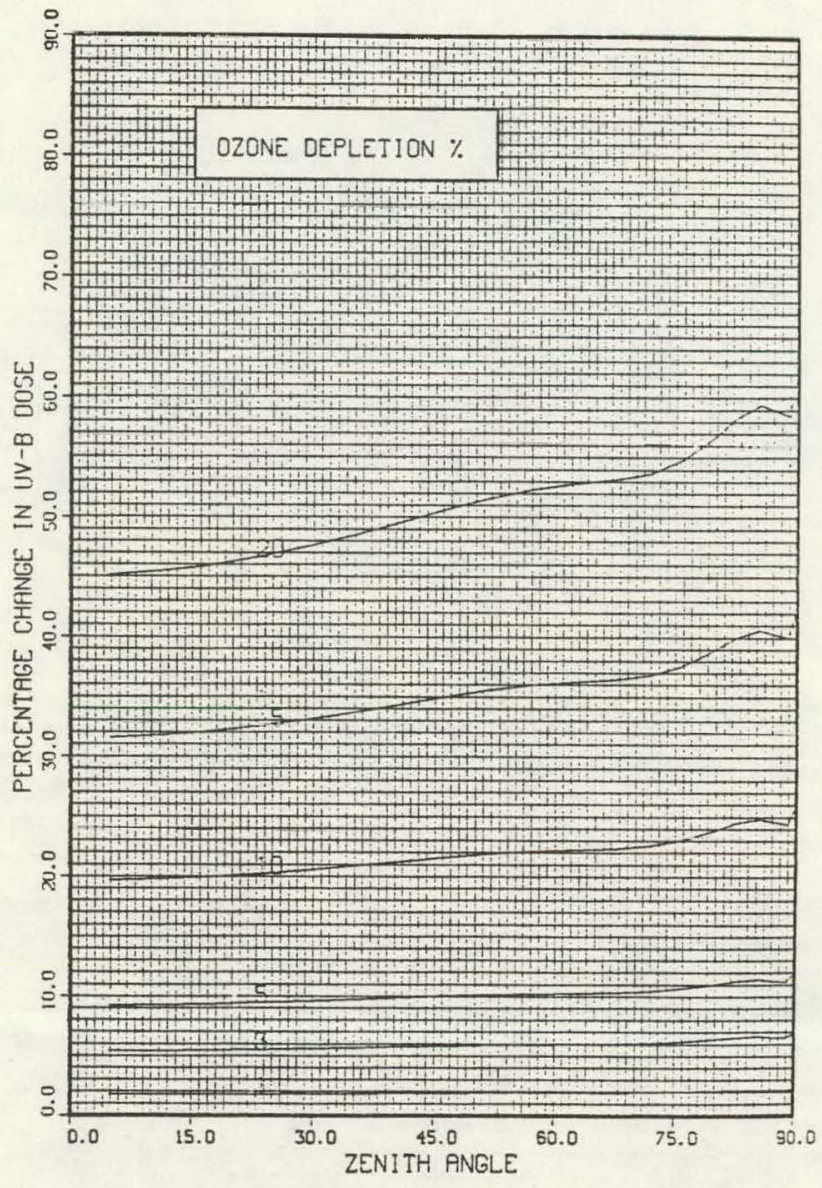

\section{Figure 51}

SUBARCIIC SUMMER MODEL; ERYTHEM=

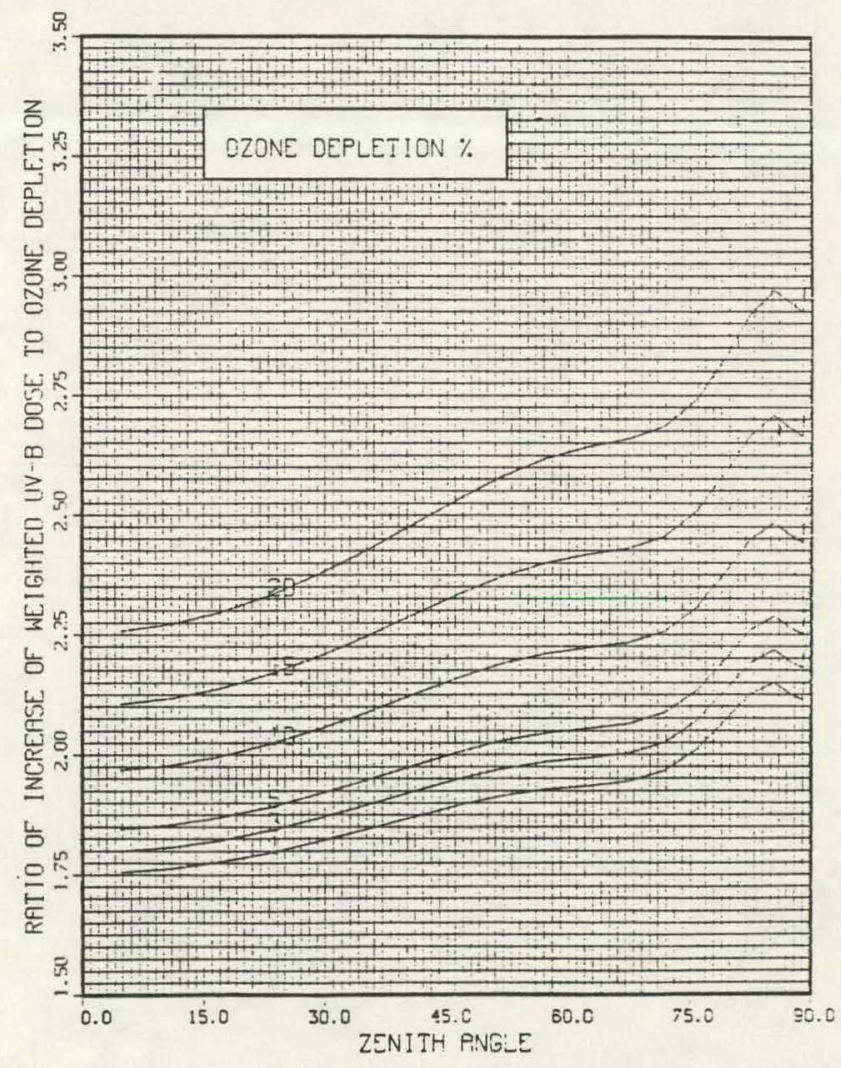

Figure 52 


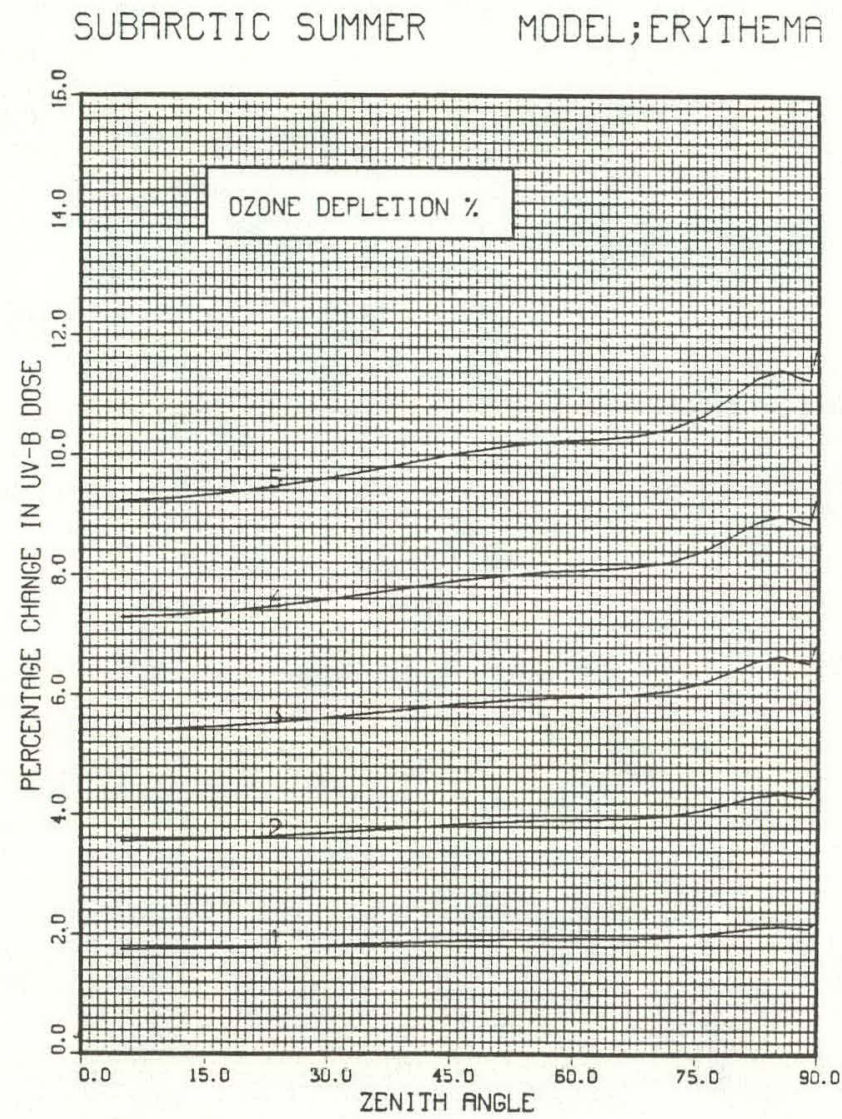

Figure 53

\section{SUBARCTIC SUMMER MODEL;ERYTHEMA}

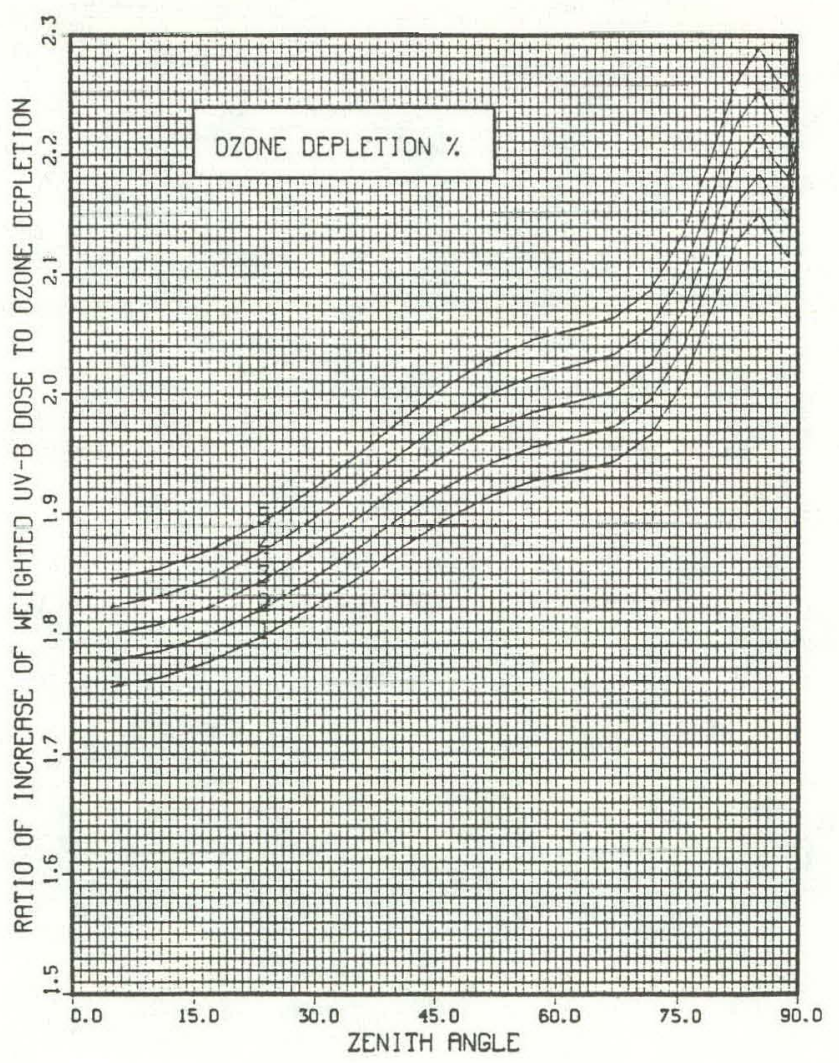

Figure 54 

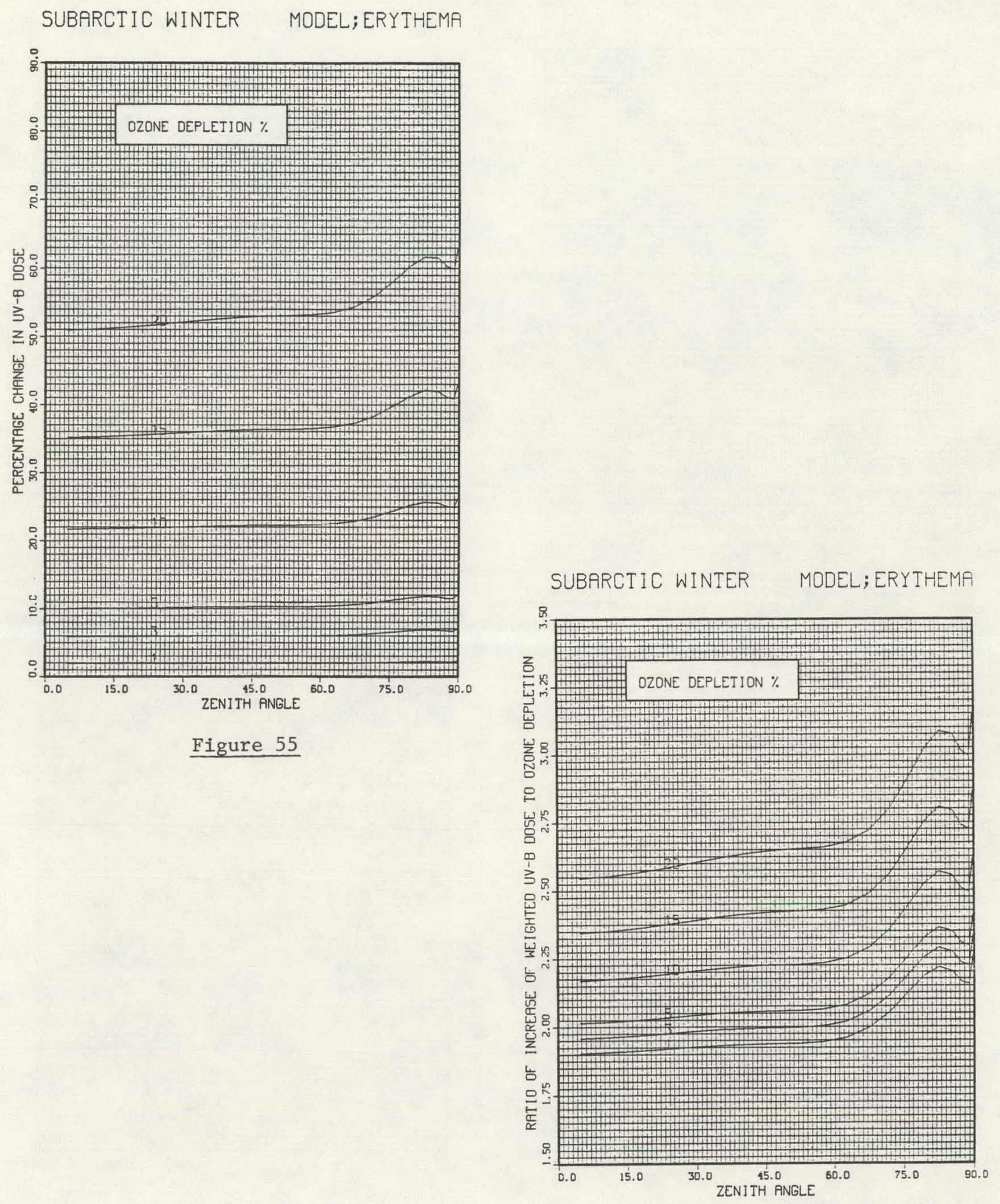

Figure 55

Figure 56 


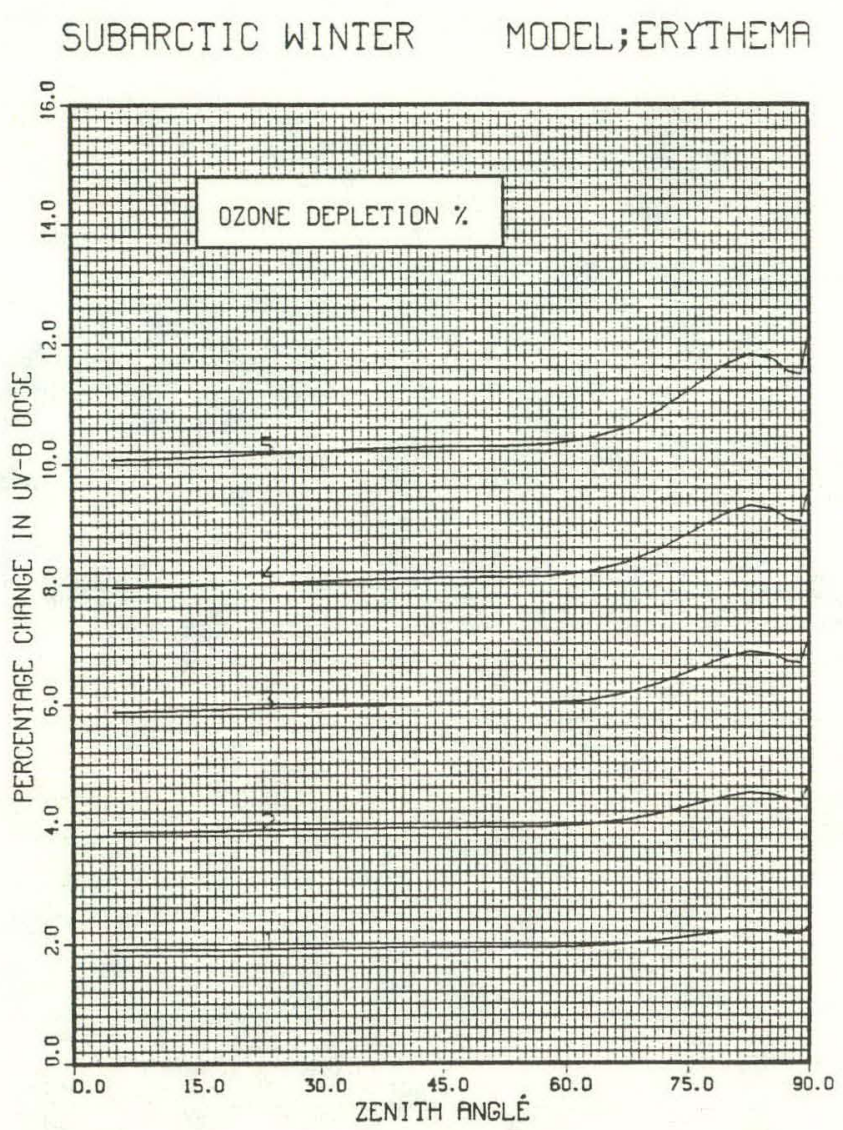

Figure 57

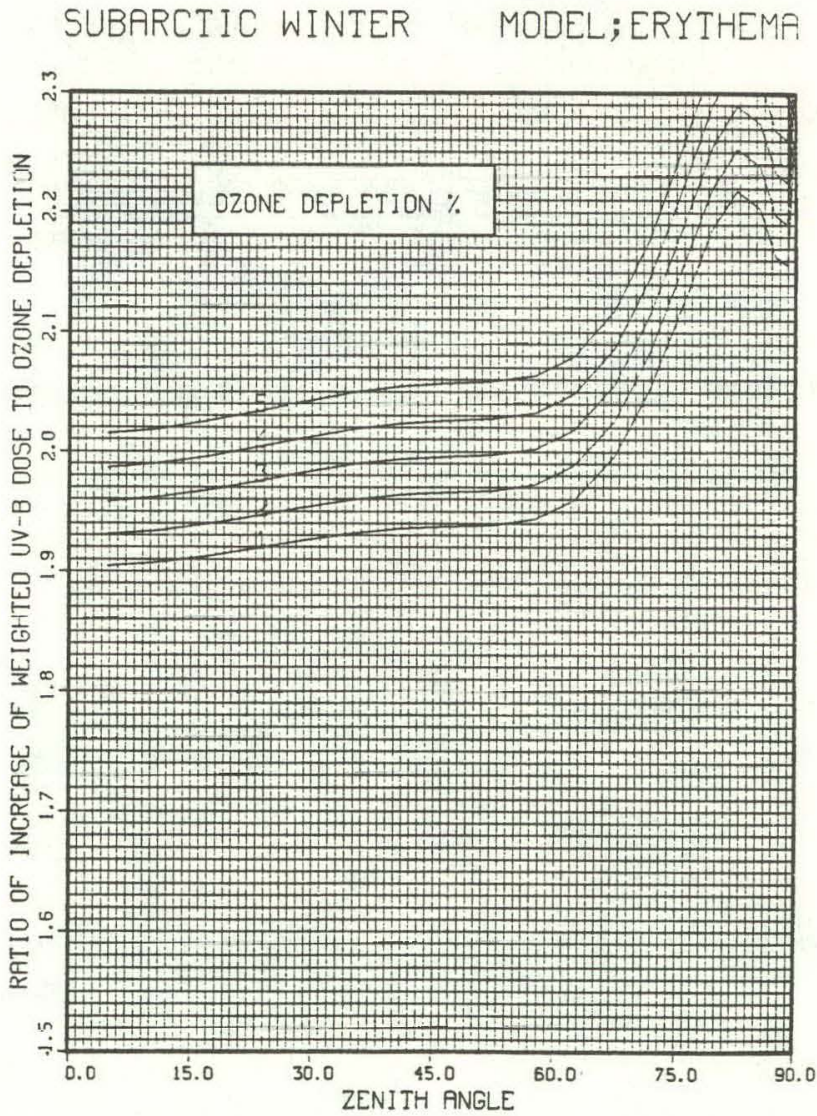

Figure 58 


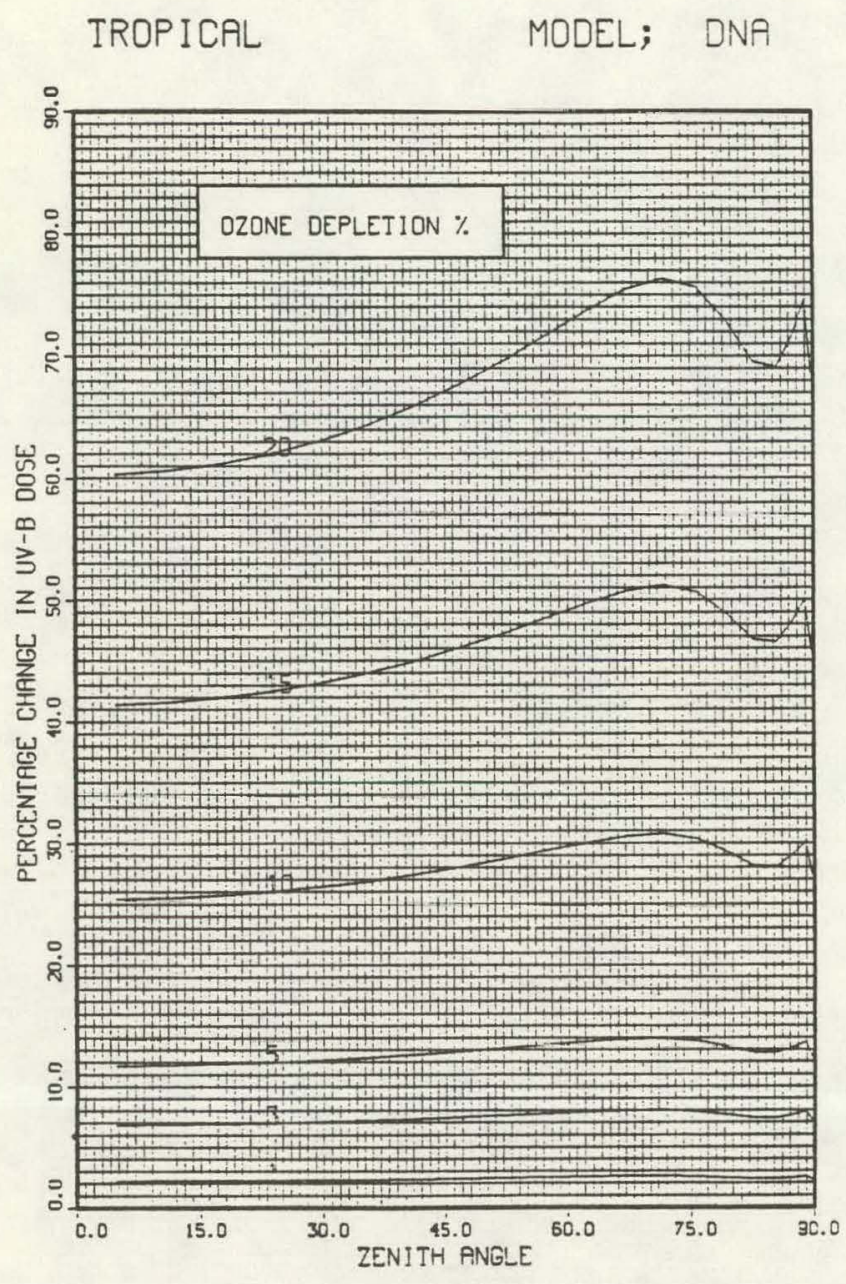

Figure 59

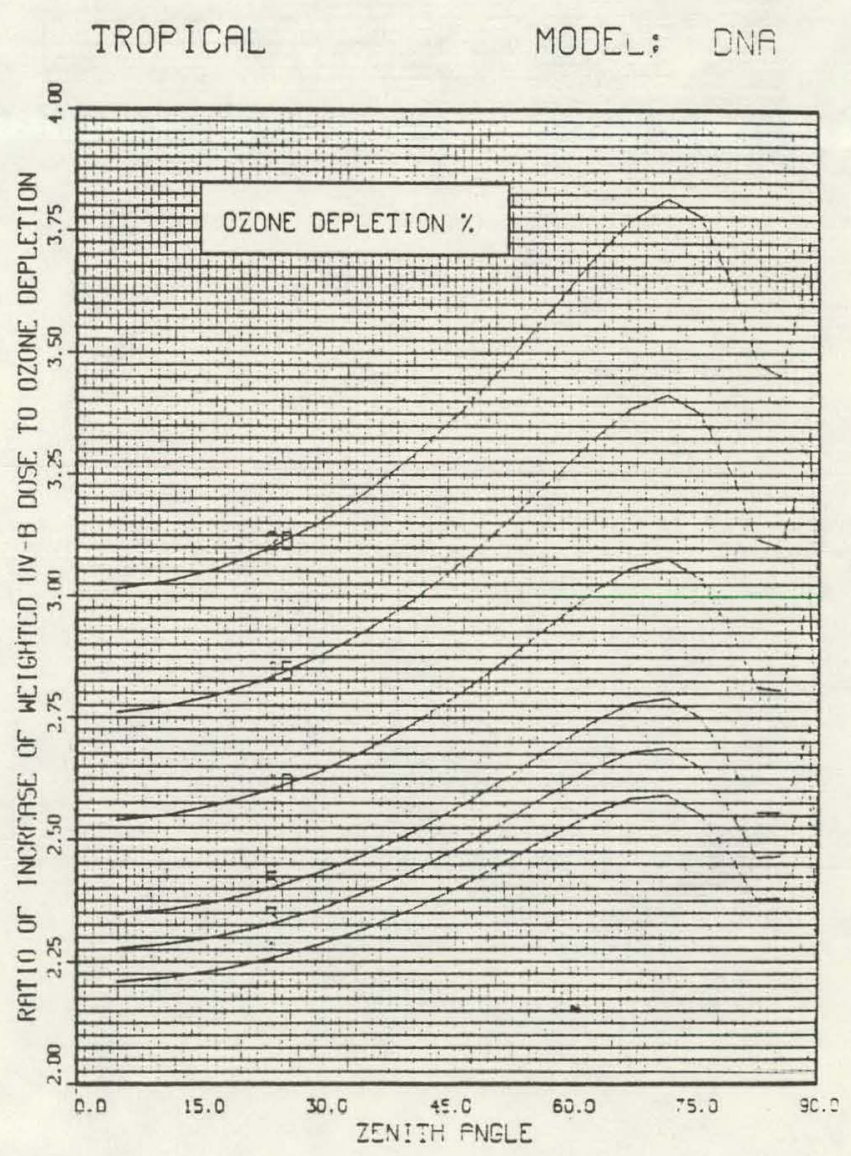

Figure 60 


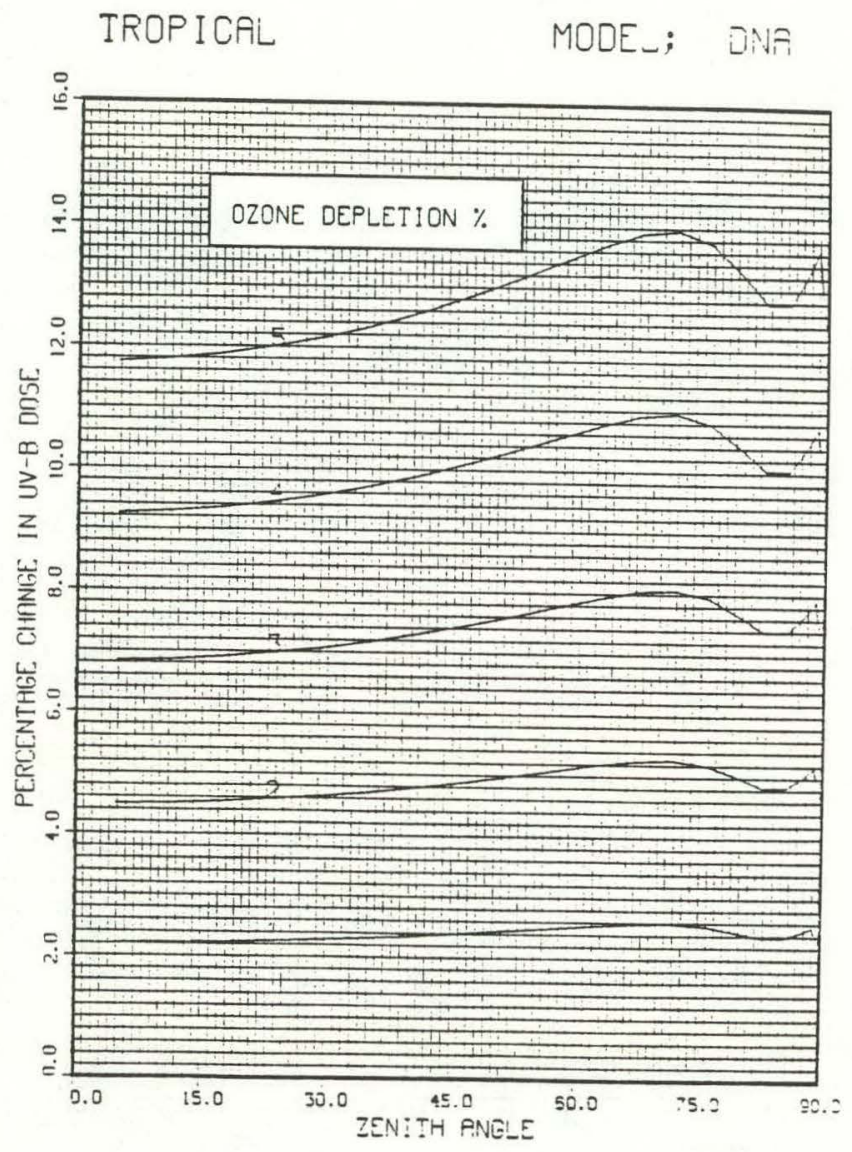

Figure 61

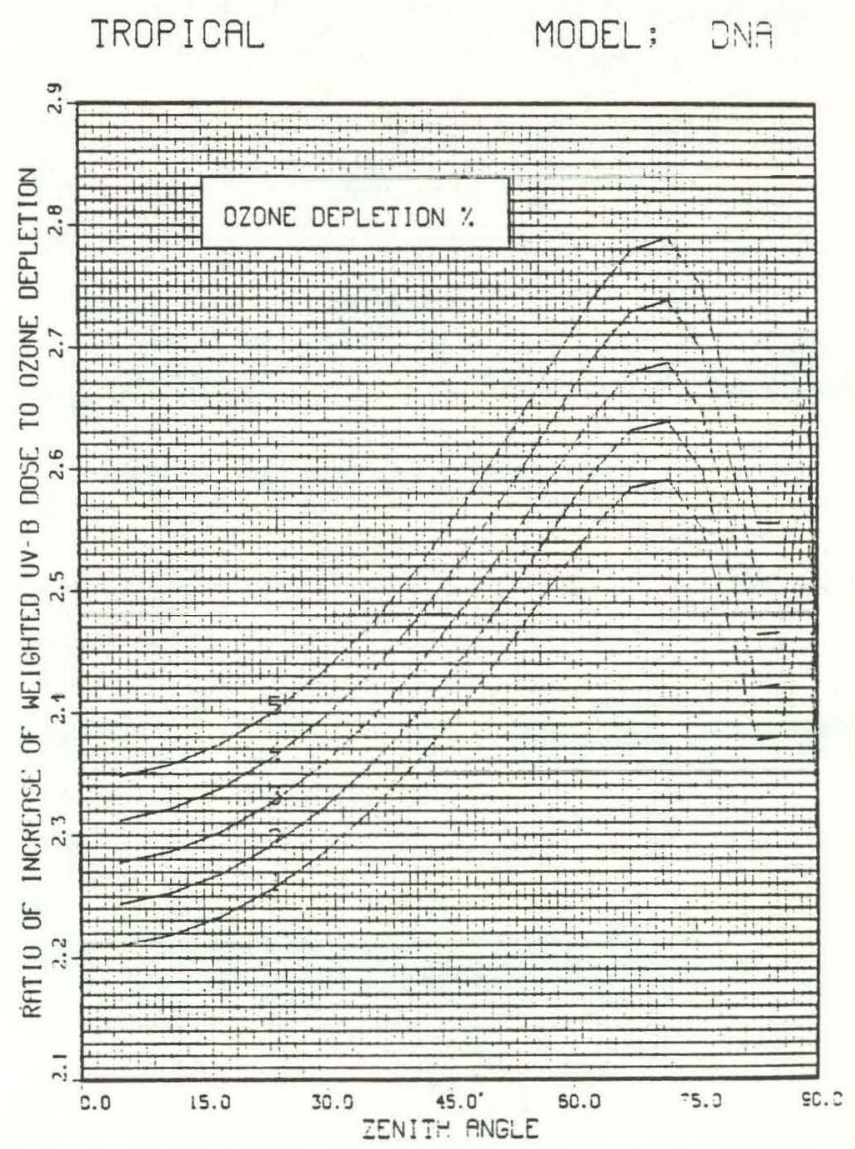

Figure 62 
MIDLATITUDE SUMMER MODEL; DNA

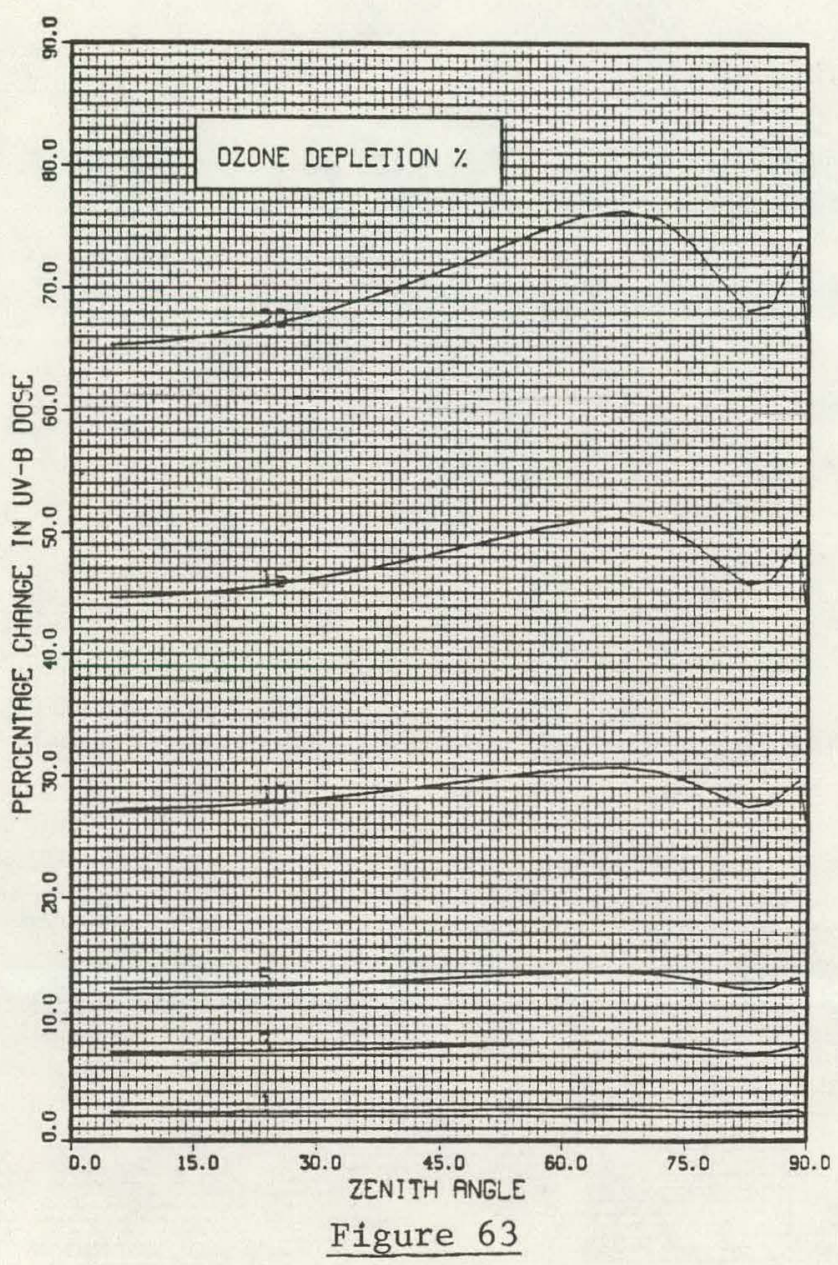

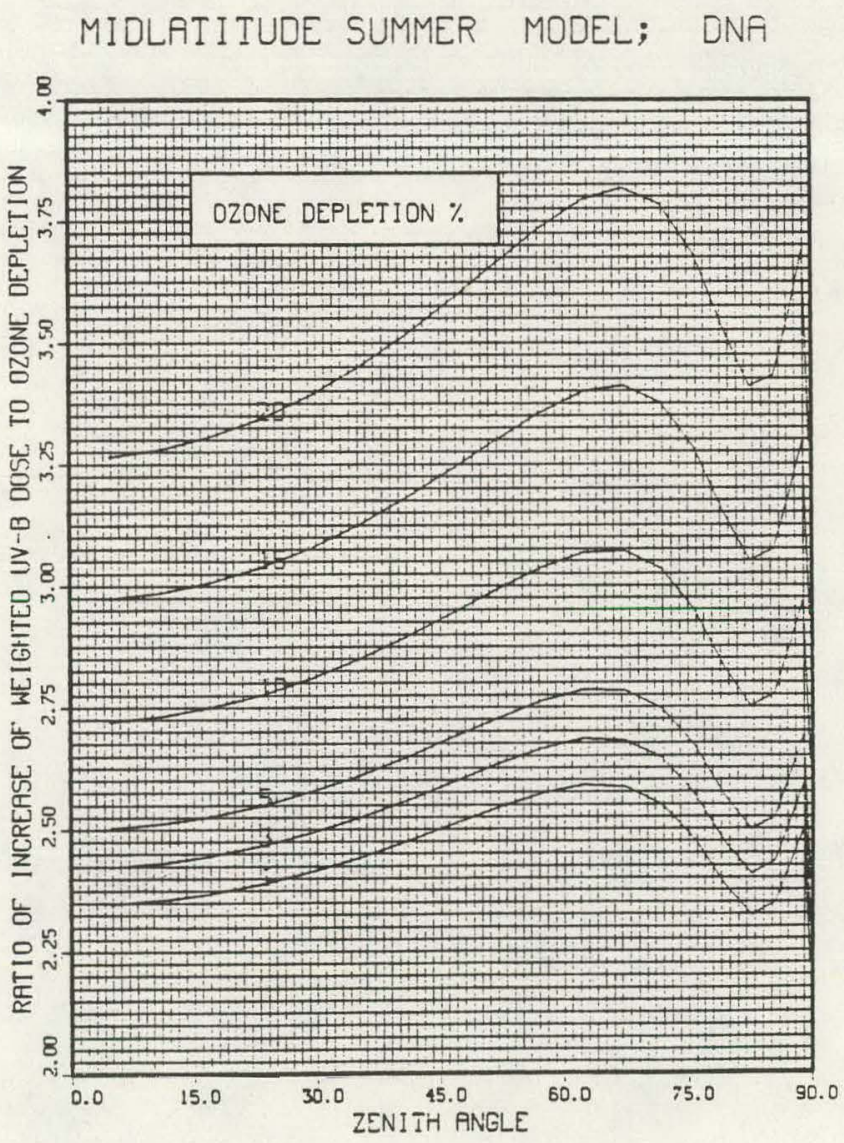

Figure 64 


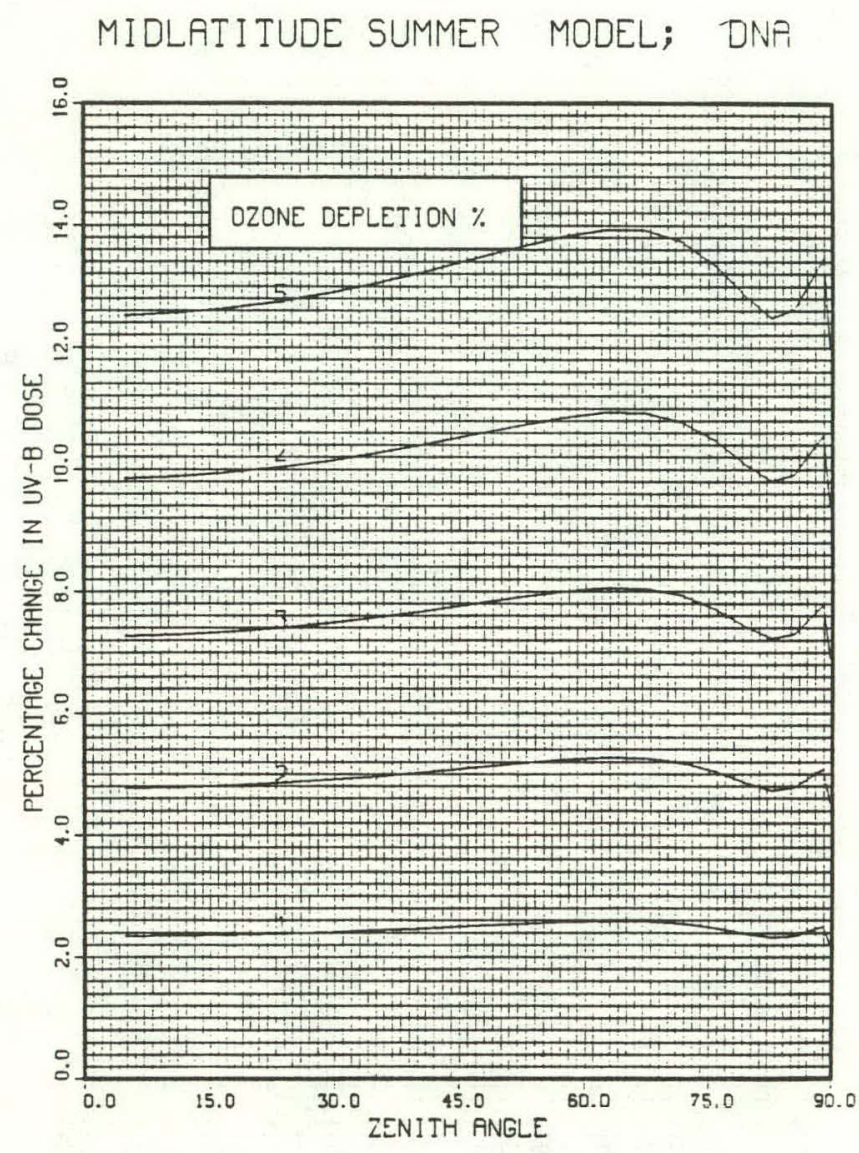

Figure 65

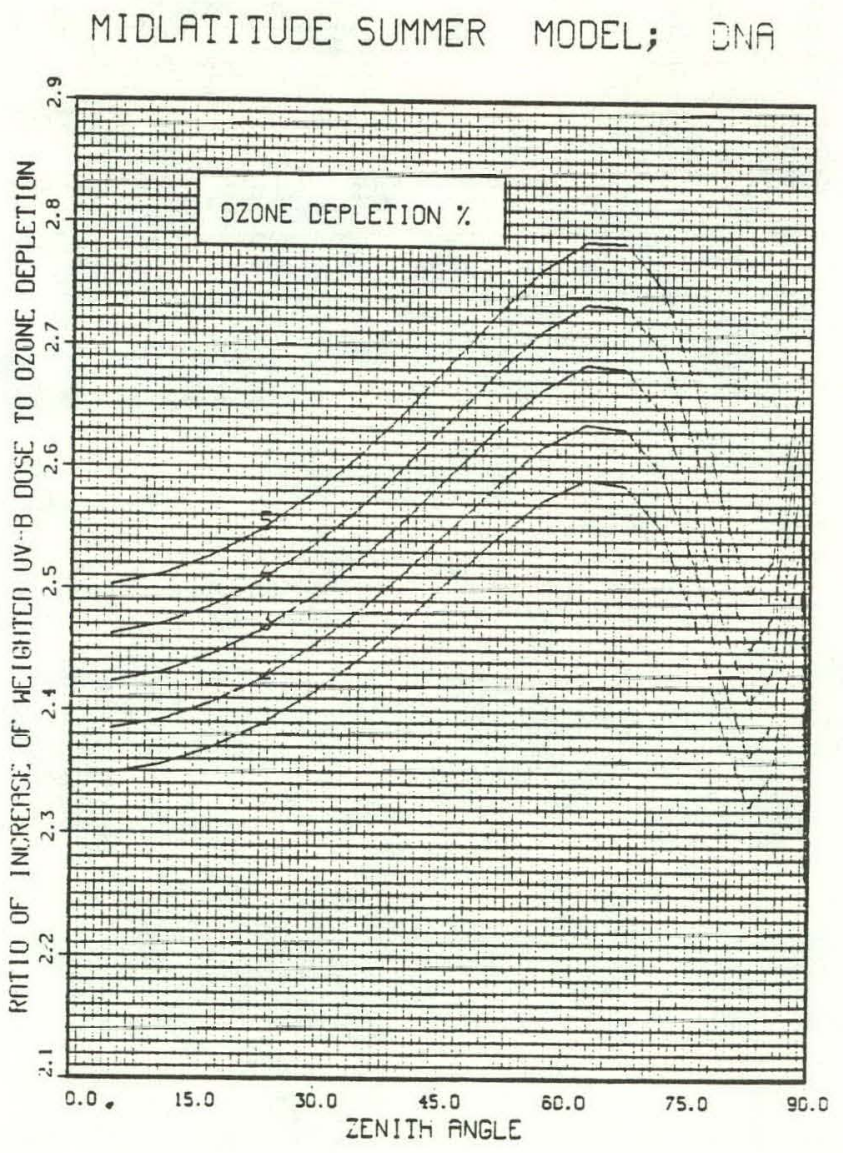

Figure 66 

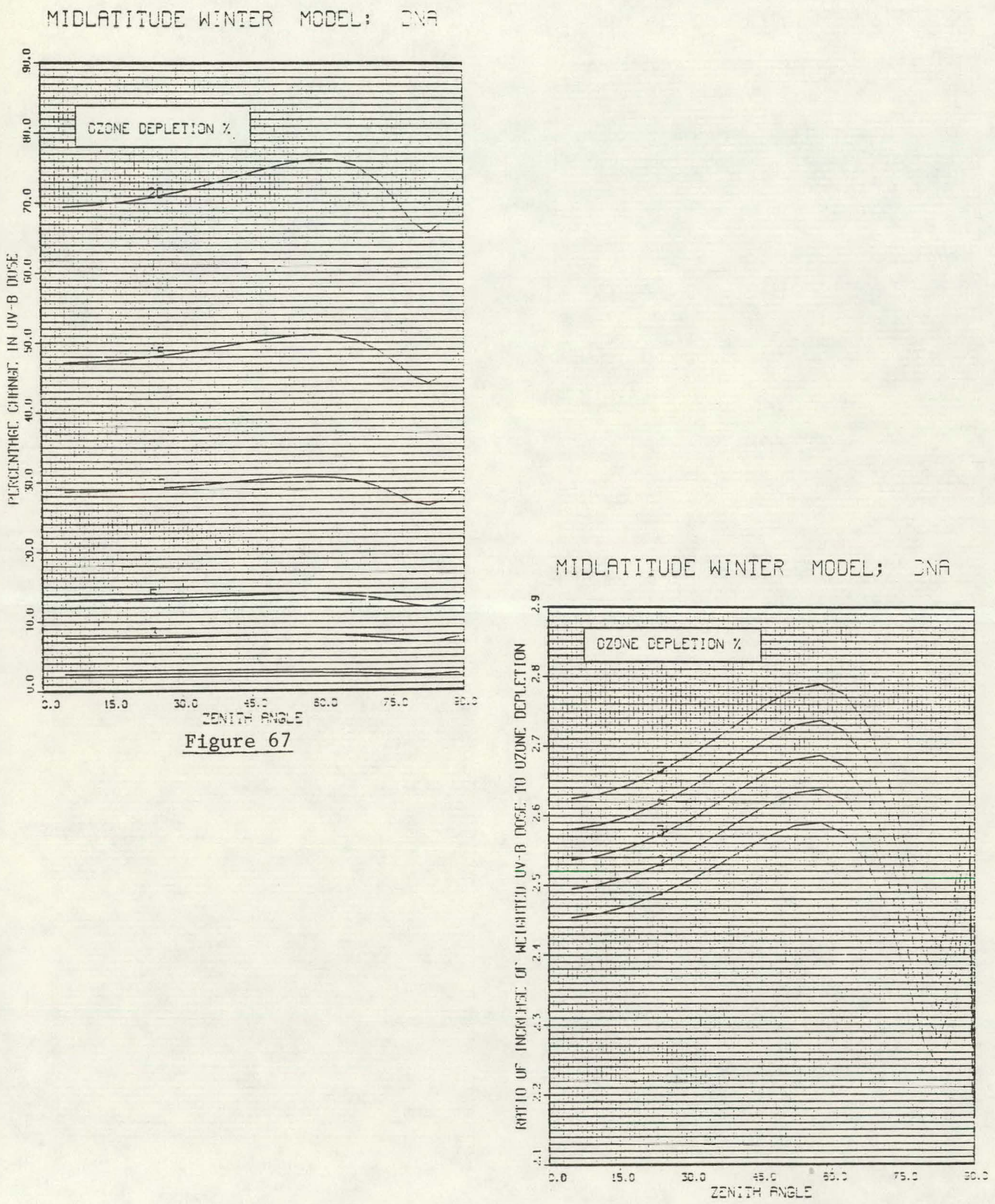

Figure 68 


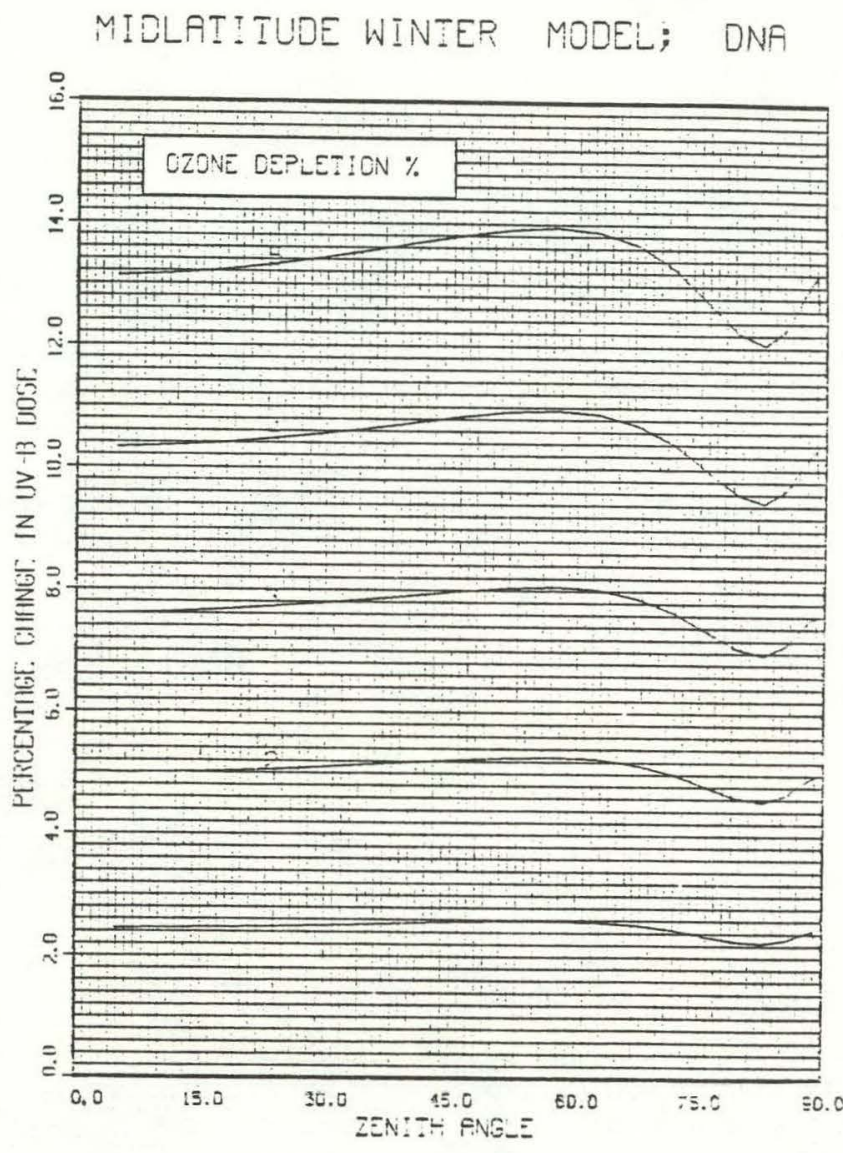

Figure 69

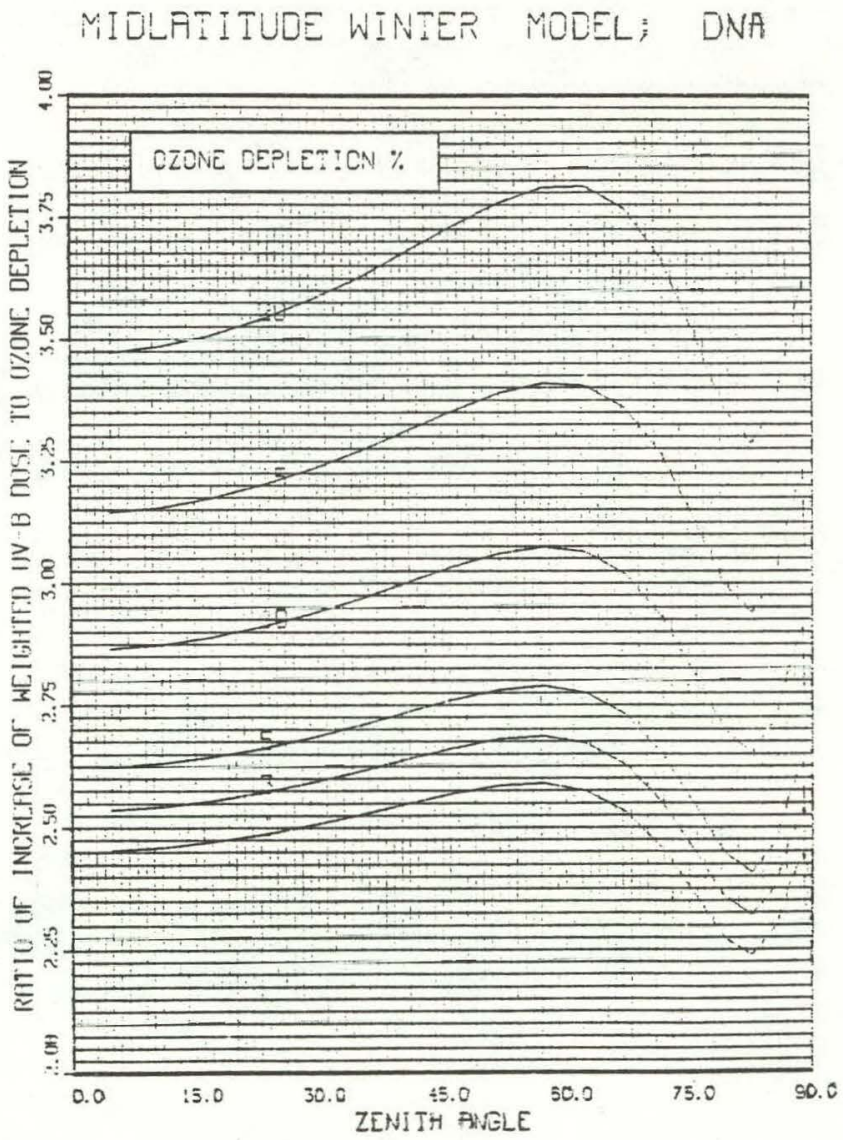

Figure 70 
SUBARCTIC SUMMER MODEL; DNA

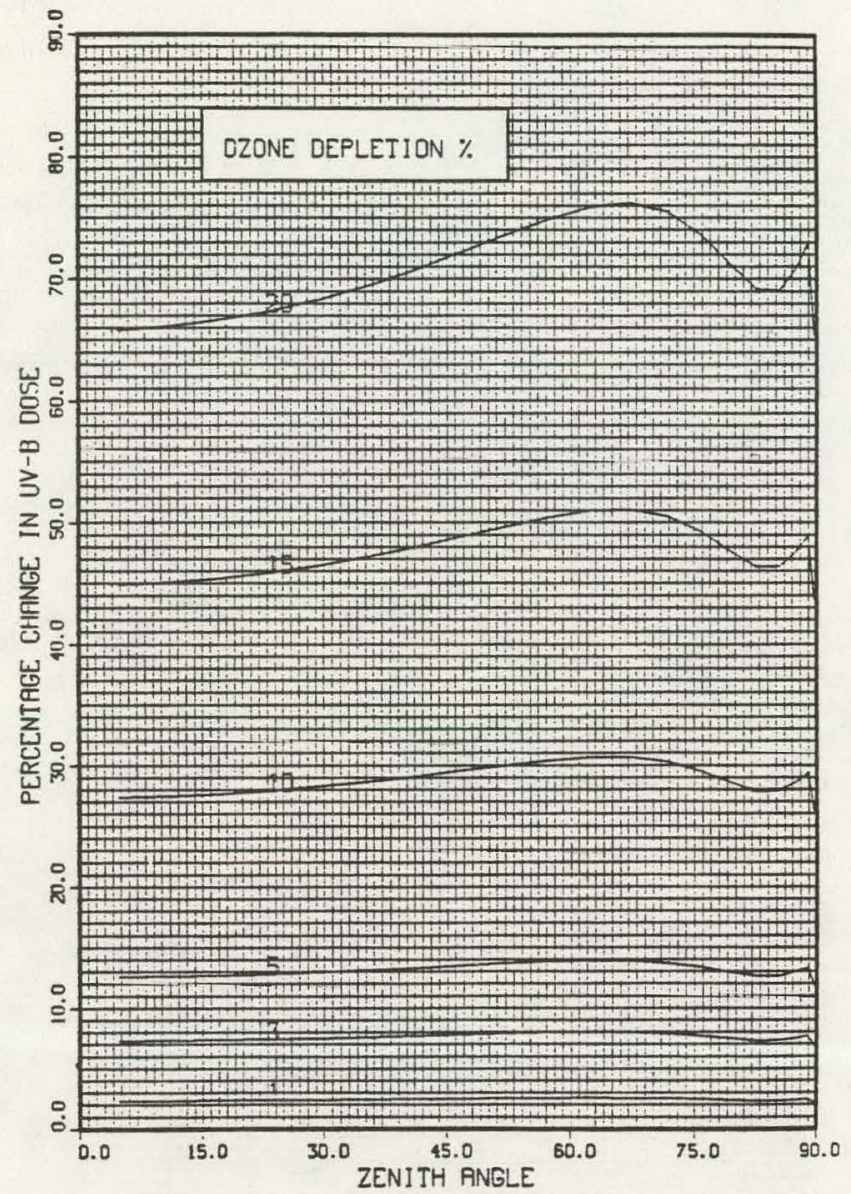

Figure 71

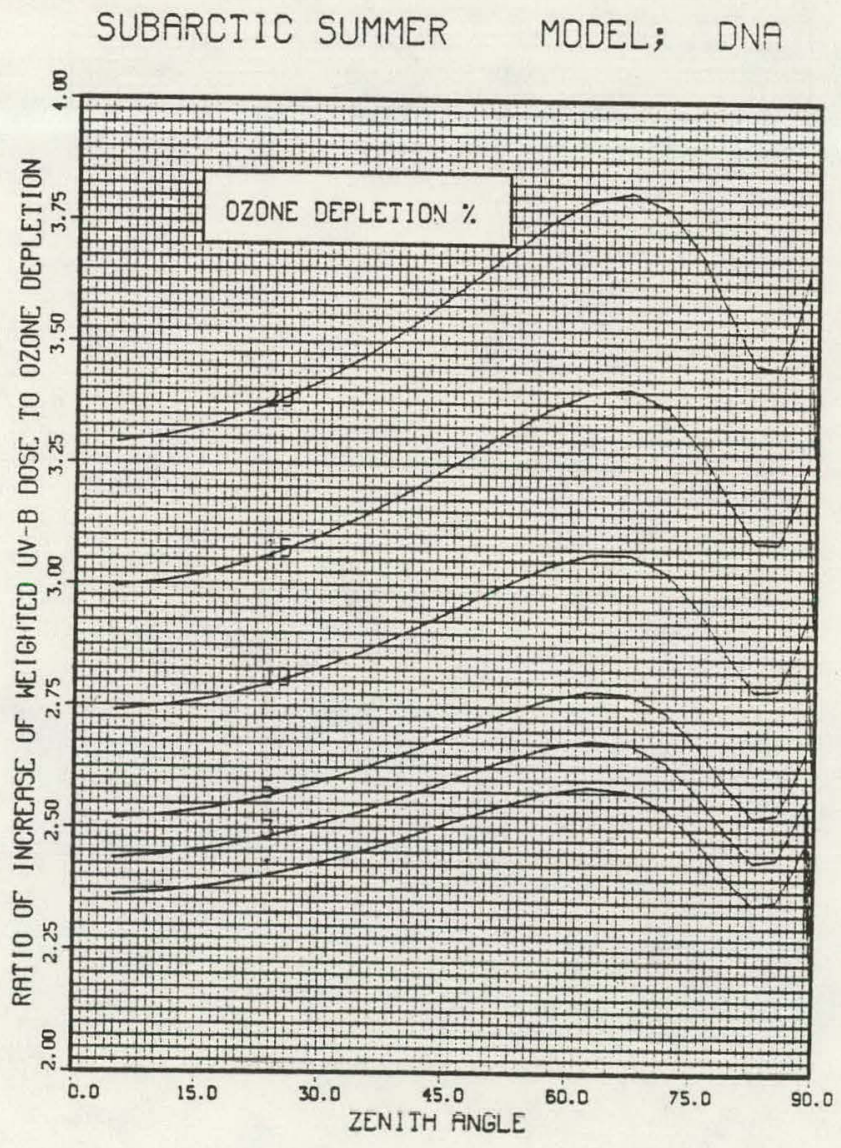

Figure 72 


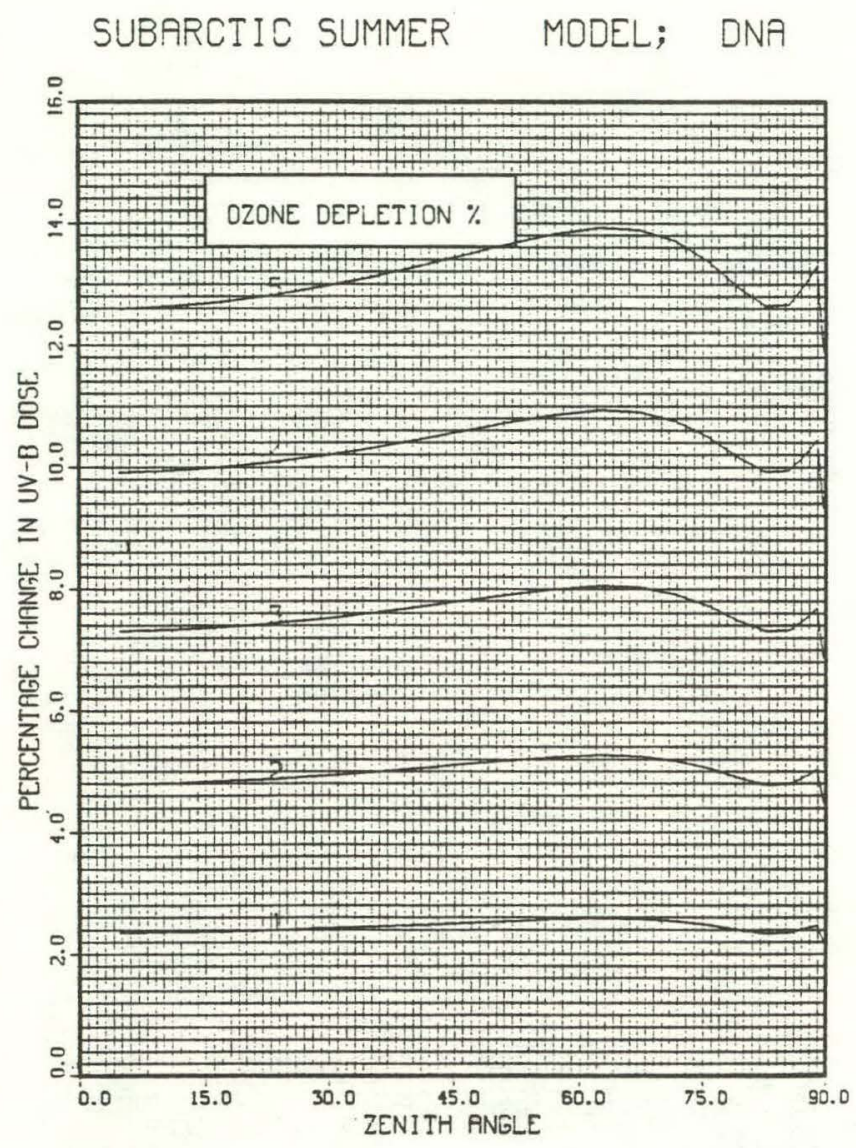

Figure 73

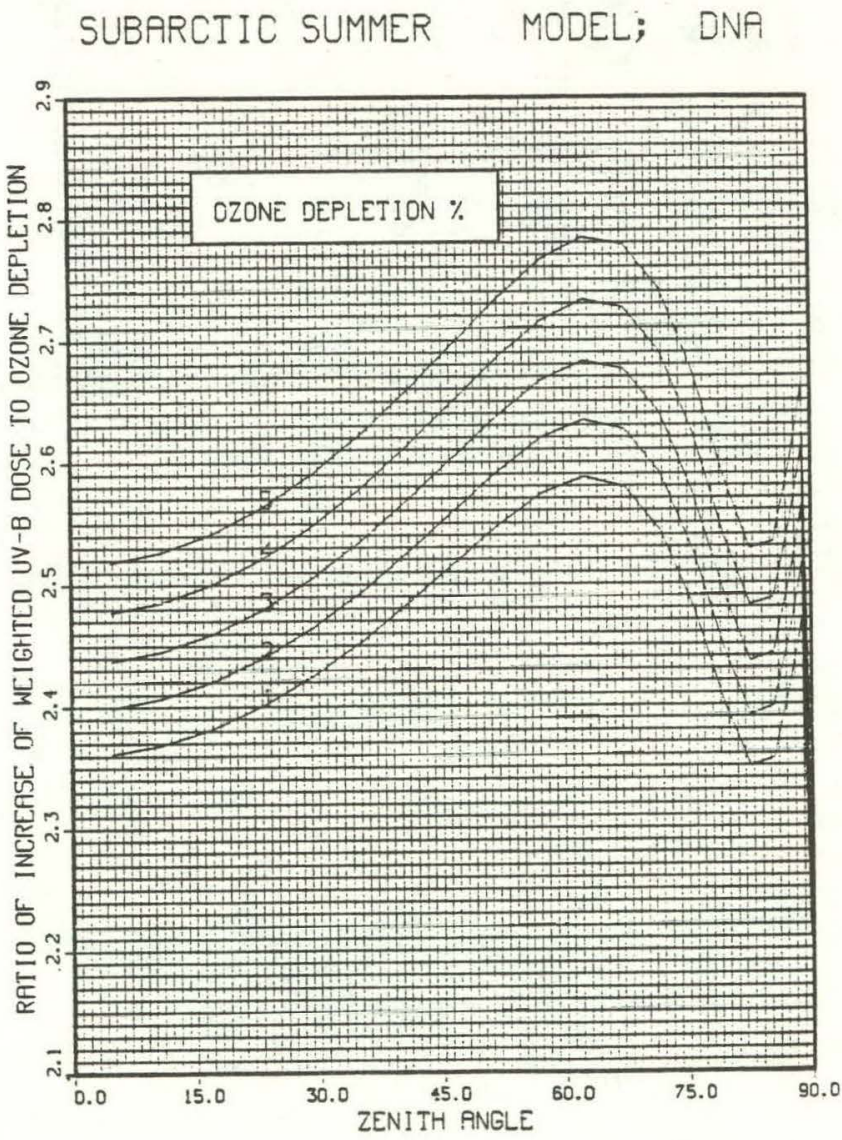

Figure 74 


\section{SUBARCTIC WINTER MODEL; DNA}

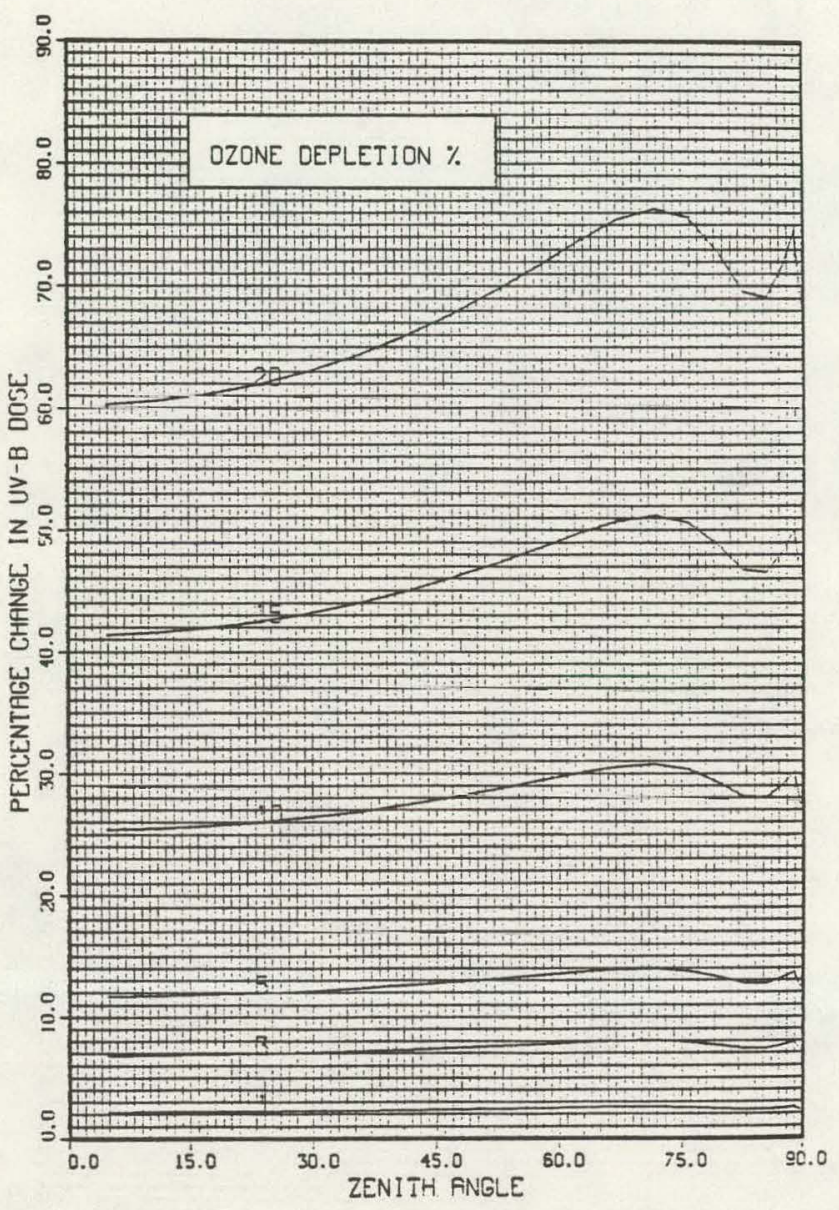

Figure 75

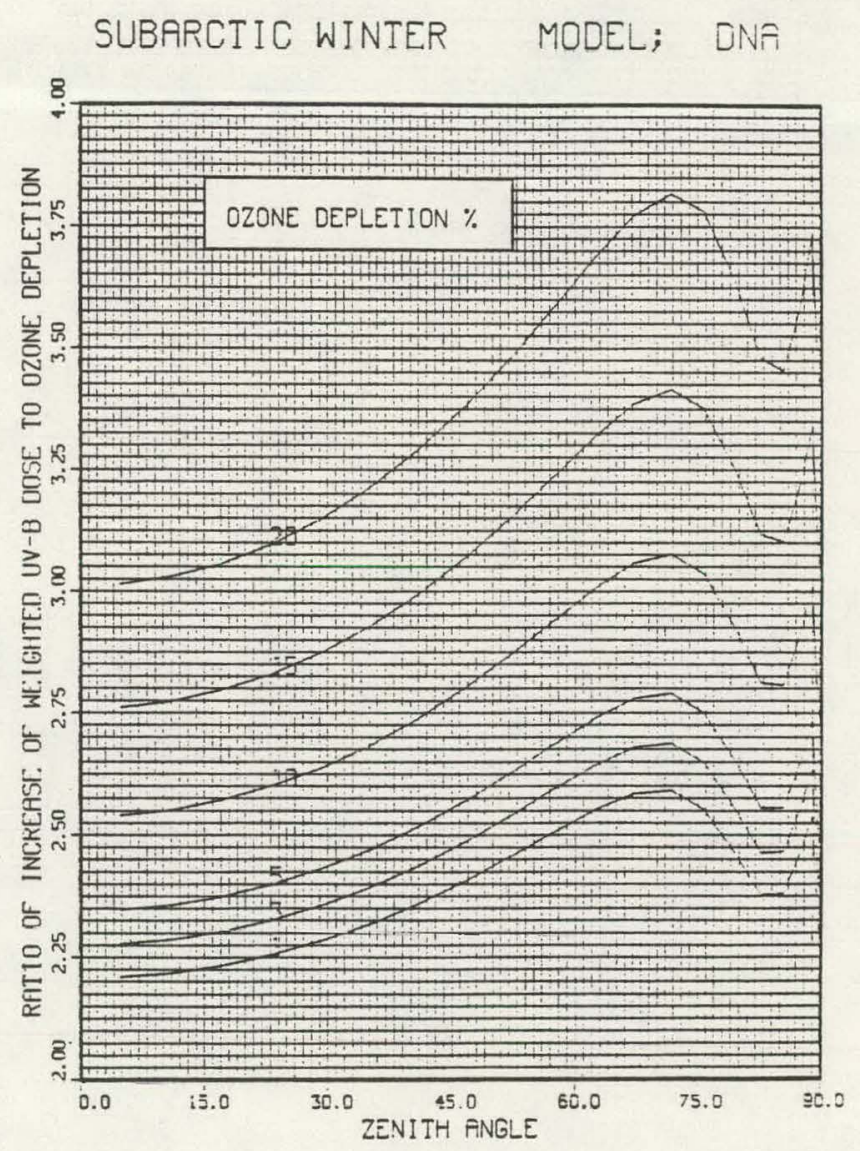

Figure 76 


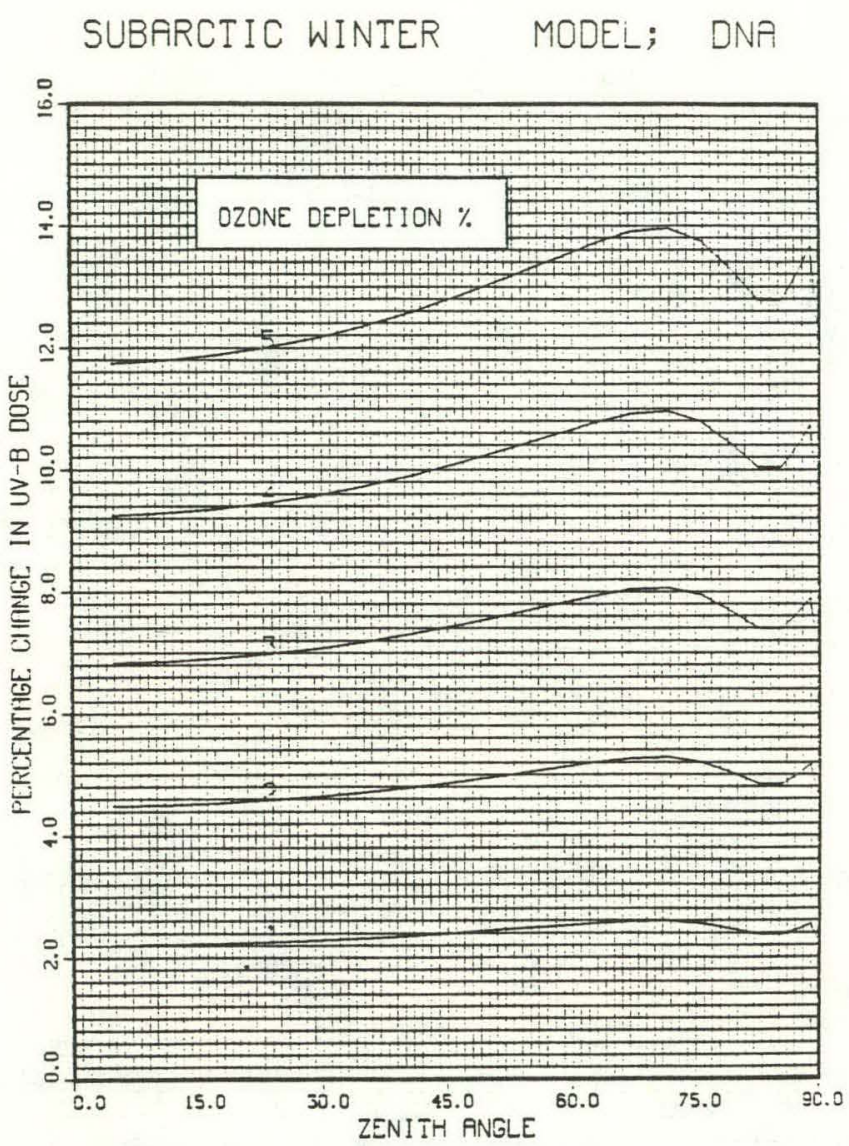

Figure 77

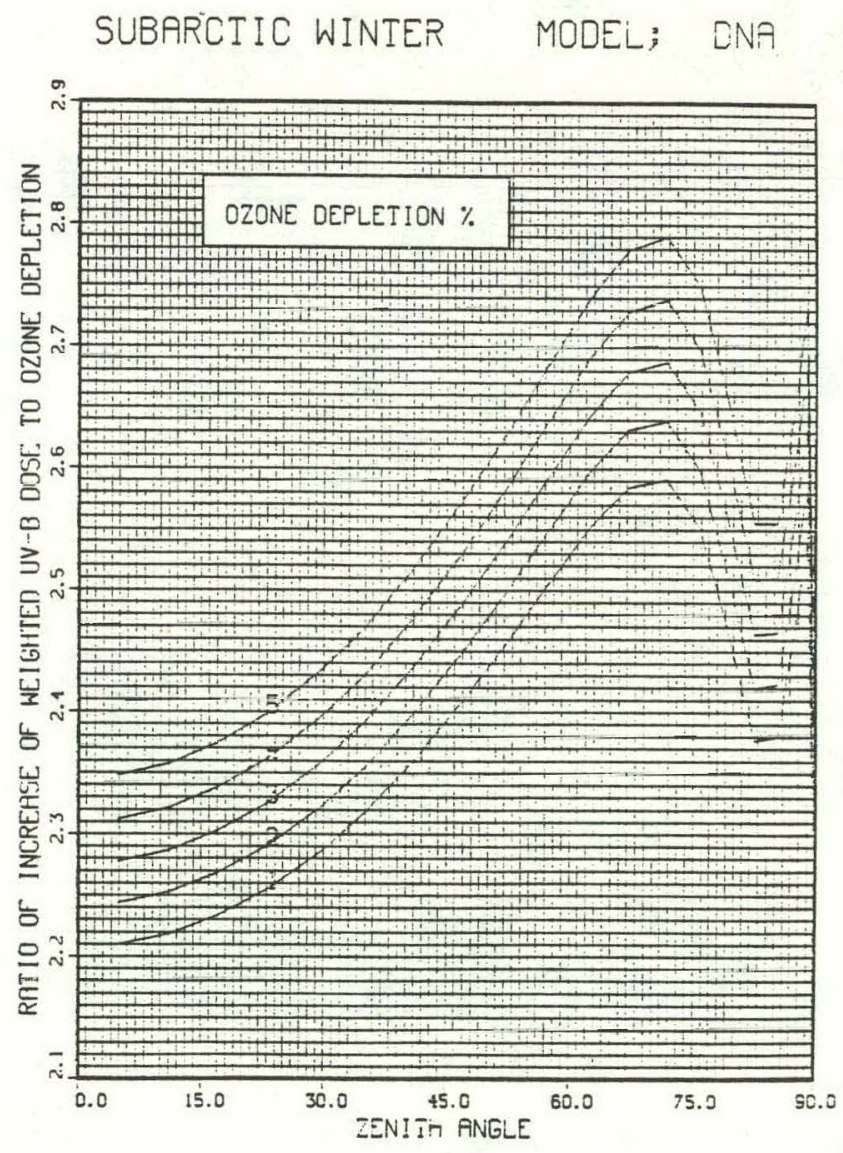

Figure 78 
Effective Solor Zenith Angle

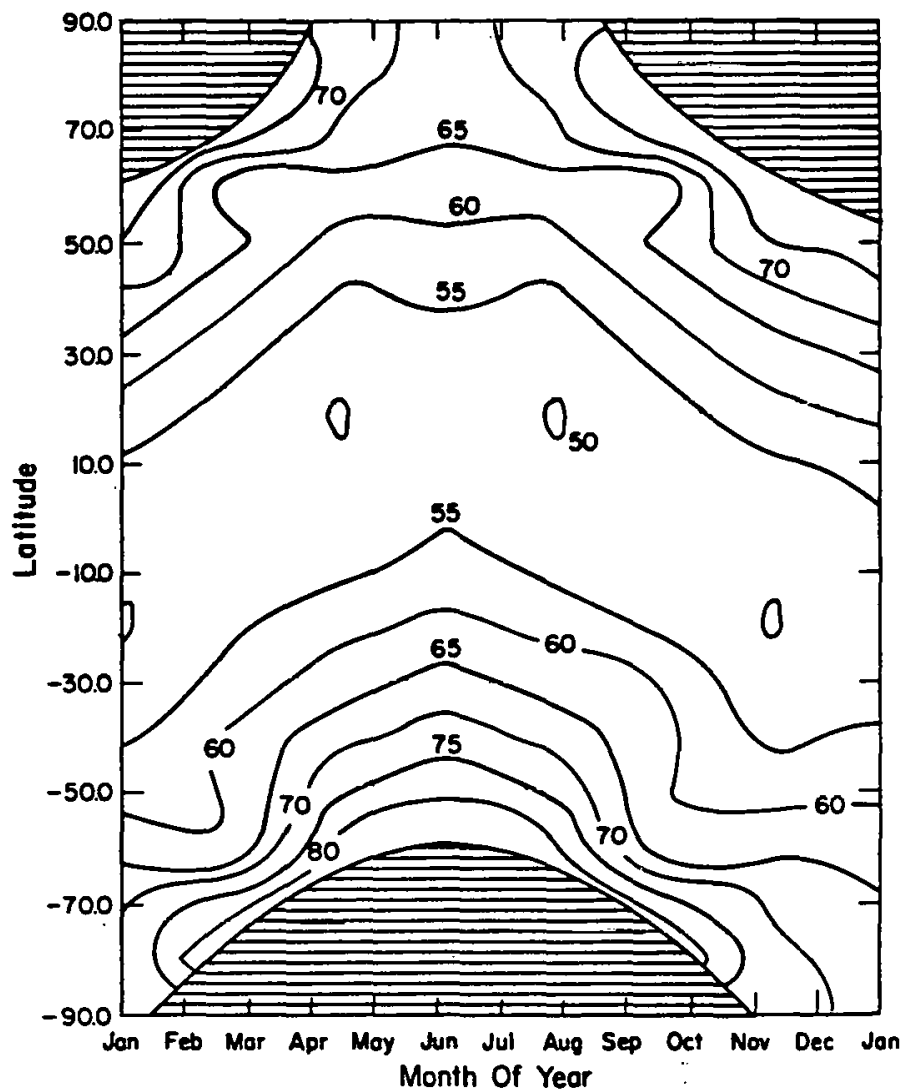

Figure 79
RAF, 10\% OZONE DEPLETION; EFYTHEMA

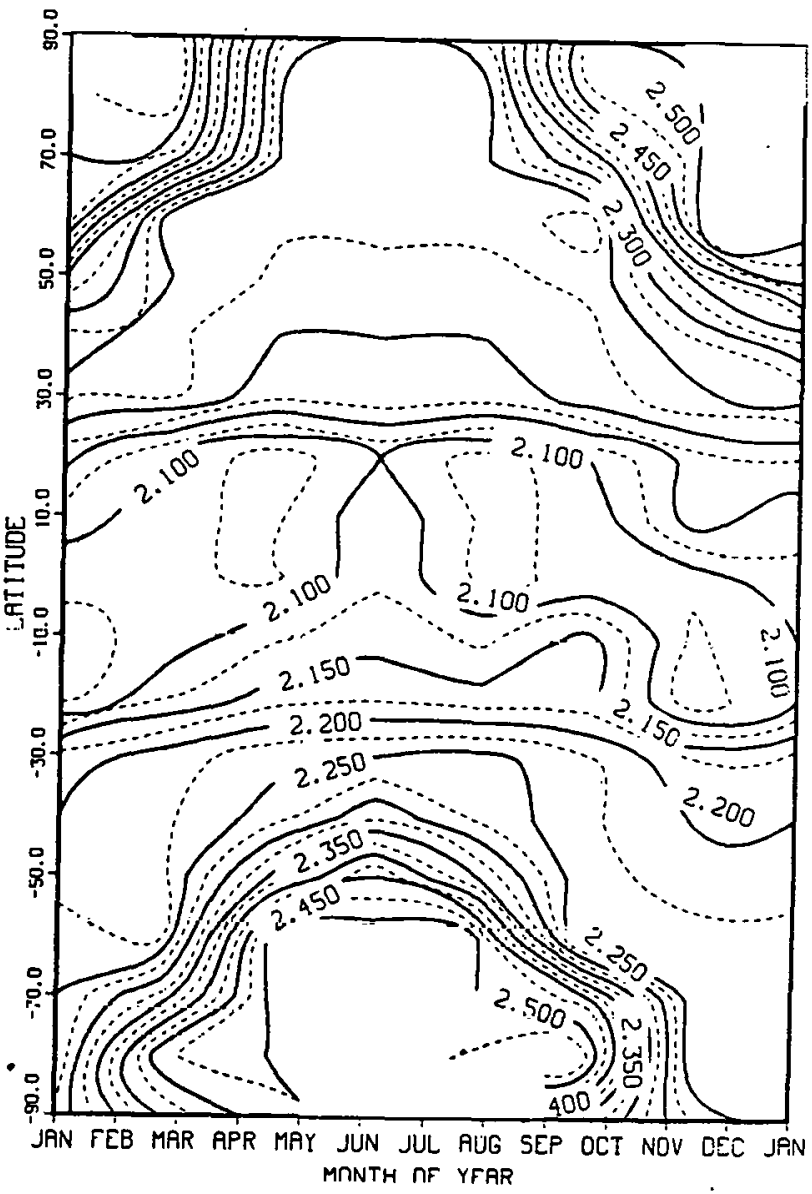

Figure 80 
RRF, 15\% OZONE DEPLETION; ERYTHEMA

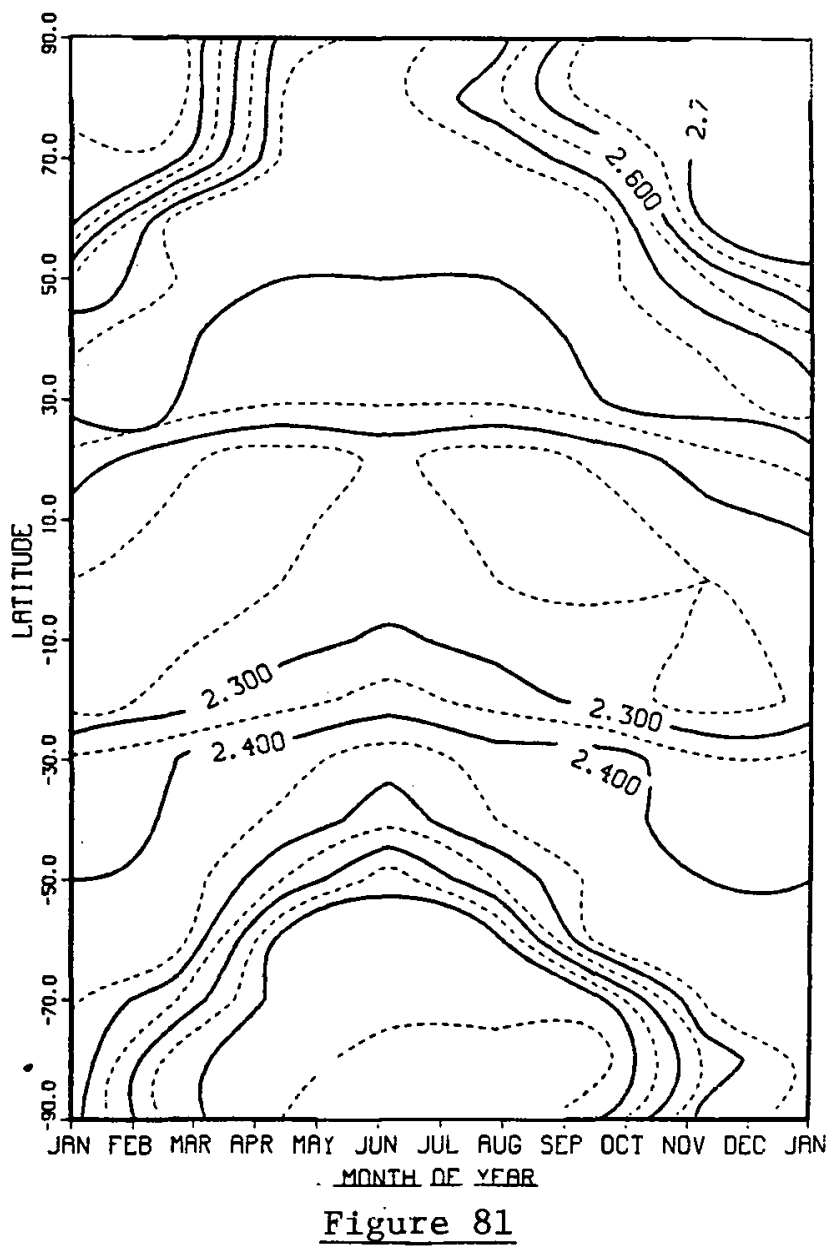

RAF, 20\% OZONE DEPLETION; ERYTHEMA

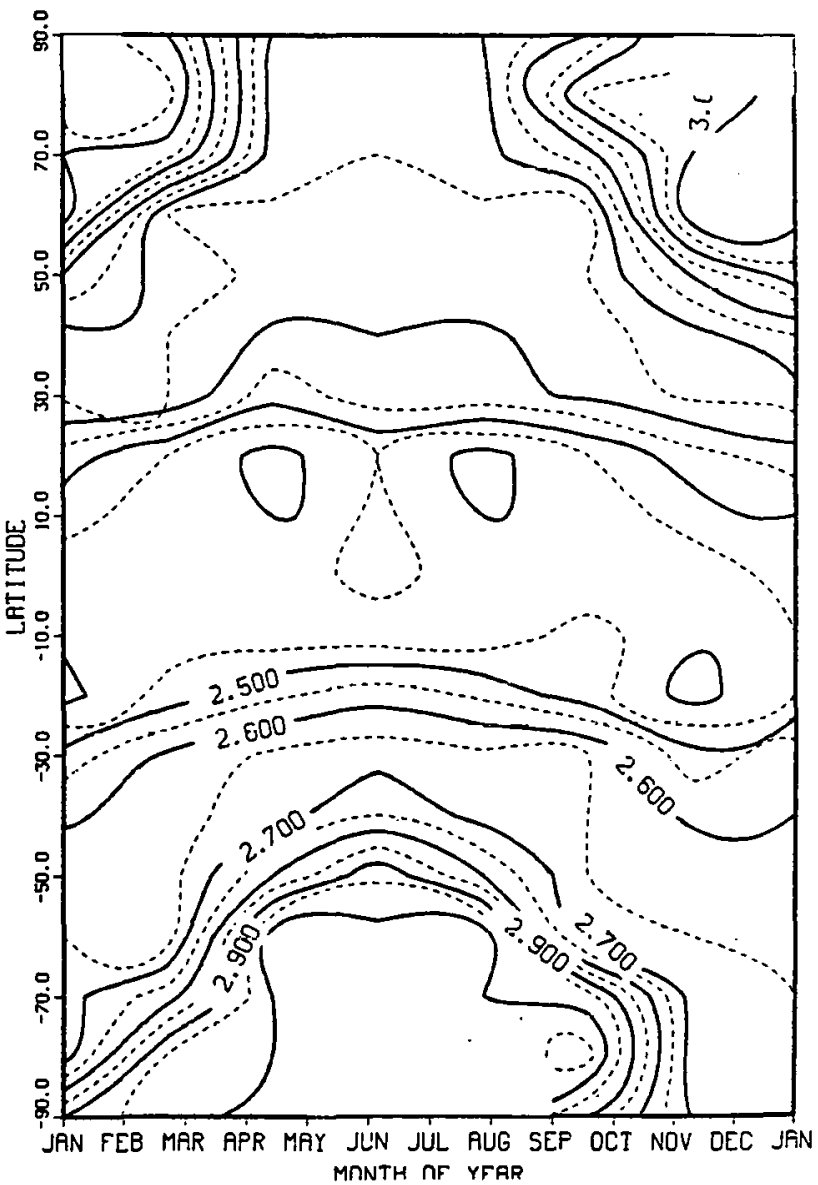

Figure 82 
RAF, 10\% OZONE DEPLETION; DNA

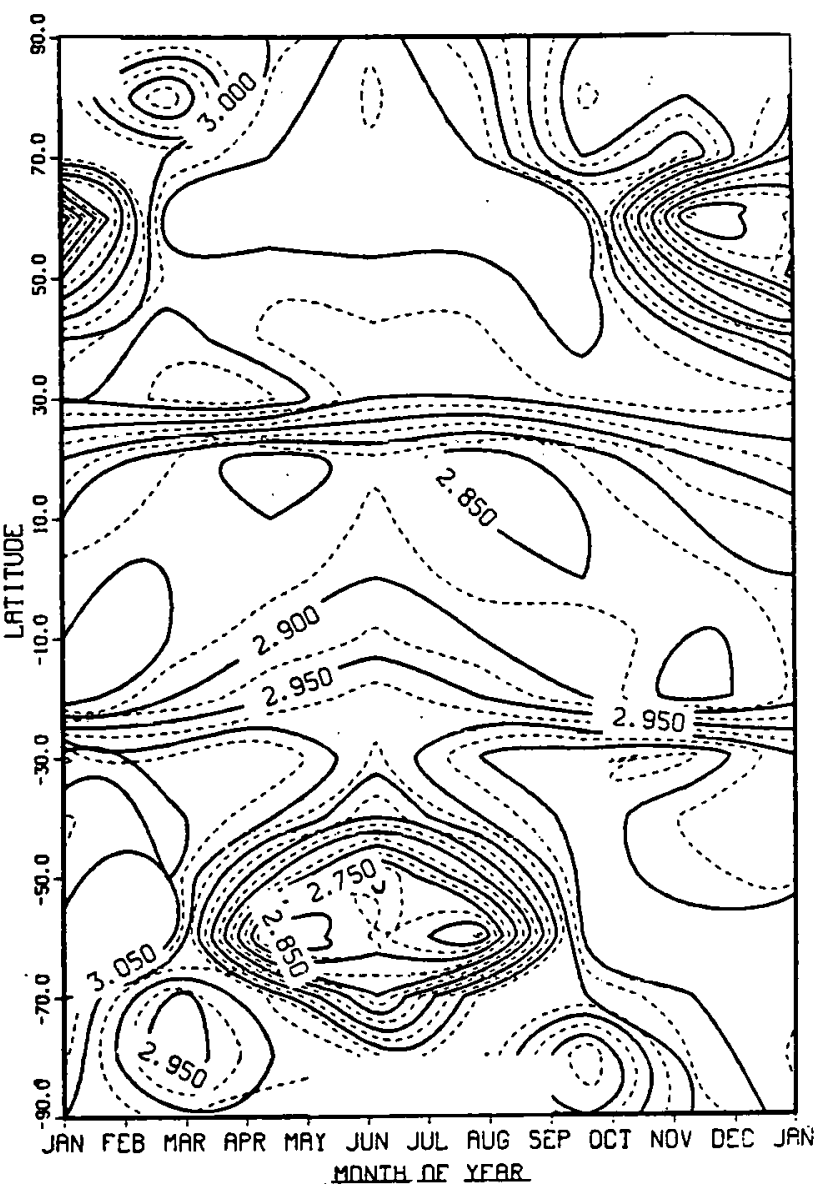

Figure 83
RAF, 15\% OZONE DEPLETION; DHA

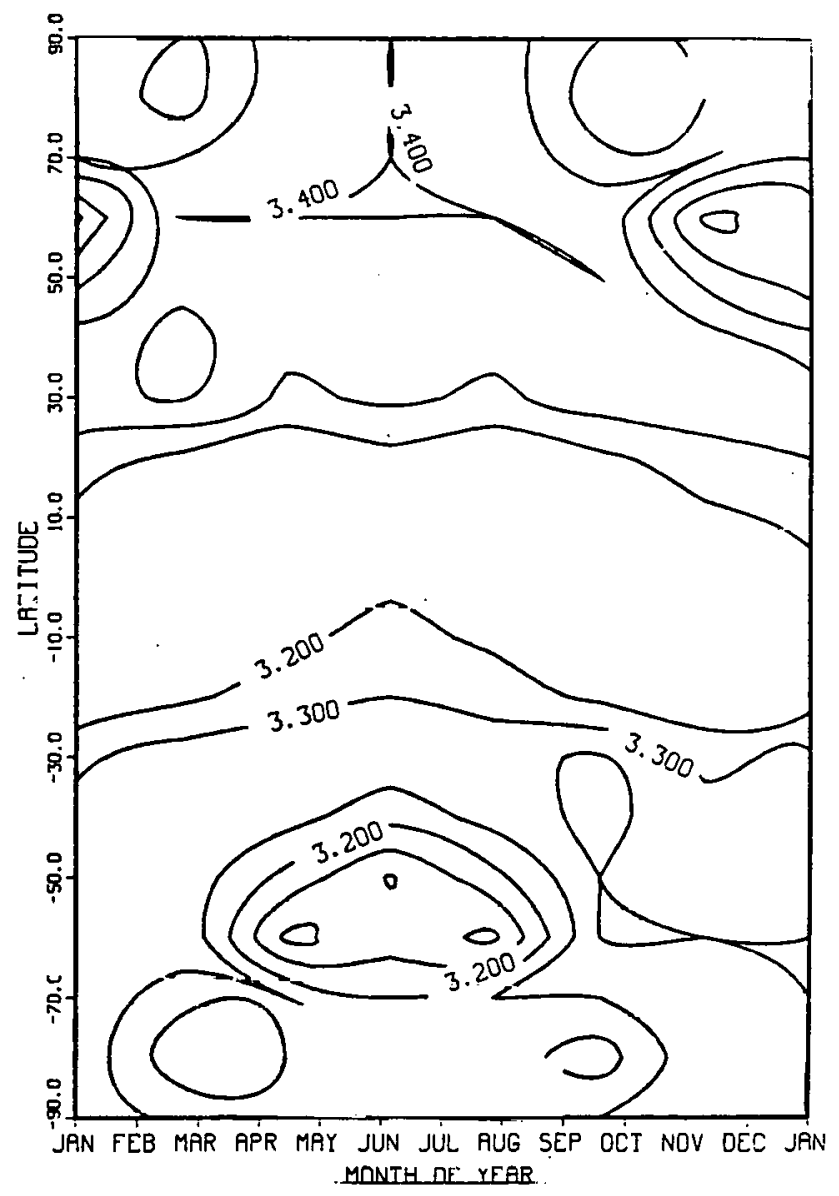

Figure 84 
RAF, 20\% OZONE DEPLETION; DNA

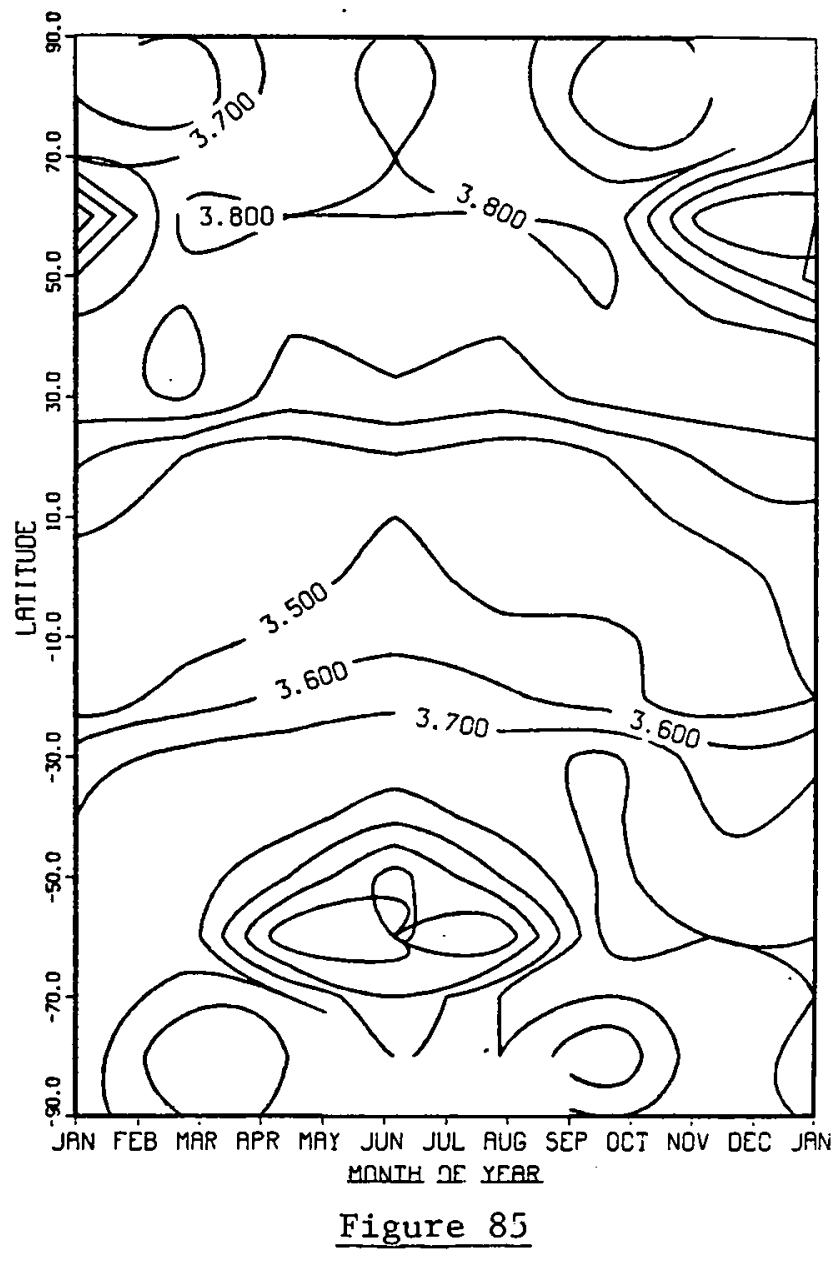

DUV CHANGE \%,15\% 03 REDUCT.; ERYTHEMA

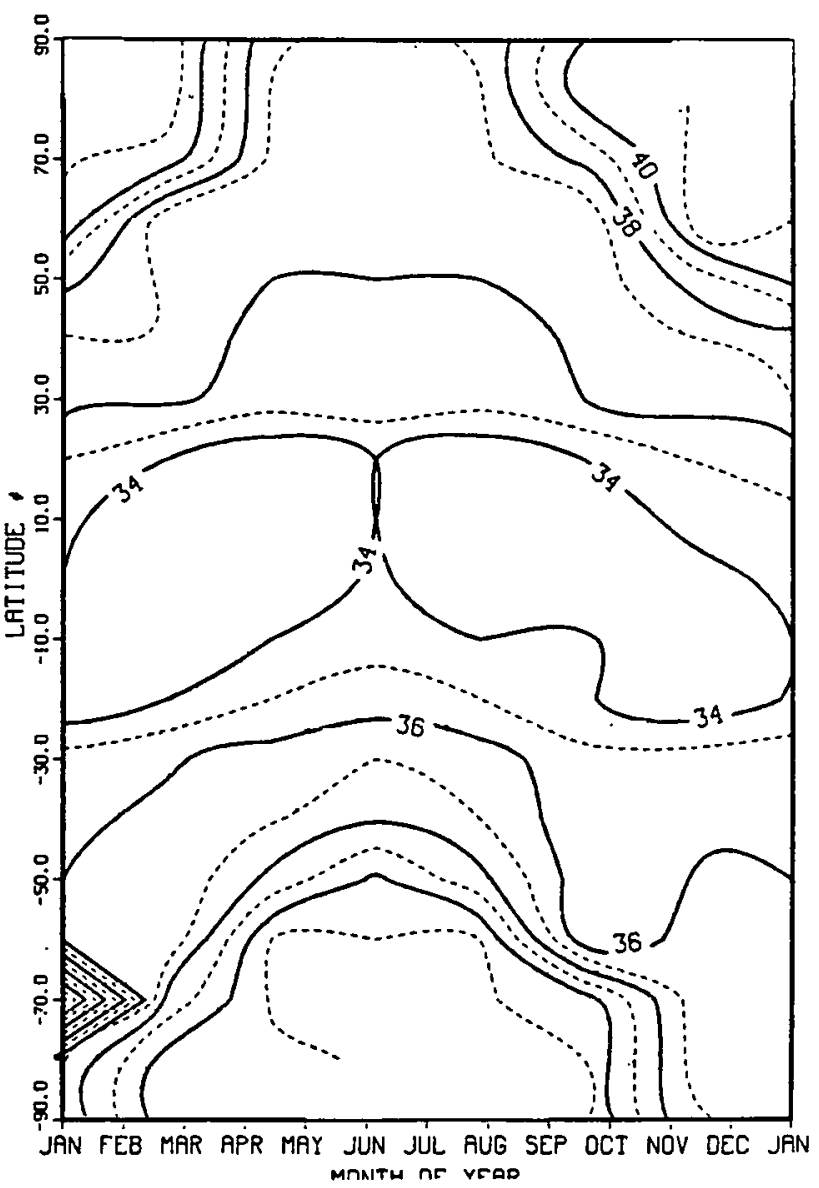

Figure 86 
DUVV CHANGE \%, 15\% 03 REDUCT. ; DNA

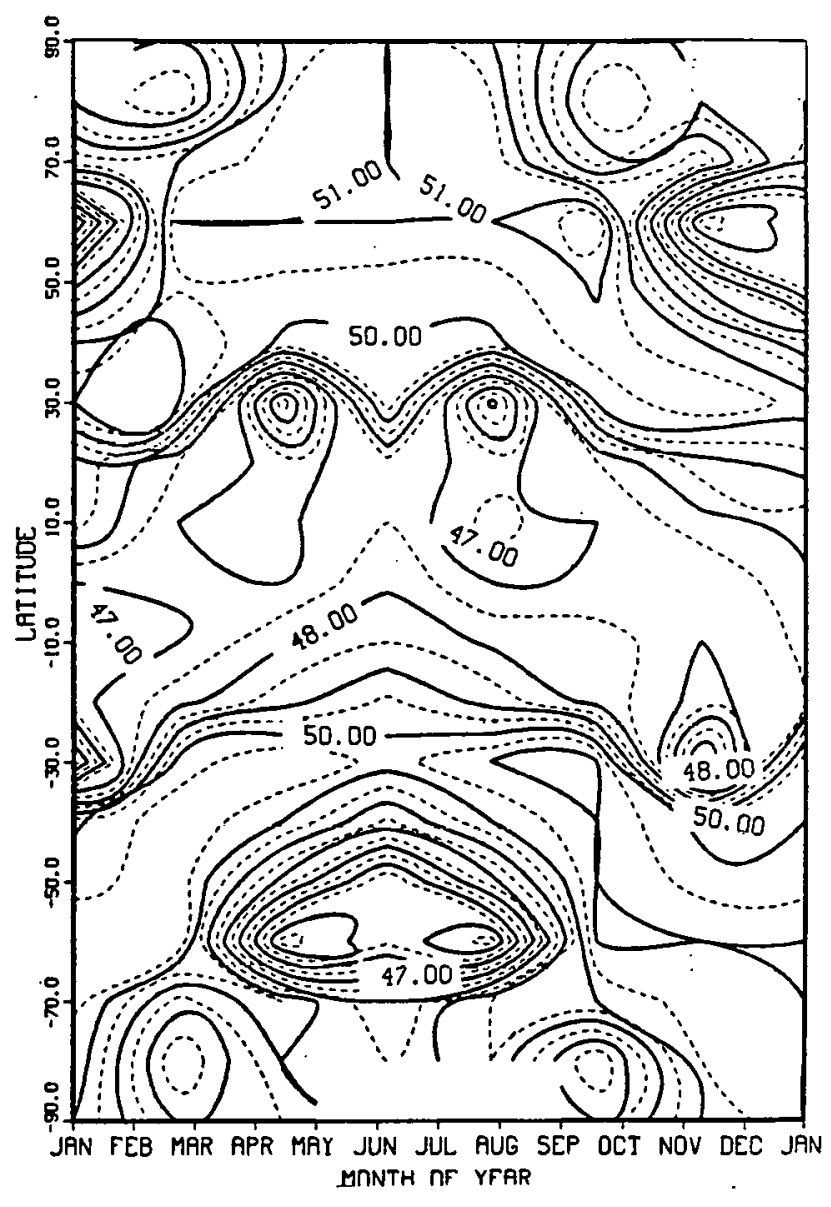

Figure 87
AMPLIFICATION FACTOR; ERY THEMA

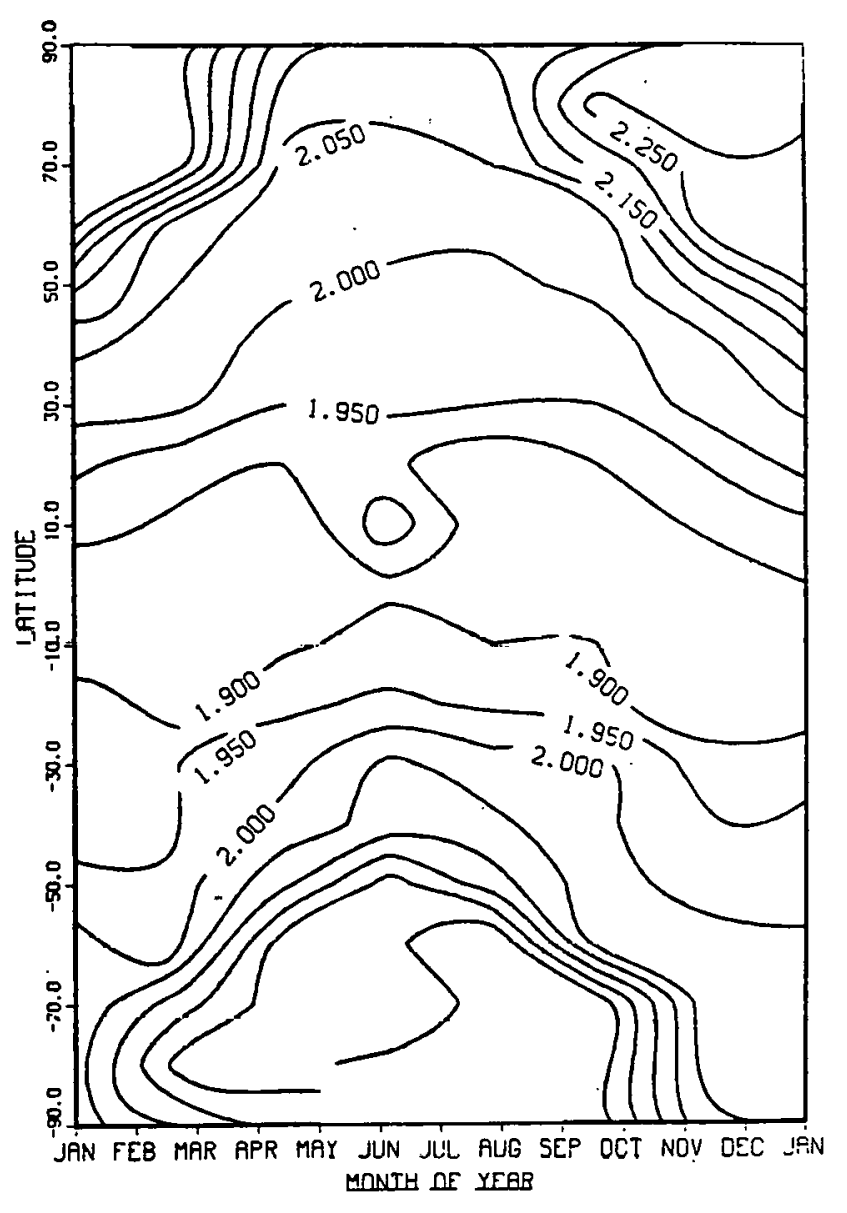

Figure 88 


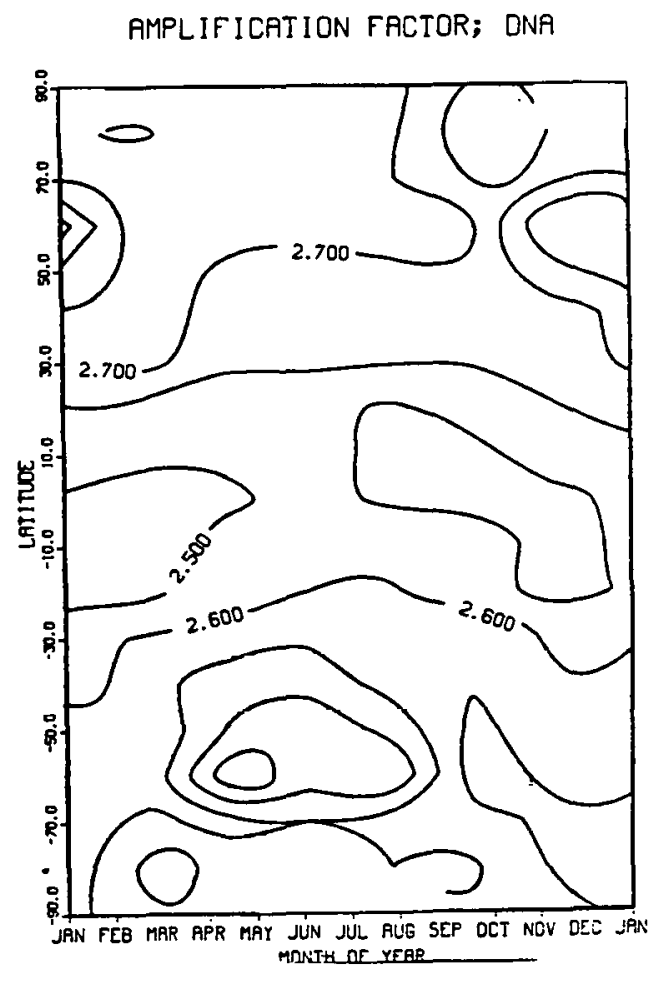

Figure 89
RAF, 1-TRAN EXIRAPOL.; ERYIHEMA

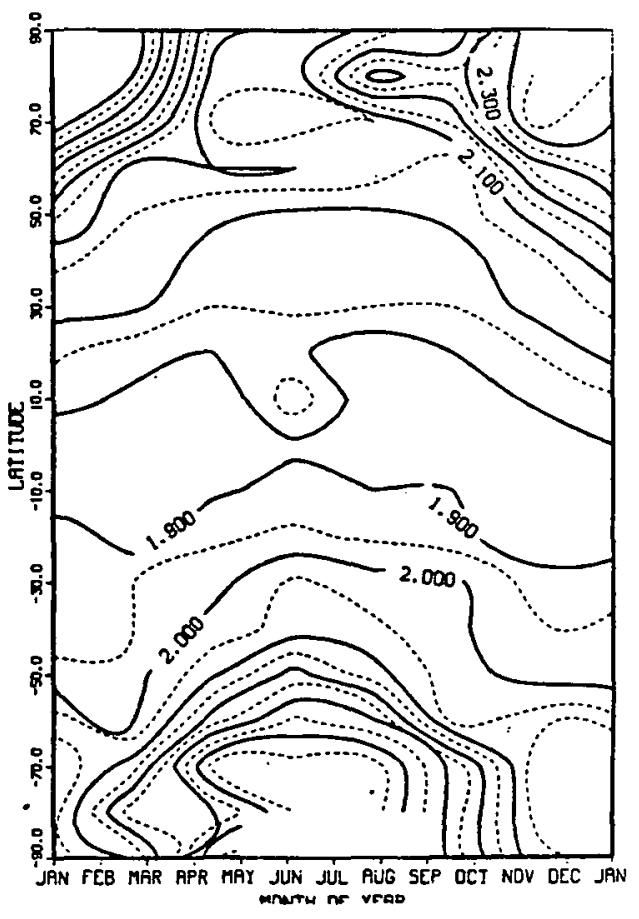

Figure 90

RAF, 1-TRAN EXTRAPOL.; DNA

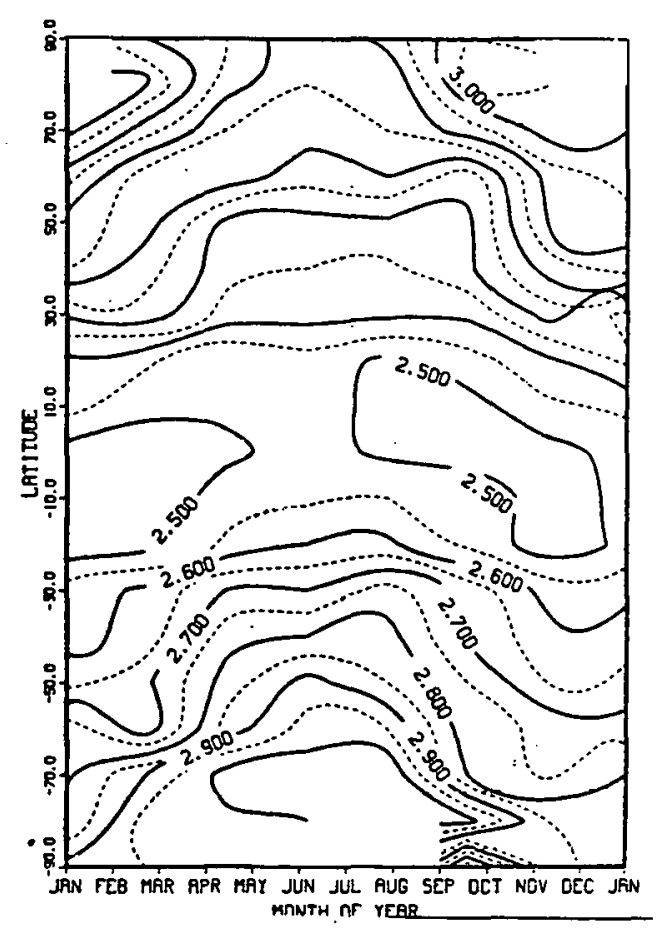

Figure 91 


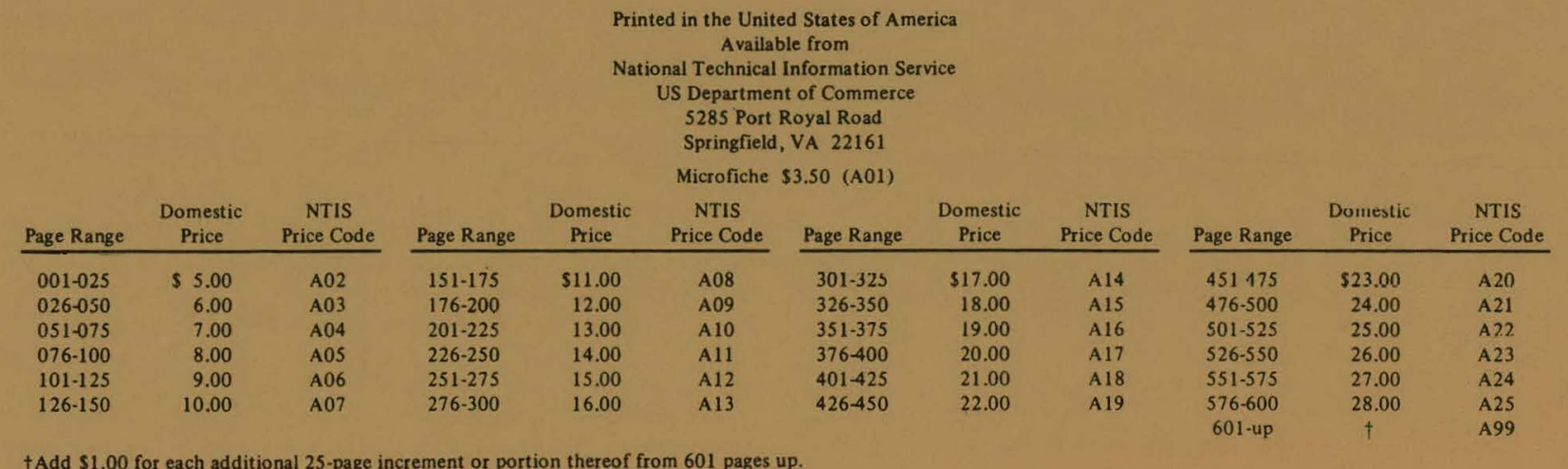


Los Alannos 